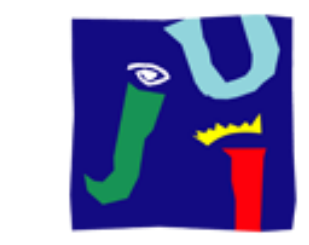

$\mathbf{U}_{\text {NIVERSITAT }}$

JAUME•I

Facultad de Ciencias de la Salud

Departamento de Psicología Evolutiva, Educativa, Social y Metodología

\title{
LOS SISTEMAS DE AYUDA ENTRE IGUALES COMO PREVENCIÓN DEL ACOSO ESCOLAR EN LOS CENTROS DE EDUCACIÓN SECUNDARIA
}

\author{
Tesis doctoral \\ Presentada por: \\ Inmaculada Usó Guiral \\ Dirigida por:
}

Dra. Lidón Villanueva Badenes 



\section{Agradecimientos}

Tener dos trabajos y realizar una tesis no es tarea fácil, de manera que me gustaría agradecer el apoyo y ánimo que siempre he recibido por los diferentes miembros del departamento de Psicología Evolutiva, Educativa, Social y Metodología: José Manuel, Raquel, Ana Belén, Rosa Ana, Keren, Clara, Juan Emilio y Miguel. Y también de mis compañeros de la Unidad de Apoyo Educativo de la UJl: Esther, Bea y Miguel Ángel.

A mi madre, por enseñarme a dar siempre lo mejor de mí, y que "sin esfuerzo, no hay recompensa". Por todo lo que aprendo a su lado en el día a día, y porque siempre sabe sacarme una sonrisa cuando las cosas se complican. Gracias a ella y sólo a ella, soy la persona que soy.

A Jose, que ha sabido esperar de manera paciente a que consiga todos los objetivos que me he marcado tanto a nivel académico, como profesional. Me encanta haberte encontrado.

Gracias también a los centros de Enseñanza Secundaria Obligatoria que han participado en esta investigación, per permitirnos acceder a los centros, a sus aulas a sus alumnos, y a sus conflictos. Muchas gracias a los profesores responsables de los equipos de mediación y a los orientadores y las orientadoras.

Y por supuesto, mi más sincero y sentido agradecimiento a la Dra. Lidón Villanueva, que ha sabido entender siempre mis circunstancias personales y laborales y aún así, se ha mantenido a mi lado de manera incondicional, animándome, acompañándome y compartiendo conmigo sus conocimientos en este tema. Lidón, siempre te estaré agradecida por todo lo que me has enseñado y has hecho por mí. Gracias de verdad, por ser mi directora de tesis. 



\section{ÍNDICE}

A. INTRODUCCIÓN ...................................................................................................... 7

PARTE I-MARCO TEÓRICO..............................................................................13

CAPÍTULO 1. CONCEPTUALIZACIÓN.......................................................................17

1.1.Delimitación conceptual. Violencia escolar y Bullying. ............................................ 17

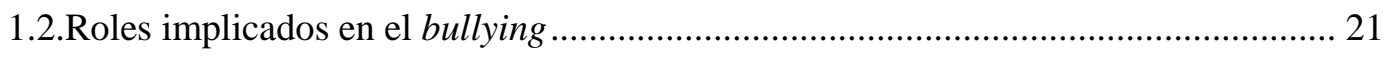

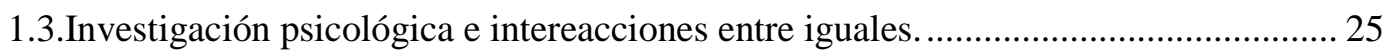

1.4. La Convivencia en los centros de Enseñanza Secundaria Obligatoria ...................... 30

CAPÍTULO 2. LOS SISTEMAS DE AYUDA ENTRE IGUALES .......................... 41

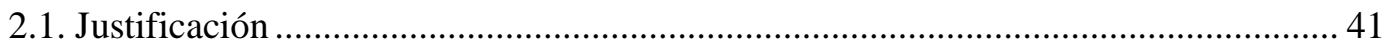

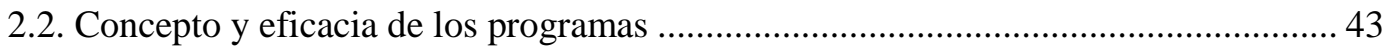

2.2.1. Concepto de sistemas de ayuda entre iguales.................................................... 43

2.2.2. Eficacia de los sistemas de ayuda entre iguales .................................................. 49

2.3. Desarrollo de los programas: Alumno Ayudante y Alumno Mediador ...................... 54

2.3.1. Aspectos a tener en cuenta para la implementación de estos programas en los

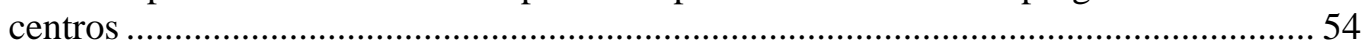

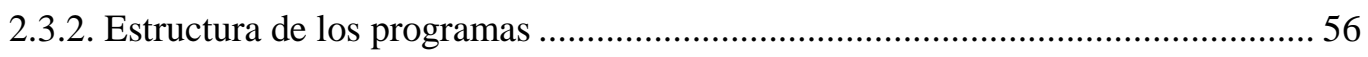

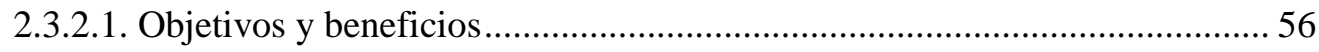

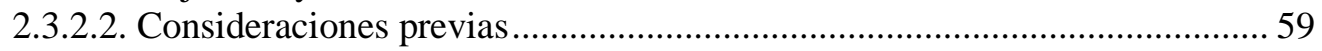

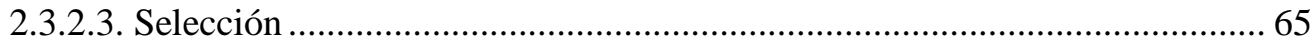

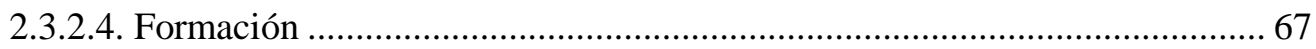

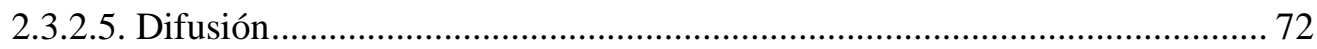

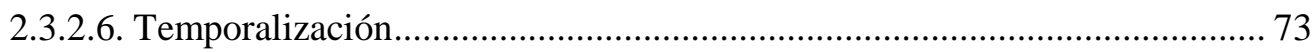

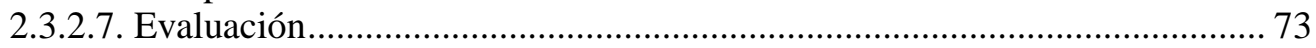

PARTE II-TRABAJO EXPERIMENTAL .............................................................. 79

CAPÍTULO 3. ESTUDIOS DE LA TESIS................................................................. 83

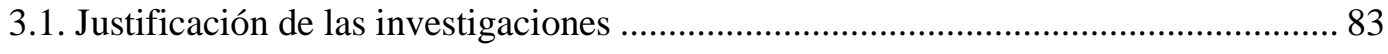

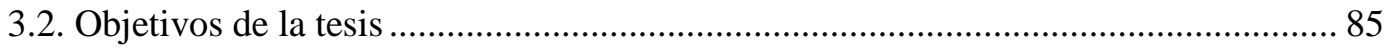


Sistemas de ayuda entre iguales: programas de innovación educativa en la convivencia escolar.

Usó, I, Górriz, A.B., Villanueva, L., y Adrián, J.E. (2011). Sistemas de ayuda entre iguales: programas de innovación educativa en la convivencia escolar. Quaderns Digitals. http://www.quadernsdigitals.net/datos/hemeroteca/r_75/nr_819/a_11063/11063.html

Los programas de mediación entre iguales: una herramienta eficaz para la convivencia escolar.

Villanueva, L., Usó, I., y Adrián, J.E. (2013). Los programas de mediación entre iguales: una herramienta eficaz para la convivencia escolar. Apuntes de Psicología, 31(1), 165-171.

Impact of peer mediation programs to prevent bullying behaviours in secondary schools

Usó, I., y Villanueva, L. (en revisión). Impact of peer mediation programs to prevent bullying behaviours in secondary schools. Enviado a Infancia $y$ Aprendizaje.

¿Son eficaces para prevenir el acoso escolar los programas de ayuda entre iguales de reciente implantación?

Usó, I., y Villanueva, L. ¿Son eficaces los programas de ayuda entre iguales de reciente implantación? Enviado a Revista de Educación.

Anexo I: Cuestionario de Roles para estudiantes, Escala "Adivina Quien” (Salmivalli, et. al., 2006)

Anexo II: Cuestionario de Actitudes para estudiantes, Escala de "Rigby \& Slee", 1991

Anexo III: Cuestionario para estudiantes sobre el estado inicial de la convivencia escolar, de Ortega y Del Rey, 2003

Anexo IV: Cuestionario para el profesorado sobre el estado inicial de la convivencia escolar, de Ortega y Del Rey, 2003. 


\section{A. INTRODUCCIÓN}



El fenómeno del acoso escolar no es un problema reciente. Tras una fuerte crisis de los valores éticos y morales, estos se han dejado de cultivar en gran medida, dando paso a comportamientos agresivos que se manifiestan también en las aulas. Las relaciones interpersonales son complicadas, y conllevan relaciones de poder y estatus dentro del grupo de iguales que pueden generar conflictos, pero trabajando de manera multidisciplinar, las relaciones de abuso podrían evitarse.

Los actos humillantes, pueden ser tan pequeños y cotidianos, que pueden confundirse con normales. A partir de una falta de respeto, con una mentira o una manipulación, si el grupo en el que aparece no reacciona, estas situaciones se transforman progresivamente en conductas poco adecuadas que tienen graves consecuencias en las víctimas, y éstas, al no tener la seguridad de que serán comprendidas, suelen callar y sufrir en silencio.

Las relaciones de agresión no son únicamente díadas víctima-agresor, sino que hay más roles implicados que favorecen que estas conductas se mantengan (Salmivalli y Voeten, 2004; Salmivalli, 2009; Sutton y Smith, 1999). De modo que no se trata de realizar tan solo una intervención directa con los implicados más evidentes, sino que se necesita un planteamiento global, que haga referencia a la convivencia, a aprender a respetar las normas y a ser tolerantes ante las diferencias de los compañeros de la sociedad plural en la que vivimos.

Los jóvenes se socializan y agrupan unos con otros para ajustarse a las expectativas de los iguales y aprender el funcionamiento de las organizaciones sociales. Las normas de grupo fomentan un sentido de pertenencia y conllevan responsabilidades y papeles como el de líder y seguidor. En estos grupos se aprenden habilidades sociales y se prueban nuevos papeles a la vez que el grupo ofrece una identidad temporal, mientras el adolescente trabaja en una de las principales tareas evolutivas: la consolidación de la suya propia. Pero los adolescentes no siguen al grupo de manera inconsciente, ni siempre se guían por los mandatos de los iguales. Mientras que los iguales tienen un impacto más poderoso en los problemas diarios de indumentaria, el gusto por la música y el comportamiento social, los padres influyen en los valores básicos de la vida y en la educación.

Si queremos conseguir un cambio positivo en las relaciones humanas con el fin de que no se trivialice la violencia, es aconsejable trabajar la educación emocional y las 
habilidades interpersonales, que permitan que los menores se sientan bien consigo mismos, tengan buena autoestima y autoconcepto, para poder defenderse de lo que les resulte amenazante. De manera que es necesario educar en la resolución de conflictos, facilitándoles estrategias y alternativas de conducta ante la agresión, mostrándoles las ventajas e inconvenientes de cada comportamiento a través del diálogo, la comunicación y la negociación.

Pero además, es importante darle un enfoque global, en el que estén implicados todos los agentes que conforman la comunidad educativa, para conocer los factores que influyen en una situación de violencia entre iguales, y poder ayudar a las personas implicadas. Y como a través del modelado de los iguales se han inspirado habilidades sociales y programas de enseñanza en el que los propios compañeros sirven como agentes de cambio de comportamiento, se considera que los sistemas de ayuda entre iguales son una buena herramienta de prevención de la violencia escolar (Bradshaw, 2014; Cowie, 2015; Lee, Kim y Kim, 2013; Olweus et. al., 2007).

Por tanto, en este trabajo se pretende conocer los sistemas de ayuda entre iguales y si la aplicación de los mismos es eficaz para disminuir las situaciones de bullying que se dan en los centros de educación secundaria.

El trabajo se estructura en dos partes: Marco teórico y Parte experimental. En la primera parte, bajo el título Marco Teórico, se cuenta con dos capítulos. En el capítulo 1, se conceptualiza el objeto de estudio: Bullying o acoso escolar. Aparece una revisión de estudios sobre la violencia, la agresividad, los factores de riesgo y de protección del bullying, así como los roles implicados en el maltrato. Y finalmente, se incluye un apartado sobre la convivencia en los centros de Educación Secundaria Obligatoria de la Comunidad Valenciana. El capítulo 2 conceptualiza los sistemas de ayuda entre iguales. Qué son, el grado de eficacia demostrado hasta el momento y se desarrollan los aspectos a tener en cuenta para implementar programas como: Alumno Ayudante y Alumno Mediador en los centros.

En la segunda parte, que lleva por título Trabajo Experimental, se cuenta con tres capítulos. En el capítulo 3, se describen los objetivos de la tesis, así como la justificación de las investigaciones que se han realizado. El capítulo 4 es una recopilación de cuatro artículos que se han elaborado a partir del análisis de datos propios de investigación, y que se centran en dar respuesta a los objetivos específicos 
planteados en este estudio. Por último, el capítulo 5 muestra las conclusiones generales encontradas a partir del trabajo realizado, así como las referencias bibliográficas que han guiado la elaboración del mismo.

El mundo no está en peligro por las malas personas, sino por aquellas que permiten la maldad.

Albert Einstein 

PARTE I - MARCO TEÓRICO 

CAPÍTULO 1. CONCEPTUALIZACIÓN 



\section{CAPÍTULO 1. CONCEPTUALIZACIÓN}

\subsection{Delimitación conceptual. Violencia escolar y Bullying.}

Los centros educativos son los lugares donde niños y adolescentes pasan más tiempo. Se trata de un entorno formal en el que se adquieren conocimientos, pero también todo un repertorio de valores y competencias que los van preparando para la vida adulta en sociedad. De manera que se establecen vínculos de compañerismo y también de amistad.

Pero también es en este contexto, donde se producen las primeras relaciones antisociales y las primeras discrepancias interpersonales. $\mathrm{Y}$ de todas las que se producen, las que tiene que ver con la violencia entre iguales es una de las que más preocupan y se estudian.

Poco consenso existe, para definir las situaciones de violencia entre iguales. Muchos han sido los conceptos que se han acuñado en nuestro país para denominar a la violencia escolar entre iguales: bullying, acoso escolar, maltrato entre iguales, intimidación, mobbing escolar, por parte de diferentes autores (Avilés, 2006; Díaz-Aguado, 2006; Informe Defensor del Pueblo, 2006; Oñate y Piñuel, 2007).

Cuando hablamos de violencia, nos referimos a un comportamiento que tiene como finalidad, provocar daño en los otros, para satisfacer intereses propios, aunque esto suponga utilizar medios coercitivos para provocar dicho daño (Ovejero, 1998; Trianes, 2000). La violencia no es instintiva, sino aprendida desde los primeros años de vida y empieza a dar sus frutos, sobre todo en la adolescencia. Siempre conlleva conflictos, aunque los conflictos, no tienen porqué implicar violencia, si se cuenta con las habilidades, estrategias rescursos y alternativas necesarias para resolverlos de manera pacífica o no violenta. Es por todo esto, que la violencia escolar es un de los fenómenos más estudiados en las tres últimas décadas, por las situaciones de indisciplina y conflictividad que implica.

Algunas investigaciones indican que la agresión está dirigida a alcanzar recompensas sociales como la pertenencia al grupo, y por tanto, el bullying se debería considerar una agresión proactiva (Roland e Idsøe, 2001; Salmivalli y Nieminen, 2002). 
Entre 1973 y 1978, Dan Olweus, realizó un estudio con preadolescentes suecos, en el que hablaba del término bullying (Olweus, 1978). En ese estudio, concluía que alrededor del 5\% de los jóvenes eran víctimas de un maltrato grave. Ya en 1993, Olweus define el maltrato que se produce entre iguales en el contexto escolar, como:

\begin{abstract}
"Una conducta física y/o psicológica que realiza el alumno o alumna contra otro, al que elige como víctima de repetidos ataques. Esta acción, negativa e intencionada, sitúa a las víctimas en posiciones de las que difícilmente pueden salir por sus propios medios. La continuidad de estas relaciones provoca en las víctimas efectos claramente negativos: descenso en su autoestima, estados de ansiedad e incluso cuadros depresivos, lo que dificulta su integración en el medio escolar y el desarrollo normal de los aprendizajes" (pág. 9).
\end{abstract}

Este maltrato se puede manifestar, como dice Olweus, de diferentes maneras: verbal, físico, psicológico, social. Pero todas tienen un aspecto en común, se prolongan en el tiempo y producen un marcado desequilibrio de poder. Algunos autores (Besag, 1989; Randall, 1996) añaden una tercera característica: la intención de hacer daño. La víctima ante esta situación, está indefensa y difícilmente puede salir sin ayuda.

Por tanto, las características del bullying entre adolescentes, según Díaz-Aguado (2006), son las siguientes:

1. Suele implicar diversas conductas: burlas, amenazas, intimidaciones, agresiones físicas, aislamiento sistemático, insultos...

2. Se repite y prolonga durante cierto tiempo.

3. Provocado por un individuo (el matón o el agresor), apoyado generalmente en un grupo, contra un víctima indefensa, que no puede salir por si misma de la situación.

4. Se mantiene por la ignorancia o pasividad de las personas que rodean al agresor y a las víctimas, y que no intervienen.

El Informe del Defensor del Pueblo y Unicef sobre violencia escolar (2006) realizado en centros españoles públicos y privados a 3000 estudiantes de ESO (chicos y chicas en igual proporción) ofrece datos sobre este tipo de violencia, por ejemplo: 
- Las más frecuentes son las agresiones verbales, le siguen las agresiones indirectas, el aislamiento, las amenazas y las agresiones físicas.

- Uso de las nuevas tecnologías como medio para recibir o ejercer el maltrato: cyberbullying. En concreto, en un 5\% de los casos, se produce en esta modalidad.

- El género y el curso son variables estadísticamente significativas en la incidencia del maltrato: los agresores son sobre todo chicos.

- También son los chicos los que verbalizan y cuentan que se "les pega" y que "reciben motes ofensivos".

- El lugar más usual para las agresiones verbales, y los robos de enseres es el aula; en el patio se llevan a cabo mayor número de agresiones físicas y el "no dejar participar".

- Estos comportamientos dañinos se dan en todas las comunidades españolas y en todos los tipos de centros.

- En el primer curso de la ESO se encuentra un mayor número de víctimas, seguido por el segundo curso y menos porcentaje en cuarto curso.

- También en segundo curso de la ESO hay un mayor número de alumnos que se describe a sí mismo como agresor.

- Los agresores suelen ser de la misma clase o curso. Pero ha aumentado el porcentaje de quienes sitúan en un curso inferior al estudiante que "habla mal de ellos" a sus espaldas.

- Para el agresor, los demás responden con pasividad o incluso le animan o ayudan cuando ocurren las agresiones.

- Los alumnos que tienen pocos amigos tienden a sufrir mayor exclusión social, agresión verbal y física.

- Cuando los estudiantes sienten miedo en la escuela lo atribuyen a alguno de sus compañeros.

- Es importante observar a quien se lo cuentan y quienes ayudan a los alumnos que sufren agresiones; de nuevo son los amigos los primeros tanto en contárselo como en ayudar, triplicando el porcentaje de cualquier otra fuente de ayuda.

- La percepción de alumnado y profesorado sobre conflictos que viven en el centro es diferente. Para los profesores el mayor problema se centra en "los alumnos que no permiten que de la clase”. Para los alumnos este hecho también es un problema, pero les preocupa mucho más la mala relación entre el 
alumnado y sobre todo el maltrato. Son ellos, además, quienes más información poseen sobre estos hechos.

También en el Informe del Defensor del Pueblo y Unicef sobre violencia escolar (2006), se distinguen los siguientes tipos de acoso: exclusión social, agresión verbal, agresión física, amenaza-chantaje y acoso sexual. La exclusión social implica conductas como ignorar o no dejar participar; la agresión verbal, englobaría situaciones de hablar mal de alguien difundiendo falsos rumores, poner motes o insultar. Dentro de la agresión física, se distinguen dos tipos, la directa y la indirecta. La primera serían conductas como pegar a un compañero, mientras que la agresión indirecta haría referencia a situaciones como esconder, robar o romper cosas. La amenaza-chantaje hace referencia a amenazar con o sin armas para meter miedo, u obligar a hacer cosas. Por último, se habla del acoso sexual, ya sea mediante actos o comentarios. Por último, a estos tipos de violencia escolar, cabría añadir el ciberbullying, debido a la incorporación de las Tecnologías de la Información y la Comunicación a la sociedad y al mundo escolar.

Autores como Smith, Mahdavi, Carvalho y Tippet (2006) definen el ciberbullying, como un acto agresivo e intencional, utilizando formas electrónicas de contacto, desarrollado por un individuo o grupo de forma repetida y mantenida en el tiempo sobre una víctima que no puede defenderse fácilmente por sí misma. Willard (2004, 2006) añade, que se produce un envío o publicación de material dañino sobre la víctima, utilizando Internet, y Belsey (2005), indica el carácter intencional de la conducta, que se repite con el único fin de hacer daño.

Las diferencias del ciberbullying respecto a las formas de bullying tradicional se han enumerado como (Campbell, 2005; Mora-Merchán y Ortega, 2007; Smith, 2006):

- Las víctimas no tienen ningún lugar seguro donde refugiarse de sus agresores, en cualquier sitio y en cualquier momento el agresor puede contactar con la víctima para cometer sus actos violentos.

- Existen un mayor número de posibles espectadores, ya que en cuestión de segundos una imagen, vídeo o texto puede ser visto y enviado a una infinidad de personas. 
- Intensidad de las agresiones, ya que la palabra escrita o la imagen tiene mucha más fuerza a la hora de hacer daño que la que posee el mensaje hablado, ya que puede ser releído una y otra vez.

- Posible anonimato del agresor. Debido a las características de las TIC, especialmente del teléfono móvil e Internet, los agresores pueden ocultar su identidad, lo que propiciará la evitación de un castigo en caso de que se descubra la agresión.

Derivado de estos datos, se entiende que el bullying es un tema que se necesita tratar puesto que continúa suscitando malestar en los centros, y las medidas adoptadas hasta el momento no han conseguido erradicar el problema. Los motivos que han llevado a esta situación son muchos y variados, pero la realidad es que debemos empezar a trabajar en red. Esta es la vía para conseguir mejoras de calidad en las relaciones entre los jóvenes, en el clima del centro, y en la educación en general, y para conseguir esto, deben coordinarse centro educativo, profesionales, familias y comunidad. Asimismo, se deben conocer las características de todos los roles implicados en estas situaciones y no tener únicamente en cuenta a los protagonistas más visibles, víctima y agresor, puesto que se trata de un fenómeno grupal, donde todos los estudiantes tienen y juegan un rol asignado.

\subsection{Roles implicados en el bullying}

El maltrato no ocurre aisladamente y en solitario, sino que se produce dentro de un grupo de iguales que tiene conocimiento de lo que ocurre, lo soporta y mantiene a partir de la expresión de cada uno de los miembros del grupo de una serie de roles claramente diferenciados (Salmivalli, Lagerspetz, Björkqvist, Österman y Kauniainen, 1996; Salmivalli, 2009). Este tipo de conductas implica, según Ortega (1998) a todos los presentes durante el maltrato:

"Tiene consecuencias negativas para todos los involucrados. Las víctimas sufren un serio deterioro en la autoestima y el autoconcepto, los agresores se socializan con una conciencia de clandestinidad, que afecta de forma grave a su desarrollo sociopersonal y moral, acercándoles peligrosamente a la 
precriminalidad; los espectadores también pueden verse moralmente implicados, teniendo sentimientos de miedo y culpabilidad” (pág. 50).

Por tanto, se trata de un fenómeno bidimensional, grupal, en el que intervienen un agresor, una víctima, los espectadores o testigos, y los adultos, bien sean padres o profesores. Desde un análisis socio-grupal del acoso, Salmivalli, et. al. (1996) distinguen diversos roles:

- Agresor: dirigen la acción intimidadora y se convierten en el modelo a seguir por los otros.

- Seguidor (incluye a animadores y ayudantes del agresor): atacan e incitan al líder a que continúe con su acción agresión. También pueden mantenerse al margen de la agresión, pero siempre dentro del grupo del agresor.

- Víctima: cuando el $20 \%$ de la clase considera que un niño tiene el rol de víctima, es porque suele ser el blanco de la mayoría de las agresiones que se producen.

- Defensor de la víctima: manifiesta su rechazo por la agresión y muestra empatía por la víctima.

- Público o espectadores: rechazan la agresión de forma pasiva convencidos de que lo que ocurre no está bien pero no lo manifiestan, por miedo a ser las siguientes víctimas.

Cuando nos referimos al ciberbullying, los roles implicados son los mismos que en el bullying tradicional: agresores, víctimas u objetivos y espectadores o testigos, aunque también se reconoce el perfil de agresor victimizado o víctima agresiva ( $\mathrm{Li}, 2006$; Patchin e Hinduja, 2006; Willard, 2006).

Ortega (1998), Olweus (1998) y de manera más reciente Martínez y Musitu (2014), realizan los perfiles psicológicos de los roles de víctimas, agresores y espectadores. Lo más relevante de cada uno de ellos se destaca a continuación:

Las víctimas

- Rendimiento académico variable

- Pocas habilidades sociales, pero puede ser abierto y extrovertido 
- Perfil provocador: estudiante bien integrado pero comete torpezas sociales, y por tanto, es víctima de burlas, marginación social y bromas pesadas. Están bien integrados en la vida académica, y mantienen buenas relaciones con los adultos, por lo que pueden generar envidias. Olweus (1998) se refiere en este sentido a víctimas activas o provocativas

- Sobreprotegidos en el ambiente familiar, que se sienten inseguros al tener que hacer frente a las agresiones

- Buscan protección con grupos reducidos que le ofrecen seguridad

- Deficiencia física o psíquica, como trastornos del aprendizaje

- Poseer una característica diferente: gafas, delgado, gordo, alto, bajo, orejas o nariz con alguna particularidad

- Puede pertenecer a una minoría étnica

- La victimización puede generar más violencia y convertir a la víctima en agresor

- Baja autoestima social

- $\quad$ Sentimientos de soledad

- Aislamiento y rechazo en el aula

Los agresores

- No obtienen buenos resultados académicos

- Hábiles en ciertas conductas sociales, sobre todo en temas de evitación de castigos, dejar en evidencia...

- Siempre tienen una excusa o explicación para justificar sus conductas, sus burlas...

- Argumentos cínicos que justifican y perpetran las conductas, como: "él se lo ha buscado, al venir vestido asî́”

- Con frecuencia son populares y simpáticos con los adultos

- Personalidad problemática, con rasgos con tendencia a la psicopatía

- Probablemente sometidos a maltratos por adultos, seguramente cercanos al ambiente familiar

- Tienen una clara dificultad para empatizar con los otros

- Baja autoestima familiar y escolar

- Actitudes negativas hacia la autoridad y hacia la escuela

- Deseo de una identidad y una reputación social transgresoras de las normas 
En este grupo de los agesores, Olweus (1998), distingue entre los que serían los agresores directos (que a pesar de ser el grupo menos numeroso, es el que establece una relación directa de agresión, con la víctima), y agresores pasivos (refiriéndose a los animadores y ayudantes del agresor. Es el grupo más numeroso, y una gran parte de la responsabilidad de la agresión, es de ellos). Es destacable, que los agresores valoran el dominio (Björkqvist, Ekman y Lagerspetz, 1982) y el prestigio social (South y Wood, 2006). Y existen evidencias longitudinales por las que se puede afirmar que intimidar a algún compañero contribuye a afianzar el prestigio en el grupo (Juvonen y Galvan, 2008). El estatus social sólo puede entenderse en el seno del grupo, puesto que es allí donde se asigna dicho estatus a sus miembros. Como los agresores necesitan testigos de sus demostraciones de poder, se entiende que los compañeros estén presentes en la mayoría de los incidentes de bullying (Hawkins, Pepler y Craig, 2001).

\section{Los espectadores}

- Conocen la problemática del acoso: quienes abusan, quienes son las víctimas, dónde se producen los abusos

- Pueden tener afectado el sistema de creencias, con problemas de disonancia moral y de culpabilidad

- Experimentan en la mayoría de los casos: La ley del silencio. Falsas normas que obligan a "callar"

- Suelen ser jóvenes dominantes, exaltados e impulsivos

- Carecen de empatía con los que les rodean

- Son rebeldes y no les gusta seguir las normas

- Para ellos la violencia es algo habitual y positivo

- Suelen tener un perfil físico más fuerte que los demás, casi siempre superiores a las víctimas

- Padres pasivos o permisivos

- Con antecedentes de intimidación en el sistema familiar

En este sentido, para entender el papel de los espectadores, se han sugerido dos motivos por los que pueden actuar con pasividad: 
- Porque aspiran a mejorar su propio estatus social pareciéndose más al agresor que es quien demuestra tenerlo, y por tanto, permite y favorece que la victimización se perpetre (Hodges y Perry, 1999)

- Por autoprotección, puesto que al posicionarse a favor del agresor, o simulando que se acepta su conducta, se disminuye el riesgo de convertirse en la siguiente víctima (Juvonen y Galvan, 2008)

Los defensores

- No les gusta la agresión y ayudan a la víctima o almenos lo intentan

- Se pueden distinguir dentro de este rol dos subtipos: los posibles defensores, son los que no aprueban el maltrato, pero no hacen nada por detenerlo, porque no saben qué hacer o no se atreven (Olweus, 2001); y los defensores propiamente dichos, que sí ayudan a la víctima, intentando parar la situación de un modo u otro

La asunción de dichos roles por parte de cada estudiante, determinan las relaciones que se establecen entre ellos, y que con el paso del tiempo pueden afectar e incluso deteriorar la dinámica del aula y el clima de convivencia, puesto que en el centro educativo coinciden con frecuencia, casi todos los días. Es por esto, que la interacción entre compañeros ha sido estudiada desde hace mucho tiempo, ya que afecta al desarrollo de la conducta social, y proporciona claves para diferenciar comportamientos adecuados de los que no lo son.

\subsection{Investigación psicológica e intereacciones entre iguales}

La investigación psicológica en temas relacionados con las interacciones entre iguales, nos lleva hasta los estudios realizados por Piaget y Vygotsky.

Piaget (1932), afirma que el niño construye su conocimiento social a partir de las interacciones que mantiene con las personas y con los objetos que le rodean. Las relaciones entre iguales son una condición necesaria para fomentar la autonomía, y al reconocer la igualdad, se favorece la reciprocidad y la cooperación. A través de dicha relación entre iguales, los niños discuten los argumentos que provocan el conflicto 
cognitivo para conseguir una resolución lógica, que les permita lograr el equilibrio. Por lo tanto, los compañeros enseñan un importante principio social que no puede enseñar la familia: la reciprocidad que caracteriza a la mayoría de las relaciones sociales, la necesidad de dar para poder recibir. Llevado a nuestros días, una de las mejores maneras de influir sobre los individuos es a través del grupo de compañeros.

Vygotsky (1978), por su parte, habla de la importancia del contexto social en el desarrollo personal, y en concreto se refiere al contexto educativo como el lugar donde se construye el conocimiento y se atribuyen significados a las cosas, realizando actividades culturales de modo cooperativo entre varias personas.

Desde la Teoría Ecológica, Bronfenbrenner (1979), asegura que la persona interactúa con cada situación del ambiente que influye sobre ella. Por tanto, con el fin de entender las relaciones y características de los diferentes componentes del acoso entre iguales, se deben considerar y analizar niveles como las condiciones de riesgo y de protección, las características individuales y evolutivas, y el contexto en el que se interactúa. Según el enfoque ecológico (Belsky, 1980; Bronfenbrenner, 1979; Díaz-Aguado, 2006) los niveles que hay que considerar en los casos de bullying, son:

- Microsistema. Se trata del contexto inmediato del individuo. Centro educativo.

- Mesosistema. Conjunto de contextos en los que se densenvuelve el individuo y las relaciones que se establecen entre ellos. Familia y escuela.

- Exosistema. Estructuras sociales en las que el sujeto no está activo, pero igualmente influyen. La televisión y las redes sociales.

- Macrosistema, conjunto de esquemas y valores culturales del cual los niveles anteriores son manifestaciones concretas. Sociedad.

Dentro del microsistema escolar, se distinguen tres subsistemas de relaciones interpersonales (Ortega y Del Rey, 2007; Ortega y Mora-Merchán, 2000).

1. El subsistema de los adultos responsables de la actividad. Compuesto por los docentes y el personal de administración y servicios de los centros. La función de este subsistema es la planificación y el desarrollo del currículo.

2. El subsistema profesorado/alumnado. Compuesto por la relación que se establece entre el profesorado y el alumnado. Subsistema caraterizado por la exigencia de obtener resultados académicos, y relaciones jerarquizadas. Los conflictos como la 
desmotivación y la indisciplina, tienden a resolverse dentro de una relación de autoridad desigual.

3. El subsistema de los iguales. Compuesto por los compañeros y compañeras de aula, entendidos como fuente de problemas, pero también de soluciones. Ante un desequilibrio del poder social de los iguales, se inician procesos de acoso y conflicto entre iguales.

El microsistema familiar, según Díaz-Aguado (2006), también tiene su influencia en niños y adolescentes con conductas agresivas. En estos casos, los antecedentes familiares cuentan con la ausencia de una relación afectiva cálida y segura por parte de los padres, que manifiestan actitudes negativas y/o escasa disponibilidad para atender al niño; y fuertes dificultades para enseñarle a respetar límites, combinando la permisividad ante la violencia, con el uso de métodos coercitivos autoritarios, como el castigo físico.

Las condiciones del mesosistema que incrementan el riesgo de violencia durante la infancia y la adolescencia, son el aislamiento de la familia de otros sistemas sociales, como vecinos y amigos, y la cantidad y calidad de apoyo que recibe una familia.

Bronfenbrenner (1979), afirma que el potencial evolutivo de los diferentes contextos que confirman parte del mesosistema durante la infancia y la adolescencia, aumenta cuando existe una comunicación recíproca, y de calidad, entre ellos. Por tanto, hay que estimular la comunicación positiva entre los microsistemas para prevenir la violencia.

Dentro del exosistema, hay que tener en cuenta la televisión y las Tecnologías de la Información y la Comunicación (TIC). Todos los recursos de los que se dispone actualmente, proporcionan a las imágenes una gran velocidad, pero aunque eso puede considerarse positivo en algunos casos, lo cierto es que no hay prácticamente tiempo para reflexionar sobre lo que se ve, sólo para disfrutar de emociones variadas y aceptar de manera pasiva los contenidos o interactuar con los mismos. Además, la repetida exposición a la violencia a través de las pantallas, puede producir habituación y falta de empatía (Díaz-Aguado, 1996; Huesmann, Moise-Titus, Podolski y Eron, 2003). 
Por tanto, debemos tener en cuenta que vivimos en la era de la tecología, y con ello se ha transformado la forma de comunicarse y relacionarse de todos, jóvenes y no tan jóvenes. Las redes sociales, las aplicaciones gratuitas que te permiten hacer prácticamente de todo, los servicios de mensajería instantánea, conllevan un gran avance y muchos aspectos positivos. Pero también es cierto que en los últimos años se ha producido un incremento vertiginoso en el número de episodios de acoso, humillación y violencia protagonizados por escolares haciendo uso de las TIC, generalizando las situaciones de bullying a nuevos escenarios, dando lugar al concepto ciberbullying (Belsey, 2005), o bullying electrónico (Kowalski y Limber, 2007; Raskauskas y Stoltz, 2007).

La cultura y la sociedad en la que se desarrolla una persona, influye. De manera que los menores, deben responzabilizarse de las tareas que le permiten estar en contacto con personas de entornos diferentes al suyo. El paso de un sistema a otro, es lo que permite el desarrollo de cada niño y adolescente, al permitirles poner en marcha nuevas conductas y relaciones.

Relacionado con los microsistemas, y las relaciones que se establecen entre los mismos, cuando hablamos de bullying, no existe una única causa que pueda explicar dicha situación. Este es uno de los temas sobre los que existe cierto consenso en la comunidad científica, puesto que se apunta a que son múltiples los factores que están relacionados con este tipo de violencia. Los factores que se relacionan con la violencia escolar entre iguales pueden ser según Martínez y Musitu, (2014), familiares, individuales (para el agresor y la víctima) y escolares.

Factores individuales

Agresor:

- Baja autoestima familiar y escolar

- Fracaso escolar

- Liderazgo en grupos conflictivos

- Actitudes negativas hacia la autoridad y hacia la escuela

- Deseo de identidad y una reputación social transgresoras de las normas

- Falta de empatía (dimensión emocional)

En este apartado se podría añadir también, que rechaza responsabilidades. 
Víctima:

- Aislamiento y rechazo social en el aula

- Sentimientos de soledad

- Baja autoestima social

- Falta de asertividad de habilidades sociales

- Rasgos físicos o culturales distintos a los de la mayoría

Factores familiares

- Carencia de afecto, apoyo e implicación de los padres.

- Problemas de comunicación familiar.

- Estilo parental autoritario y uso excesivo del castigo

- Permisividad y tolerancia de la conducta agresiva del hijo

- Disciplina inconsistente, inefectiva y demasiado laxa o demasiado severa

- Conflictos frecuentes entre cónyuges o entre padres e hijos

- Utilización de la violencia en el hogar para resolver conflictos familiares

- Problemas psicológicos y conductuales en los padres

Factores escolares

- Clima escolar negativo

- Tolerancia en la escuela hacia la violencia (o hacia alguna de sus formas)

- Valores competitivos e individualistas

- Falta de modelos cooperativos

- Normas de convivencia no consensuadas y aplicadas de forma arbitraria

- Elevado número de alumnos en situación de aislamiento y rechazo social

- Bajos niveles de apoyo percibido del profesor

- Escasa importancia concedida al desarrollo de compentencias personales y sociales en los alumnos

- Carencia de habilidades sociales en los alumnos para resolver los conflictos interpersonales de forma pacífica

De todos los factores que se han comentado, los que pueden deteriorar más el clima de centro y la convivencia en los centros, son los factores escolares. Para ofrecer una solución a dichas dificultades, se crearon una serie de normas, objetivos y estrategias 
para prevenir y actuar en temas de violencia entre iguales, recogido todo ello en un documento único y público en los centros educativos: los Planes de Convivencia. Desde todos los ámbitos, órganos de gobierno y coordinación, equipo directivo y tutores, se fomenta el aprendizaje y la práctica de conductas de responsabilidad y respeto hacia los demás.

\subsection{La Convivencia en los centros de Enseñanza Secundaria Obligatoria}

Según Andrés y Barrios (2009), el maltrato entre iguales es un fenómeno que afecta en sus formas más graves o llamativas a un pequeño sector del alumnado, pero actúa como un indicador de la calidad de las relaciones de convivencia, por lo tanto, hay que intervenir de manera intencionada y planificada.

El Plan de Convivencia de un centro se recoge en un documento público en el que se concreta el funcionamiento del centro y la organización que se va a llevar a cabo en temas de convivencia, así como los objetivos que pretenden alcanzar, y el modo en el que se va a actuar para conseguirlos. Por lo tanto, resulta el marco operativo donde se insertan los sistemas de ayuda entre iguales. Este documento trata de desarrollar en el alumnado del centro, comportamientos adecuados basados en el respeto, que les permitan resolver problemas y obtener una educación de calidad a través de una resolución pacífica de los conflictos. No se debe entender la convivencia como un aspecto a trabajar de manera aislada en los centros, ya que tiene que ser un contenido transversal que va más allá de una mera aplicación de medidas disciplinarias. Se debe producir una enseñanza en tolerancia, aceptación de la diversidad, respeto, resolución de conflictos a través del diálogo, etc. Para conseguir una buena convivencia en cualquier centro educativo, es necesario potenciar conductas participativas y de comunicación. El tema de la convivencia y los conflictos en el aula, pueden causar preocupación e inquietudes en los diferentes miembros de la comunidad educativa. Y este es un motivo más que justificado para centrarse en la prevención de dichas situaciones, y conseguir recursos y apoyos que permitan prevenir situaciones como el bullying en las aulas.

Algunos de los aspectos más relevantes de la Orden de 31 de marzo de 2006, de la Consejería de Cultura, Educación y Deporte, que es la que regula el Plan de Convivencia, son los que se detallan a continuación. 
La composición de las comisiones del consejo escolar del instituto debería ser como mínimo del director/a, dos profesores, dos padres o madres de alumnos, y dos alumnos elegidos por el sector correspondiente. Los padres junto a los profesores, han de denunciar situaciones inaceptables, pero a la vez han de participar en grupos de discusión y crear equipos de mediación o de ayuda entre iguales dentro de la comisión de convivencia.

Según la Confederación Valenciana de Padres de Alumnos (COVAPA), los principios de tolerancia, respeto y cooperación han de jugar un papel importante, y se ofrece como recursos:

- Las comisiones de convivencia de los Consejos Escolares, como la comisión delegada encargada de la prevención y corrección de conductas.

- Los equipos de mediación, como agentes de intervención directa, dinamizadores de la cultura del diálogo y resolución de conflictos.

- Las AMPA en su papel de impulsoras de la cultura de participación de las familias en los centros educativos.

Serán los centros docentes los que deberían fomentar la convivencia entre los miembros de la comunidad a través de la prevención de las situaciones conflictivas, la resolución pacífica de aquellos conflictos que puedan producirse y, la rehabilitación del alumno que tenga un comportamiento que se desajuste a la norma, para conseguir un adecuado clima del centro. Y por lo tanto, dentro de esta prevención pueden encajar perfectamente los programas alumno ayudante y alumno mediador.

Es interesante resaltar que el papel de la función tutorial tal y como aparece reflejado en la Orden, parte de la idea de que para conseguir un buen clima de convivencia a nivel de centro, es mejor adoptar soluciones grupales, en lugar de individuales. Para conseguirlo, se precisa la creación de una Comisión de convivencia, que recabe información sobre los problemas reales de convivencia en el centro, y que elabore normas que vayan acordes a dichas dificultades reales.

La acción tutorial, por lo tanto, es un elemento crucial en el fomento de la convivencia en el centro y se debe orientar al desarrollo de una serie de actividades que mejoren las relaciones entre los miembros del centro y potencie el desarrollo de los valores. De 
hecho, en el artículo cuarto se comenta que se prestará especial atención al tiempo de tutoría para la educación en la convivencia y la mediación de conflictos.

En la Orden de 31 de marzo de 2006, de la Comunidad Valenciana, no se hace referencia en ningún momento a la posibilidad de crear un servicio de mediación como una medida adicional en los centros para mejorar la convivencia.

En el Decreto 39/2008, de 4 de abril, del Consell, sobre la convivencia en los centros docentes no universitarios sobre los derechos y deberes de todos los miembros de la comunidad educativa, se persigue el mismo objetivo que la Orden de 2006, conseguir una buena convivencia escolar que permita el desarrollo integral del alumnado y facilite el trabajo docente con total normalidad para que el sistema educativo alcance los fines y objetivos previstos. Y lo más destacable es que el artículo 7 dedicado a la mediación, sí contempla la posibilidad de crear un servicio de mediación para gestionar los conflictos que puedan surgir:

1. La mediación es un proceso de resolución de conflictos que fomenta la participación democrática en el proceso de aprendizaje, posibilitando una solución del conflicto asumida y desarrollada con el compromiso de las partes.

2. Dentro del ámbito de su autonomía organizativa, en los centros docentes se podrán constituir equipos de mediación o de tratamiento de conflictos. Los componentes de estos equipos serán docentes del propio centro y recibirán la formación específica necesaria para la realización de esta tarea por parte de la consejería competente en materia de educación.

3. El plan de acción tutorial potenciará el papel de la tutoría en la prevención y mediación para la resolución pacífica de los conflictos en la mejora de la convivencia escolar.

Más adelante, en el artículo 38, entre las competencias para aplicar las medidas educativas correctoras, de nuevo declara que será el director/a del centro y la comisión de convivencia los que deberán facilitar la mediación en la resolución de conflictos. De manera que serán estos órganos los que decidan qué casos son proclives a participar en la mediación y cuales no.

Por último, en el artículo 54 sobre los deberes del profesorado, es interesante resaltar el apartado n), que sostiene que es un deber formarse en la mejora de la convivencia en los 
centros docentes y en la solución pacífica de conflictos. Por lo tanto, es interesante que los profesores tengan interés por una formación continua que les permita adquirir destrezas para tratar estos temas de manera transversal o de manera específica en tutoría

El Decreto 39/2008, de 4 de abril, del Consell, sobre la convivencia en los centros docentes no universitarios, en su artículo 6, establece los instrumentos básicos para la consecución de un adecuado clima de convivencia en el centro.

1) Elaboración de un plan de prevención de la violencia y promoción de la convivencia.

2) Incluye el Registro Central, creado por la Orden de 25 de noviembre de 2005, que había sido derogada por la Orden de 12 de septiembre de 2007, de la Conselleria de Educación.

3) Establece pautas para la elaboración del reglamento de régimen interno del centro.

4) Ordena la creación del plan de convivencia del centro.

Desde la promulgación del Decreto del Gobierno Valenciano 233/2004, de 22 de octubre, por el que se crea el Observatorio para la Convivencia Escolar, se han propuesto e impulsado medidas de carácter preventivo que han dado lugar al Plan de Prevención de la Violencia y Promoción de la Convivencia en los Centros Escolares de la Comunitat Valenciana (PREVI), que establece medidas y facilita protocolos de actuación con el fin de ayudar a los centros a prevenir y gestionar situaciones de conflicto. Este plan que ofrece una atención global, integra las siguientes medidas, para que estén al alcance de toda la comunidad educativa:

1. Medidas de prevención dirigidas al sistema educativo para que se pueda intervenir con instrumentos sencillos y operativos así como favorecer un clima escolar en el que la violencia no se tolera. Con este fin, se ofrecen recursos, formación e información tanto para profesores, como familias, equipo directivo y persnal de los centros. El fin último, trabajar para que estos se sientan seguros y protegidos. 
2. Medidas de prevención concretas dirigidas a la población de riesgo. Con el fin de ofrecer una respuesta inmediata a los estudiantes que sufren alguna situación de violencia, se desarrollan unidades de atención y prevención que atienden consultas e incidencias y ofrecen asesoramiento. Protocolos de asistencia jurídica a docentes, y protocolos conjuntos Educación-Oficina de atención del delito.

3. Y por último, medidas de prevención y sensibilización dirigidas a toda la sociedad, a través de campañas de publicidad y sensibilización, charlas informativas, talleres y congresos.

De manera que todas las medidas planificadas para el sistema educativo se centran en la prevención e intervención, para favorecer un clima escolar seguro.

Finalmente, la Orden 62/2014, de 28 de julio, de la Conselleria de Educación, Cultura y Deportes, por la que se actualiza la normativa que regula la elaboración de los planes de convivencia en los centros educativos de la Comunidad Valenciana y se establecen los protocolos de actuación e intervención ante supuestos de violencia escolar, aporta información y medidas de actuación más acordes a las demandas de la sociedad.

En el artículo 5, indica que el plan de convivencia debe conseguir el clima de convivencia adecuado, a través de acciones para concienciar, y sensibilizar a toda la comunidad educativa, puesto que es responsabilidad de todos los que participan en la vida del centro.

Destacables son los artículos 8 y 10. Artículo 8. Medidas y acciones orientadas a la promoción de la convivencia y a la prevención de conflictos, para conseguir un adecuado clima educativo en el centro.

a) Actuación de éxito escolar, modelo dialógico de prevención de conflictos. Éste se fundamenta en el diálogo como herramienta para superar las desigualdades que tiene como objetivo evitar agresiones en el centro educativo.

b) Acciones de diagnóstico que faciliten la detección y prevención de violencia.

c) Acciones que fomenten la participación del alumnado a través de estrategias basadas en la ayuda entre iguales. 
d) Actividades que faciliten la participación de toda la comunidad educativa en acciones de prevención y promoción de la convivencia del centro, para conseguir espacios libres de violencia.

e) Acciones para dar a conocer el plan de convivencia y el reglamento de régimen interno a toda la comunidad educativa.

f) Acciones que fomenten el respeto a la diversidad y la igualdad entre hombres y mujeres, a través de la educación de los sentimientos y de las emociones.

g) Acciones y medidas de atención a la diversidad, que generen o fomenten medidas inclusivas con el fin de crear un clima de respeto entre todos los miembros de la comunidad educativa.

h) Acciones que contribuyan, a través del currículum, a mejorar la convivencia a través de competencias básicas

i) Actividades de acogida para el alumnado que se matricula en el centro por primera vez y para sus familias.

j) Actividades de sensibilización a toda la comunidad educativa a los casos de violencia escolar grave, para facilitar la prevención, detección y eliminación de estas manifestaciones.

k) Actividades dirigidas a prevenir y resolver conflictos en contextos interculturales.

Artículo 10. Mediación en la resolución de conflictos.

El Decreto 39/2008 de 4 de abril, en su artículo 7, autoriza a los centros docentes para constituir equipos de mediación escolar. En el plan de convivencia del centro se incorporarán las acciones en que participen los equipos de mediación y se especificará:

- Casos de conflicto que son derivables hacia los equipos de mediación.

- Procedimiento para derivar un caso de conflicto al equipo de mediación.

- Agentes que intervienen en la mediación en el centro.

- El procedimiento a seguir para la mediación.

- El procedimiento de seguimiento del compromiso pactado entre las partes.

También se indica que el equipo de mediación podrá estar constituido por profesorado, por alumnos y/o alumnas y por padres y/o madres. Además, podrán realizar también 
tareas de mediación otros profesionales externos al centro, con formación para ello, como es el caso de los mediadores interculturales acreditados según la Orden 8/2011, de 19 de mayo.

Cuando el procedimiento de mediación afecte al alumnado, éste no estará exento del cumplimiento de las correcciones educativas o disciplinarias que le correspondan, por el incumplimiento de las normas de convivencia. Pero, el hecho de utilizar de manera voluntaria el recurso de la Mediación, y cumplir con los compromisos acordados, se podrá tener en cuenta como atenuante.

Los profesores del equipo de mediación escolar que realicen formación del alumnado, del profesorado y de las familias, tendrán reconocimiento y certificación como ponentes en el plan de formación del centro, según la Orden 65/2012, de 26 de octubre, de la Conselleria de Educación, Formación y Empleo, que establece el modelo de formación permanente del profesorado.

La dirección general correspondiente a la Conselleria de Educación, Cultura y Deporte tendrá en cuenta la existencia de equipos de mediación en los centros escolares, en los criterios de valoración para la autorización de los programas experimentales que contemplen acciones de compensación educativa y/o relacionados con la mejora de la convivencia escolar. Asimismo, podrá ser considerada como una acción de calidad dentro de los planes estratégicos de los centros educativos.

En el próximo capítulo, se analizan dos programas de ayuda entre iguales, como posible medida de prevención del maltrato, analizando las características y estructuras de dichos programas. Esta opción es muy interesante, puesto los iguales juegan un papel importante a la hora de ofrecer protección a los compañeros y pueden prevenir incluso la victimización. También se implica a los espectadores y defensores, con el fin que se creen redes de apoyo a las víctimas y el clima en el centro sea más agradable y seguro para todos. 


\section{Para resumir...}

- Existe poco consenso a la hora de establecer un único concepto para definir el proceso de violencia que se da entre iguales en el ámbito académico: Bullying, acoso escolar, maltrato entre iguales, intimidación, mobbing escolar.

- Las características de bullying son: conducta física o psicológica que ejerce un alumno/a (agresor) contra otro (víctima) de manera intencional. Por tanto, existe desequilibrio de poder, con un marcado componente grupal o colectivo, puesto que el agresor suele estar apoyado por un grupo y aparecen observadores pasivos. Este hecho se prolonga y repite en el tiempo, produce indefensión en las víctimas, y puede pasar inadvertida a los adultos.

- Las características del cyberbullying son: agresión repetida que se mantiene en el tiempo con intención de causar daño, utilizando las TIC (en todas sus variedades). Agresor y víctima pueden tener relación o contacto en la vida real, aunque puede no haber situaciones de bullying en el contexto físico. En esta modalidad de acoso, la cantidad de observadores es incalculable.

- El bullying se debe analizar a partir de los factores de riesgo y protección, características individuales, evolutivas de cada implicado, así como los contextos familiar y escolar en los que se interactúa. Para ello, hay que tener en cuenta sobre todo, el microsistema y el mesosistema de cada individuo.

- El maltrato entre iguales es un fenómeno grupal, en el que se distinguen diversos roles: agresores, seguidores (animadores y ayudantes del agresor), víctima, defensor de la víctima y público o espectadores. Cada rol tiene unos perfiles psicológicos asociados, que hay que considerar para llevar a cabo la intervención psicoeducativa.

- Los centros educativos cuentan con el Plan de Convivencia, para establecer procedimientos y actuaciones y así resolver conflictos de manera pacífica. En la Comunidad Valenciana la normativa existente en temas de Convivencia Escolar, más destacable es la siguiente:

- Orden de 25 de noviembre de 2005, de la Conselleria de Cultura, Educación y Deporte, por la que se regula la notificación de las 


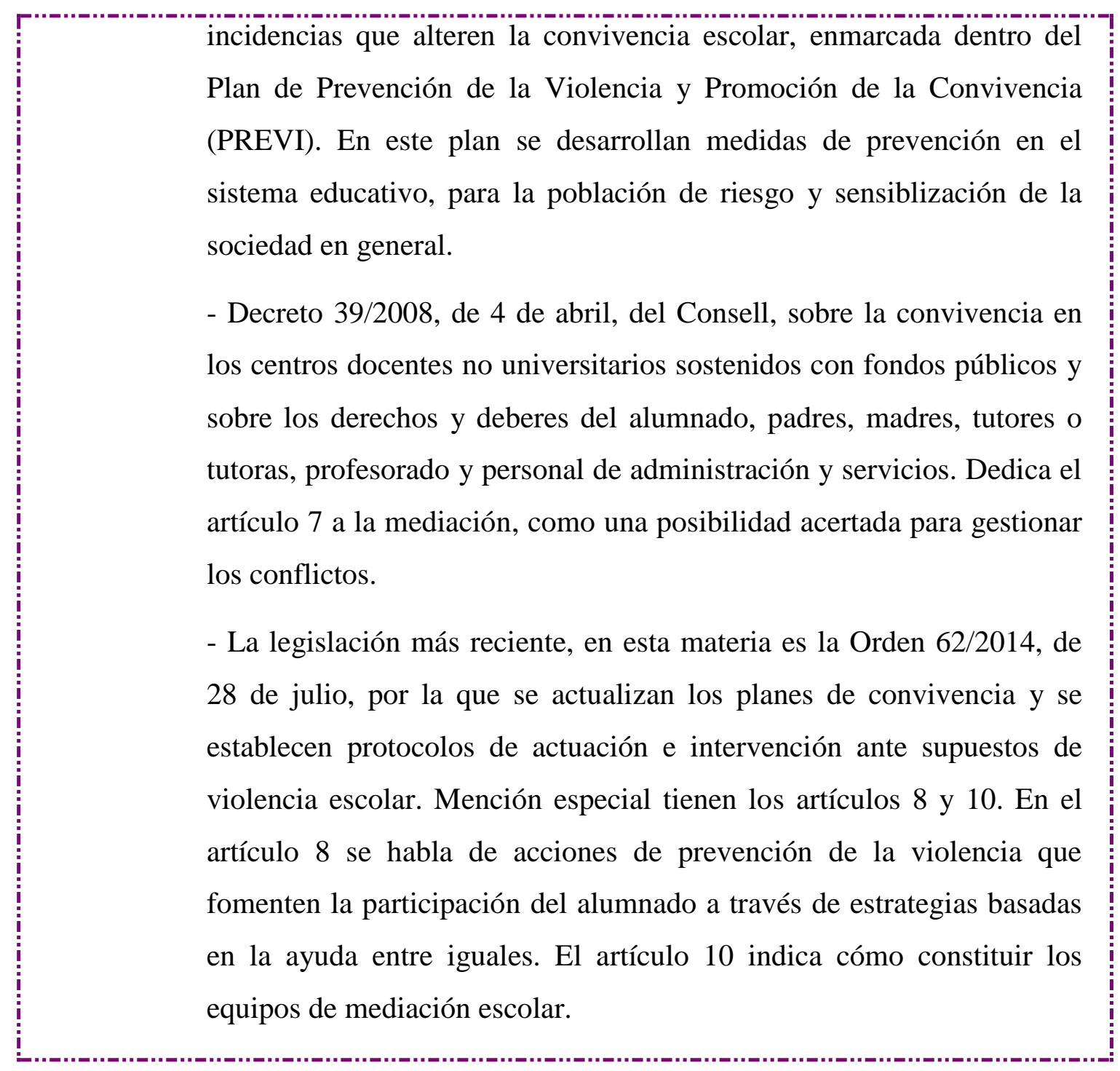




\section{CAPÍTULO 2. LOS SISTEMAS DE AYUDA ENTRE IGUALES}





\section{CAPÍTULO 2. LOS SISTEMAS DE AYUDA ENTRE IGUALES}

\subsection{Justificación}

La prevención del bullying, sin duda es fundamental para evitar que un alumno se convierta en maltratador. Pero también lo es que exista un clima social y una conciencia personal y colectiva en la que sea palpable el rechazo hacia ese tipo de conductas de maltrato entre iguales (Informe del Defensor del Pueblo y UNICEF, 2006).

La aparición de manifestaciones de violencia se relaciona, habitualmente, con una diversidad de factores de diferente naturaleza. Y de este carácter multifacético y multidimensional de la problemática de la violencia y la convivencia escolar se deduce según Adrián y Clemente (2004), que cualquier abordaje preventivo o corrector será, necesariamente, complejo, evitando estrategias de actuación unilaterales e implicando a diferentes ámbitos de actuación.

Los programas más efectivos de prevención de la violencia, son los que van dirigidos a los menores de entre once y catorce años, es decir los primeros cursos de la Educación Secundaria Obligatoria (Farrington y Ttofi, 2009; Yeager, Fong, Lee y Espelage, 2015), antes de que los hábitos se consoliden, mientras son influenciables y todavía existe la oportunidad de reforzar el autocontrol, la autocompasión, la tolerancia, el sentido a la autocrítica y la empatía. Si se consigue que un menor, incorpore estas cualidades a su repertorio o bagaje personal, tendrá un impacto positivo, puesto que esa manera de ser y de actuar lo acompañará a lo largo de la vida, de manera que también se transmitirá a las generaciones siguientes.

Las intervenciones dirigidas a los grupos de iguales para combatir la intimidación deben ser siempre reforzadas, puesto que si actuamos sobre los testigos, la repercusión esperable será mucho mayor. Además, estos sistemas de apoyo entre iguales, pueden involucrar a los estudiantes, docentes, personal de administración y servicios, familias, etc., en definitiva, a todos los implicados en la comunidad educativa para combatir sutilmente el acoso y la victimización en el contexto entre iguales (Gázquez, Cangas, Padilla, Cano y Pérez, 2005).

Según Naylor y Cowie (1999), hay una diferencia relacionada con la intimidación y el género a medida que se avanza a través de los años de adolescencia. Alternativamente, 
es posible que al aumentar la edad hasta la adolescencia, los niños se vuelvan más reacios que las niñas a ser intimidados o a informar de dichas situaciones, cosa que las niñas cada vez están más dispuestas a hacer. Aproximadamente el 15\% de las víctimas (dos tercios de los cuales son niños) no comunican su situación a nadie para que no sea un motivo de preocupación. Sin embargo, cabe señalar que este porcentaje es sustancialmente inferior a los obtenidos en otros estudios. Whitney y Smith (1993) encontraron que el $50 \%$ de alumnos acosados no se le dijo a nadie, y Smith, Shu y Madsen (2001) hallaron que el 30\% no se lo dijo a nadie. Esto sugiere que la presencia de un sistema de apoyo entre iguales puede ser favorable en estos casos, en los que las víctimas se deciden a contar a alguien de confianza lo que ha sucedido. Hay que apostar por la prevención de los conflictos entre iguales en el ámbito educativo, para conseguir una mejora de la calidad. Tal y como encontraron en sus trabajos Naylor y Cowie (1999), Cowie y Olafsson (2000) o Arellano (2008), los métodos de ayuda entre iguales pueden no reducir la totalidad de la incidencia del acoso escolar en los centros, pero aún así los usuarios se sentían tan satisfechos que consideraron que la puesta en marcha de sistemas de ayuda entre iguales redujo el impacto negativo del acoso que estaban sufriendo e hizo más aceptable para ellos informar sobre el mismo. Así, aumentó el número de víctimas que contaban su sufrimiento a un profesor o amigo y encontraron útil la protección y seguridad que les daba la presencia de alumnos ayudantes en la escuela, porque entendían que era un centro que se preocupaba por ellos.

Ya a finales de la década de los noventa, el Consejo de Europa, a través del informe Vettenburg (1999), apostaba por una opción preventiva de estas situaciones en el que toda la comunidad educativa (profesores, familias, alumnos, comunidad) se viera implicada en la prevención de la violencia y la mejora de la convivencia (Ortega, 2006; Rigby y Slee, 2008).

Por todo ello, resulta difícil concretar qué se entiende por educación entre pares de una manera rigurosa, ya que podemos hablar de situaciones informales en las que los iguales se juntan de manera espontánea como ya se ha comentado, o de situaciones más estructuradas a partir de propuestas cooperativas pedagógicas concretas, para planificar una intervención y por lo tanto, hablar de una situación formal estructurada, como los servicios de mediación escolar. 


\subsection{Concepto y eficacia de los programas}

¿Qué se entiende por programas de ayuda entre iguales? ¿Realmente son eficaces para mejorar la convivencia en los centros y prevenir las situaciones de violencia escolar?

\subsubsection{Concepto de sistemas de ayuda entre iguales}

Todavía en la preadolescencia, el énfasis de la relación se centra en las cualidades personales de los participantes en busca de cooperación, intimidad, confianza y respeto mutuo. El amigo se convierte en la persona irremplazable (Erwin, 1998). En la adolescencia, se incrementa el sentido de identidad compartida valorándose muy especialmente la confianza, la lealtad, el apoyo y el compartir intimidades entre los iguales. En este sentido, los objetivos de las relaciones de amistad-ayuda (Cowie, 1995, 2014) son los siguientes:

- Promover el desarrollo personal de los alumnos ayudantes.

- Utilizar ayudantes-compañeros para el cuidado y apoyo de otros compañeros.

- Tener una influencia positiva en el clima emocional del centro escolar.

- Aportar un vínculo entre alumnos con problemas y el ámbito de orientación-tutoría.

Según Cowie y Sharp (1996), los jóvenes pueden asumir responsabilidades acordes a su edad, para abordar de forma constructiva los problemas que pueden encontrar en sus vidas. Dichos problemas se relacionan con tres grandes campos de intervención educativa:

- Visión cooperativa e inclusiva del bienestar general en el centro escolar.

- Puesta en práctica de habilidades sociales que mejoran la autoestima de los alumnos y evitan comportamientos violentos en la comunidad educativa, y

- Un desarrollo gradual de las técnicas de solución de conflictos en el día a día en la vida en los centros escolares.

Actualmente, las situaciones que se dan en las instituciones escolares, se resumen en que los alumnos se vuelven vulnerables a las posibles ofensas o agresiones de sus propios compañeros. Sin embargo, son los propios compañeros quienes ofrecen el 
consuelo y a quienes se acude para pedir y recibir ayuda, además de ser los primeros informados de situaciones personales difíciles.

Los sistemas de ayuda entre iguales tienen como base la actuación dentro del medio escolar donde se potencia la comunicación y negociación de los conflictos, dando voz y espacio para que toda la comunidad educativa pueda manifestar sus necesidades personales, creando situaciones de aprendizaje en el medio escolar en las que los alumnos se escuchan entre sí, se preocupan unos por los otros y se ayudan. El objetivo de estos programas, por tanto, es reducir las conductas que favorecen el bullying, y aumentar el apoyo a la víctima. Las formas en las que se ha expresado esta ayuda de los iguales tanto en primaria como en secundaria, según Ortega y Del Rey (2001), han sido:

a) La mediación escolar. No se aconseja en situaciones de bullying. Para que haya mediación, debe haber simetría en las relaciones. Se podría realizar, sólo cuando se haya restablecido la simetría, haya diálogo y se haya reducido la ansiedad de la víctima y la prepotencia conductual del agresor.

b) La ayuda entre iguales. Finalidad es que chicos/as con problemas encuentren en la conversación y el apoyo con otros/as un lugar de comunicación optimizada, de estímulo a la reflexión sobre los propios sentimientos y los ajenos, y en general de apoyo a la autoestima de los escolares en riesgo (Ortega y Del Rey, 2001). Mediante ellos, las víctimas desarrollan habilidades sociales necesarias para utilizar estrategias de afrontamiento eficaces y elevar su autoestima al encontrar en ellas mismas las respuestas a sus problemas. Todo el alumnado se ve enriquecido por este tipo de programas, ya que gracias a ellos observan que la ley del silencio no siempre les resulta positiva, que es necesario ayudar a los que lo necesitan y que una víctima hoy puede ser un líder mañana.

c) Programas de fortalecimiento de la asertividad. Entre sus objetivos principales destacan: necesidad de afianzar sentimientos de seguridad y confianza en uno mismo; conseguir distancia emocional hacia los que les pueden dañar; conocer y dominar los sentimientos y emociones propios, así como las actitudes, gestos y lenguaje corporal; $\mathrm{y}$, en última instancia, que defiendan el derecho de todo ser humano a "Decir NO".

d) Programas de desarrollo de la empatía. Trabajar directamente con los agresores. Hay que desarrollar la capacidad de empatía del agresor, y que entienda lo que está sintiendo la otra persona que interactúa con él/ella. 
e) Método Pikas o Método de Reparto de Responsabilidades (Ortega, 1998; Pikas, 1989), consiste en intervención directa con todos los que se ven envueltos en problemas de violencia interpersonal, independientemente del rol que tengan. Requiere de la intervención de expertos para su puesta en marcha.

El rol de ayuda se describe como el de un compañero que ampara, escucha y ayuda a sus iguales cuando surge un conflicto o se sienten desvalidos, tristes, solos, etc., con un marcado carácter preventivo, dado que reduce las posibilidades de situaciones violentas y de sufrimiento y favorece una mejor integración social del alumnado en su conjunto. Por tanto, se enfatiza el beneficio de contar con apoyo social, con buenos compañeros (que no tienen que ser necesariamente amigos) durante la trayectoria académica (Andrés y Barrios, 2009).

Un aspecto que hay que tener muy en cuenta es que la imagen de ayuda va asociada a la feminidad, y por lo tanto, la participación de los chicos suele ser bastante menor en número.

En la mayoría de las intervenciones descritas hasta el momento, los compañeros están en una posición clave, tal y como comenta Cowie (2014) y Salmivalli, Kaukianien y Voeten (2005). Ellos son los que junto a la formación de los adultos, pueden ayudar a tomar medidas contra el acoso. Esto ocurre de manera informal y espontánea en sus interacciones cotidianas. Sin embargo, los compañeros también pueden ser utilizados para atribuir funciones de ayuda oficial a sus iguales. Diferentes prácticas de asesoramiento entre pares han sido ampliamente utilizadas en los ámbitos de la educación para la salud y la enseñanza de las habilidades académicas, así como en la prevención y la reducción de la intimidación (Cartwright, 1995; Del Rey y Ortega, 2001) y en la promoción social de habilidades de interacción (Bradshaw, 2015; Gardner, 1999).

Cuando se trata de la intimidación, el asesoramiento entre iguales ha sido utilizado principalmente para prestar apoyo a los niños víctimas. Sin duda, es importante que las víctimas no obtengan apoyo sólo de los adultos, sino también de sus compañeros. En este sentido, la tradicional labor de los alumnos ayudantes y mediadores como oyentes y seguidores de cada uno de los niños, niñas y adolescentes es muy valiosa. 
Por ejemplo, en una investigación sobre el autoconcepto social de las víctimas (Salmivalli, 1998) se ha demostrado que los diferentes dominios de contenido (académicos, relacionados con la familia, de comportamiento, físico, emocional y social) son negativos, ya que se sienten rechazados por sus compañeros e incompetentes en sus relaciones sociales con ellos. Y es que aunque el apoyo prestado por los profesores y los padres es importante para las víctimas, sus mayores problemas no los pueden compartir o solucionar los adultos, aunque se sientan queridos y aceptados por ellos (Salmivalli, 1998). Lo que necesitan son las experiencias positivas con sus compañeros, y el apoyo de los iguales puede ser un punto de partida para conseguirlo.

Por tanto, con todo esto, se puede comentar brevemente qué es y qué no es un alumno ayudante, para conseguir una idea más clara de las funciones de dicha figura:

Qué no es un Alumno Ayudante: el alumno cotilla, el que cuenta lo que ha visto a los demás, el ayudante del profesor, un tutor, el que siempre queda bien con el profesor, un alumno superior al resto.

Qué es un Alumno Ayudante: una persona que intenta ayudar, hablando con los que están aislados y facilitando o ayudando en su integración en el centro, y también escucha, anima, acompaña, se pone en el lugar del otro, da confianza, ofrece apoyo, media de manera informal y deriva los problemas graves a los adultos que puedan ofrecer soluciones.

Cuando se habla de ayuda entre iguales, muchas son las denominaciones que se le pueden dar al joven que participa, para ayudar a otros alumnos, a combatir el bullying desde la prevención. Por eso es necesario que antes de continuar, se puntualicen las diferentes definiciones que se pueden dar, según las funciones que éstas impliquen:

- Acompañante: este sería un "alumno-sombra", que acompañaría durante un período de tiempo a otro alumno en sus movimientos por el centro (Fernández, 1998).

- Amigo: en este caso, un alumno ayuda a un compañero a incorporarse a la vida relacional del resto de sus compañeros. Su participación se consideraría una mediación informal.

- Ayudante: compañero que ampara y ayuda a sus iguales cuando surge un conflicto o están en situaciones de desconsuelo o con necesidad de apoyo por 
falta de integración en el centro, se sienten desvalidos, tristes, etc. (Fernández, Villaoslada y Funes, 2002).

- Ayudantes de recreo: son figuras singulares puesto que hasta el primer ciclo de secundaria el recreo es el lugar de mayor riesgo y donde se produce el mayor número de incidentes de violencia entre compañeros (Fernández y Quevedo, 1989).

- Consejero: este sistema supone un nivel superior de entrenamiento y complejidad. Una serie de alumnos de forma voluntaria se presta a ser consejero de otros compañeros con necesidad de ser oídos. Éstos actúan como oyentes de los problemas o necesidades de comunicación de otros compañeros. Se les indican unas pautas claras sobre cuándo contar a los profesores los hechos comunicados. La supervisión corre a cargo de un profesor especializado en estas tareas (Cowie y Sharp, 1996).

- Delegado: ejerce la representación del alumnado de su clase, y es el portavoz, para hacer llegar las propuestas de la clase, junto con el subdelegado, al tutor del grupo, así como de informar de los acuerdos conseguidos, al resto del profesorado. Debe preocuparse y velar por el buen uso de las instalaciones del aula y del centro. En resumen, cumple las funciones de representatividad y liderazgo.

- Hermano mayor: representa a un alumno de un curso superior que se encarga de ayudar a alumnos recién llegados al centro. Este modelo es adecuado para la transición de la escuela al instituto, y los alumnos más veteranos, pueden servir de guías de las actividades colectivas para los recién llegados de menor edad al centro, que estadísticamente muestran un elevado nivel de ansiedad y miedo a la llegada al nuevo centro escolar (Fernández y Quevedo, 1991).

- Informadores/orientadores: de expectativas académicas y muchos otros formatos de asociaciones basadas en elementos de amistad. Consistiría en alumnos de cursos superiores, con experiencia en aspectos administrativos, continuación de estudios, que pueden informar y orientar a los compañeros más jóvenes a la hora de tomar decisiones académico-formativas.

- Mediador: un alumno mediador ayuda a través de una negociación cooperativa a resolver conflictos interpersonales a las dos partes enfrentadas que recurren a este servicio, para llegar a un acuerdo satisfactorio. Este programa es el que 
utilizan los centros que se comparan en este trabajo, y por tanto, son objeto de estudio de esta tesis.

- Tutor: un alumno explica a otro los contenidos de aprendizaje. Con esta figura se obtienen diferentes objetivos. En primer lugar, el alumno que enseña aprende mejor lo que está explicando y el que aprende, puede comprender mejor ya que en la relación alumno-alumno se rompen barreras de lejanía y autoridad que pueden dificultar la misma tarea realizada por el profesor. En segundo lugar, ambos alumnos aprenden a pensar juntos, a compartir ideas, a comprender los sentimientos del otro a través del proceso mismo de enseñanza aprendizaje (Fernández, 1998).

- Voluntario: las funciones de este grupo de alumnos tendrán que ver con el contenido del voluntariado al que se hayan apuntado. Es decir, se promueve en los alumnos la capacidad de desarrollar sus destrezas de ayuda en sus interacciones diarias (Fernández, 1998).

En función de los tres tipos de sistemas que plantean Cowie y Sharp (1998) y de los objetivos que persiguen dichos sistemas en sus relaciones, se pueden agrupar las denominaciones de los diferentes sistemas de ayuda entre iguales del siguiente modo:

- Basados en interacciones de amistad, se podría hablar de alumnos acompañantes, ayudantes de recreo o amigos.

- Basados en orientación a compañeros, se engloba a los alumnos consejeros, hermanos mayores, voluntarios o ayudantes.

- Mediadores escolares y resolución de conflictos, se trata de alumnos mediadores, como se analiza a lo largo de este trabajo.

Se podría añadir un cuarto tipo que recogería los sistemas de ayuda entre iguales basados principalmente en interacciones académicas, y que incluirían: alumnos tutores, voluntarios, delegados e informadores/orientadores.

Sin duda alguna, diferentes evaluaciones corroboran que los miembros de la comunidad educativa participantes en el programa, profesorado, alumnado y comunidad educativa, 
son los mayores beneficiarios de éste. Esto ocurre por varias razones, según Fernández, Villaoslada y Funes (2002), entre las que destacan las siguientes:

- El entrenamiento en las habilidades de escucha y resolución de conflictos y su posterior uso en la vida cotidiana mejora la competencia social de los usuarios.

- Mejora la autoestima de las personas involucradas.

- Se desarrollan las capacidades empáticas y hace que la gente se sienta bien consigo misma. Creen en lo que están haciendo.

- Aumenta el estatus social del alumnado y del profesorado participante en el conjunto de la escuela.

- Se trabaja con valores muy cercanos al sentir personal, permitiendo que el individuo manifieste sus sentimientos y emociones.

- Se siente que se comparte, que se es miembro de un equipo con metas y fines compartidos.

- Se genera confianza en los otros.

No obstante los claros beneficios para los participantes, se analiza con más detalle en el próximo apartado, la eficacia de los sistemas de ayuda entre iguales.

\subsubsection{Eficacia de los sistemas de ayuda entre iguales}

La mayoría de los sistemas estudiados se encuentran en proceso de desarrollo, ya que el apoyo de los iguales es un concepto relativamente nuevo. En el Reino Unido, donde sí hay más trayectoria de dichos programas, la eficacia de los sistemas de apoyo contra la intimidación, se valora teniendo en cuenta si el desarrollo de la relación entre las personas implicadas se lleva a cabo de la misma manera o con mayor éxito gracias a la solución adoptada.

A la hora de analizar los resultados de los programas de ayuda entre iguales existen dificultades debido a la variedad de las evaluaciones realizadas y los pocos estudios que confirman la eficacia de dichos programas. Son muchos los estudios basados en impresiones personales de estudiantes y profesores, con interpretaciones subjetivas de los resultados obtenidos. Sin embargo, otros estudios han seguido otro tipo de evaluaciones, que han apuntado varias ventajas de la ayuda entre iguales. A continuación se detallan los resultados de algunos de los estudios más rigurosos en la 
materia, que se agruparán en función de los beneficios en los alumnos y ayudantes/mediadores, en las mejoras en las relaciones de agresores y víctimas y en los avances en el clima social del centro escolar.

a) Beneficios en los alumnos ayudantes/mediadores.

Cowie (1998) entrevistó en su estudio a alumnos y profesores preguntándoles por los beneficios del programa de alumnos ayudante, y ambos colectivos coincidieron en que habían obtenido beneficios personales debidos a su participación y del entrenamiento recibido. También en este estudio, Cowie (1998) indica que los alumnos ayudantes pueden obtener beneficios personales, aunque este no sea el objetivo principal de participar en el programa, además de creer que el clima de toda la escuela se ve influido positivamente por su intervención. Esta autora afirma que sería útil descubrir los efectos de apoyar la formación de iguales en las personas que han sido identificadas como testigos por sus compañeros de clase.

Un año después, en el informe realizado por Naylor y Cowie (1999), sobre un estudio con estudiantes y profesores pertenecientes a 591 escuelas, el 78\% de los alumnos ayudantes también comentaron que gracias al entrenamiento recibido, habían adquirido y mejorado sus habilidades sociales e interpersonales, sobre todo, la escucha activa, así como el sentimiento de interés de unos hacia otros dentro de la escuela.

Smith, Talamelli, Cowie, Naylor, y Chauchan (2004) encontraron que los alumnos ayudantes que habían participado, comentaron que les había influido tan positivamente, que les había ayudado a descubrir su vocación y les había llevado a elegir para sus estudios universitarios una profesión asistencial de ayuda y cuidados hacia los demás.

En un estudio realizado a nivel nacional con centros de primaria y secundaria del Reino Unido, en el que participaron 834 alumnos y 204 profesores, Smith y Watson (2004) identificaron que la eficacia del programa de ayuda entre iguales, dependía del papel y las horas de dedicación que asumían los ayudantes, es decir, de las ganas que ponían los alumnos ayudantes a la hora de desarrollar sus funciones. Más o menos la mitad de los estudiantes (53\% en primaria, y 52\% en secundaria) tenían conocimiento de alguien que había hecho uso de la ayuda entre iguales. 
Finalmente, autores como Vreeman y Carroll (2007) o Smith (2011) indican las ventajas que estos programas proporcionan a los alumnos ayudantes, en cuanto al fomento de la autonomía y de las habilidades y relaciones sociales.

b) Mejoras en las relaciones de agresores y víctimas.

En el mismo estudio de Naylor y Cowie (1999), las víctimas valoraban lo que la escuela estaba haciendo por ellos, ya que les proporcionaba un ayudante-amigo que les ayudaba a superar los problemas, les escuchaba y les atendía si lo precisaban. De los 65 alumnos que fueron usuarios del sistema, el $82 \%$ lo consideró útil y les dio fuerza para afrontar el bullying. El $80 \%$ dijo que recomendaría el sistema a algún amigo, y sólo el $18 \%$ tuvo pensamientos negativos acerca del programa, expresando, por ejemplo, que no lo encontraron útil o que fue desagradable.

Por otro lado, Naylor y Cowie (1999) indicaron que los métodos de ayuda entre iguales no redujeron la incidencia del bullying en los centros, pero aún así, los usuarios se sentían tan satisfechos que consideraron que la puesta en marcha de sistemas de ayuda entre iguales redujo el impacto negativo del bullying e hizo más aceptable para ellos informar sobre el mismo.

Los mismos resultados se obtuvieron en un estudio de menor envergadura realizado por Cowie y Olafsson (2000). En este estudio, se administró el cuestionario de Olweus antes de la introducción del programa de ayuda entre iguales y siete meses después de la puesta en marcha del programa, sin obtener resultados alentadores. Pero aún así, las víctimas valoraron positivamente el tener un alumno ayudante, igual que él/ella, dispuesto a escuchar sus problemas y ayudarlo en todo lo que necesitara. Asimismo, aumentó el número de víctimas que contaban su sufrimiento a un profesor o amigo y encontraron útil la protección y seguridad que les daba la presencia de alumnos ayudantes en la escuela, porque entendían que era un centro que se preocupaba por ellos.

Menesini, Codecasa, Benelli y Cowie (2003) muestran en un estudio en el que se realizó una intervención en dos clases de secundaria, lo contraproducente que puede ser que un alumno agresor, se convierta en un alumno ayudante. Aunque los beneficios que obtendrían los agresores al formar parte de los sistemas de ayuda entre iguales, a través del entrenamiento permitiría desarrollar una mayor conciencia de los efectos de su 
conducta, las víctimas de dicho estudio manifestaron que estaban muy contentas con la puesta en marcha en el centro de un programa de ayuda entre iguales, pero que preferían ser asesorados o ayudados por alumnos que no se identificaran como agresores previos.

Por su parte, del estudio de Smith y Watson (2004), se desprenden los siguientes datos: el $44 \%$ los estudiantes que había usado el sistema en escuelas de primaria lo consideraron bastante útil, el 50\% lo calificó como algo útil, y el 6\% no lo encontró útil. En escuelas de secundaria, el $47 \%$ lo calificó como bastante útil, el $42 \%$ dijo que era algo útil, y el 11\% restante afirmó que no era de utilidad. No hubo diferencias de genero en escuelas de primaria, pero en escuelas de secundaria en su mayoría, los chicos frente a las chicas dijeron que no era de ayuda (18\% vs. $7 \%$ ). Además los profesores comentan una notable reducción en la ocurrencia de pequeños incidentes de bullying, consiguiendo que a su vez, se aumentara la concienciación de los estudiantes más vulnerables, para solicitar la participación en este programa, dado que era evidente que los estudiantes eran más capaces de resolver las situaciones por ellos mismos de forma pacífica.

En otros estudios, muchas de las víctimas informaron que participar en estos programas les había dado fuerza para superar el problema de la intimidación. Esto, junto con el hecho de tener un amigo o defensor, actúa como un amortiguador frente a la intimidación (véase, por ejemplo, Boulton, Trueman, Chau, Whitehand y Amatya, 1999).

Cowie y Olafsson (2000) o Arellano (2008), observaron que los métodos de ayuda entre iguales no redujeron la incidencia de acoso escolar en los centros, pero aún así los usuarios de los mismos, se sentían satisfechos por la puesta en marcha de los programas, puesto que se redujo el impacto negativo del acoso que estaban sufriendo, y facilitaba que se informase sobre la situación.

De manera más reciente, Del Barrio, et. al., (2011), indican que los beneficios que los estudiantes refieren tras la aplicación de los programas de ayuda entre iguales, son alivio emocional de los usuarios del servicio, lo que supone una mejora en la vía del ajuste y cambio emocional de quienes se encuentran en distintas situaciones, ya sea como víctimas, perpretradores u observadores de situaciones negativas. También, Cowie y Smith (2012) afirman que los alumnos ayudantes informan sobre el beneficio que les aporta el proceso de ayuda, puesto que ganan confianza en sí mismos, y 
aprenden a valorar más a las personas. Y Palladino, Nocentini y Menesini (2012), concluyen que la frecuencia e intensidad de la intimidación disminuyen.

c) Avances en el clima social del centro escolar.

En el estudio realizado por Cowie (1998), se obtuvieron unos resultados contundentes: el programa de alumno ayudante había afectado positivamente al conjunto de la escuela. El estudio español de Avilés, Torres y Vian (2008) compara dos centros, uno con un programa de ayuda entre iguales y el otro no, con estudiantes de ESO, de entre 12 y 14 años. La comunidad educativa coincide en que se han reforzado las habilidades sociales y comunicativas de los alumnos que han participado en el programa. Y aunque se considera el programa como una buena medida de prevención que no les importaría seguir teniendo en el centro, no hay evidencias de que se hayan reducido realmente las situaciones de maltrato entre iguales. Asimismo, la percepción que tienen los agresores/as sobre sus actuaciones antes y después de aplicar el programa ha cambiado, produciéndose una mayor reflexión de las situaciones de bullying en un clima de concienciación que genera un programa de ayuda. Otros autores como Cowie, Boardman, Dawkins y Jennifer (2004), afirman que estos programas tienen el potencial de mejorar el bienestar y salud emocional de los alumnos. Además los centros se perciben como más seguros (Andrés, Barrios y Martín, 2005; Arellano, 2008; Azaredo, Rinaldi, de Moraes, Leyand y Menezars, 2015; Lane-Garon y Richardson, 2003; Ortega-Ruiz, Casas y Del Rey, 2014).

Existen además otras condiciones que facilitan que los programas de intervención resulten eficaces: el modo en que se implementa en la escuela, la formación del personal docente, el contar con supervisión externa y, el apoyo del equipo directivo del centro escolar y la duración de la intervención educativa.

En un estudio realizado por Del Barrio, et. al. (2011) en el que se preguntó a 166 estudiantes de primer y tercer curso de ESO, sobre los beneficios de los programas de ayuda entre iguales y en concreto, Alumno ayudante que se desarrollaban en su centro, el 44,5\% hacía referencia a las mejoras del clima de centro, tras la disminución de problemas. Por tanto, consideran el programa beneficioso tanto para prevenir (disminuye el número de conflictos) como para intervenir (contribuye a resolverlos). 
Otros estudios aportan datos sobre la frecuencia con la que los docentes informan de que el ambiente de la escuela se convierte en más seguro y más solidario tras la introducción de un sistema de ayuda de los compañeros y que las relaciones entre iguales en general, mejoran (Cowie, Naylor, Talamelli, Chauhan y Smith, 2002; Cremin, 2007; Houlston, Smith y Jessel, 2011).

\subsection{Desarrollo de los programas: Alumno Ayudante y Alumno Mediador}

En este apartado, se van a desarrollar en primer lugar los aspectos a tener en cuenta para implementar estos programas en los centros. Y a continuación se comentará la estructura de dichos programas, así como cuales son los objetivos y beneficios, las consideraciones previas que se deben tener en cuenta, la selección y formación de los alumnos ayudantes y mediadores, la difusión, temporalización y evaluación de ambos programas.

La estructura que se sigue en cada uno de los apartados anteriores siempre es la misma, en un primer momento se explican los aspectos comunes de los dos programas, y a continuación se especifican las características concretas y particularidades de cada uno de los programas, si es que existen.

\subsubsection{Aspectos a tener en cuenta para la implementación de estos programas en los centros}

Todos estos sistemas pueden presentar dificultades en su desarrollo tanto desde la perspectiva de la organización escolar como desde el modo en que se trabajan los valores y se gestionan los conflictos. Y es por esto que no todos los centros educativos muestran predisposición a incluir en sus proyectos educativos la educación entre iguales. La razón es que estos modelos complementan y enriquecen las metodologías de trabajo y prevención del centro escolar, pero a su vez también presentan aspectos a tener en cuenta y limitaciones (Fernandez, Villaoslada y Funes, 2002):

- Cowie y Wallace (2000) mantienen que las escuelas deben proceder a un análisis de necesidades, y que no todas deberían aplicar un sistema de ayuda si no es por un claro convencimiento y que estén dispuestos a llevarlo a cabo a pesar de sus dificultades de ejecución. 
- Torrego (2001) habla de un modelo integrador en la resolución de los conflictos de las escuelas, donde funcionen paralelamente sistemas de ayuda entre iguales y las medidas correctoras. Los alumnos, y con ello el personal adulto de los centros deben acotar los límites justificables de actuación de los diversos sistemas de acuerdo con la cultura de ese centro y propiciar espacios intermedios donde se trabaje la convivencia desde una visión reparadora además de valorar las correcciones debidas.

- Los servicios de ayuda entre iguales deben ser percibidos como "propios" por los alumnos implicados, y con ello contribuir a una participación auténtica. Si se intentan reproducir estos modelos en escuelas altamente jerarquizadas, donde la autoridad toma la mayoría de las decisiones, entonces, probablemente estas experiencias estén abocadas al fracaso, a no ser que se den márgenes de actuación que permitan un contexto de intervención relativamente creíble para los alumnos.

- Los sistemas de ayuda entre iguales no sólo son instrumentos para hacer frente a las dificultades, sino que favorecen la convivencia.

- Una vez puesta en marcha una experiencia de ayuda entre iguales la confidencialidad de los hechos y de las personas involucradas deben tenerse en cuenta en todo momento.

- En la elección del alumno, se han de valorar las capacidades de los mismos e intentar asegurar su equilibrio personal sin colocarles en situaciones que les puedan ser incómodas.

- La mejor forma de justificar sus beneficios es hacer sentir y realizar intervenciones en las que se demuestre que los alumnos son capaces de resolver sus propios conflictos y que eso trae ventajas percibidas. No hay mejor antídoto que "ver para creer".

Resumiendo, las limitaciones se pueden encontrar básicamente, en tres situaciones: cuando el sistema no es aceptado por los alumnos y los profesores, si existen actitudes negativas de algunos profesores respecto al programa, o si participan pocos usuarios. Es interesante señalar que los efectos nocivos de una actitud negativa por parte del profesor y alumnos podrían afectar al éxito o al fracaso de cualquier iniciativa. Pero en el caso del estudio de Naylor y Cowie (1999), no se han encontrado evidencias de este tipo de situaciones. Lo que normalmente ocurre es que los profesores dedican gran cantidad de 
su tiempo a la gestión y la administración de los sistemas de apoyo, básicamente en la formación y supervisión de los alumnos ayudantes participantes.

\subsubsection{Estructura de los programas}

\subsubsection{Objetivos y beneficios}

Ante el maltrato, es imprescindible crear un clima de respeto mutuo hacia y entre todos, y de sensibilidad y empatía ante las necesidades de protección, apoyo o ayuda especialmente de los más débiles. Los alumnos ayudantes y los mediadores no son policías al servicio del orden público, son compañeros con un claro código ético de actuación, y ejemplos de pro-socialidad frente a lo antisocial, que irá calando en los demás paulatinamente.

La percepción de los usuarios de estos sistemas es que se evitan los efectos negativos de ser intimidado, y sin duda, se trata de un motivo más que justificado para apostar por estos sistemas de ayuda entre iguales. Como resultado de la puesta en marcha de estos programas los beneficios que se perciben y que ya se han comentado son: mejora de la convivencia, disminución de la intensidad de los efectos negativos del maltrato, e incremento de la participación del entorno social, así como el fomento de la colaboración, el conocimiento y la búsqueda de soluciones cooperativas. Con estos sistemas, se crean canales de comunicación y diálogo, se valoran sentimientos, intereses, necesidades y valores a través de la responsabilidad compartida, entre otros.

Como comenta Torrego (2001), uno de los fines de las instituciones educativas es la socialización, y los conflictos y las diferencias entre las personas forman parte de nuestras relaciones sociales, de manera que el sistema educativo debe asumir que ese proceso de socialización incluya el hacer frente a los problemas de convivencia, el resolver los conflictos. Sobre todo, cuando parte de la sociedad señala a la juventud como foco potencial de violencia. El marco para el desarrollo de la mediación es la pedagogía pacífica o educación para la paz y la convivencia escolar, junto con los conocimientos en el campo del desarrollo organizativo y curricular. Por ello, Torrego (2006) concreta los rasgos principales del programa alumno mediador: proporciona una concepción positiva del conflicto, ya que entiende el conflicto, como algo sustancial de 
los seres humanos y sus formas de vida social, y que según como se afronte, puede resultar constructivo y beneficioso para las partes. También se potencia el uso del diálogo como alternativa a otras posibles respuestas menos constructivas ante los conflictos como son las de agresión y violencia o las de huida o sumisión, así como los contextos cooperativos en las relaciones interpersonales. La concepción es "yo gano/tú ganas", de manera que quede patente que la obtención de los intereses propios no conlleva que los otros no consigan los suyos. Permite que los participantes desarrollen habilidades de autorregulación y autocontrol, como elemento clave para favorecer en los individuos la toma de decisiones de forma autónoma y ajustada al entorno social, contribuyen a una mejor integración y desarrollo de la autoestima, así como el desarrollo de actitudes de apertura, comprensión y empatía que implica un compromiso de atención al otro, hacia lo que cuenta, lo que necesita, lo que desea, intentando ponerse en su lugar. Y a nivel general de centro, se fomenta una práctica de la participación democrática, ya que a través de estos procedimientos, los miembros de la comunidad educativa experimentan la importancia de sus opiniones y su contribución a la mejora de las situaciones injustas o desagradables. La responsabilidad de la resolución de un conflicto recae en las partes directamente implicadas en él.

Según Cava (2009), las principales características de la mediación son tres: la voluntariedad, la participación y la flexibilidad. Por una parte, decimos que la mediación es voluntaria porque son las partes las que deciden iniciar el procedimiento, y en cualquier momento pueden decidir no continuar. Por otra, cuando se habla de participación, se refiere a la implicación activa de las partes, en el sentido que son las partes las que buscan gestionar el conflicto. Y finalmente se dice que la mediación es flexible porque el procedimiento se adapta a las necesidades de las partes, aunque dentro de la flexibilidad se tienen que establecer unos requisitos mínimos que se concretan en la primera reunión con el mediador.

El papel del mediador consiste en facilitar vías de diálogo teniendo en cuenta estas características, para gestionar los conflictos de la forma más satisfactoria posible para todos. Después de una primera fase de pre-mediación, en la que evalúa y tantea las posibilidades, se realiza una mediación con cada una de las partes implicadas. En el caso de acceder, se trata de aclarar el problema. Son las partes en conflicto las que con ayuda y orientaciones del alumno mediador, generan propuestas de solución a su 
situación. El mediador ayuda a evaluar las distintas propuestas, aunque la voz cantante también la llevan las partes. La tarea que sí hace exclusivamente el mediador es consensuar y recoger las opciones de cada parte, refundirla en una solución que le resulte satisfactoria a las partes en conflicto, y acordar un seguimiento del problema, para ver si en el futuro van a necesitar una nueva mediación, o van a cumplir los acuerdos a los que se han comprometido.

Por otra parte, los objetivos del programa alumno ayudante son: fomentar la colaboración y búsqueda de soluciones para resolver los problemas interpersonales en los centros escolares, con el fin de mejorar la convivencia y reducir los casos de acoso escolar, favoreciendo la participación directa del alumnado, mientras se crean canales de comunicación entre alumnado y profesorado, e incrementando los valores de ciudadanía y clima afectivo de la comunidad.

Por lo tanto, si se compara el programa alumno mediador, utilizado en los centros de Educación Secundaria, que se han analizado en esta tesis, con el programa alumno ayudante, pueden encontrarse:

- En el sistema del alumno ayudante: se trabaja para prevenir los conflictos. La solución de ayuda está ligada al alumno ayudante que es quien toma decisiones directamente sobre el conflicto planteado. Por tanto, la solución depende de ambos, del alumno ayudante, y del ayudado. El alumno ayudante, dirige, coordina y también realiza actividades de grupo en el recreo o en clase.

- En el sistema del alumno mediador: se trabaja para enseñar a los alumnos en conflicto, cómo buscar las soluciones autónomas y negociadas, a través de orientaciones pero manteniéndose siempre neutral, al margen de la solución definitiva del conflicto, que surge de las partes. Este alumno interviene únicamente cuando le convocan para resolver un conflicto.

- El programa de alumno ayudante, se lleva a cabo, únicamente entre alumnos, mientras que el programa de mediación suele ir dirigido a todos los sectores de la comunidad educativa, y se pueden dar mediaciones entre alumnos, entre padres, entre profesores o en cualquiera de todas las combinaciones que pueden surgir de la comunidad educativa, aunque dichas combinaciones únicamente son recomendables en secundaria y no en cursos inferiores. 
- Ambas figuras tienen que saber relacionarse con los demás, pero en el caso del alumno mediador, además, debe armonizar los intereses de las partes implicadas en la resolución del conflicto.

Por tanto, lo ideal sería que ambos programas coexistieran, y que los estudiantes mediadores y ayudantes, se complementasen unos a otros, para ofrecer una cobertura integral a las necesidades que pueden presentar los centros educativos.

\subsubsection{Consideraciones previas}

Como ocurre en la implementación de otros modelos de resolución de conflictos basados en la figura de alumnos, como por ejemplo: alumno consejero y alumno negociador (Cowie y Sharp, 1996), en el caso de los programas de alumno ayudante y alumno mediador, se tiene que proponer e implantar en el centro, teniendo en cuenta el visto bueno de la mayoría de la comunidad educativa.

Según Torrego y otros (2000), se deben dar una serie de pasos previos a la puesta en marcha de un programa de mediación en las escuelas, que coinciden con los sistemas de ayuda entre iguales. Estos deberían ser, la toma de conciencia, apoyo del equipo directivo, implicación del profesorado, presentación a la comisión pedagógica, tutores y claustro, aprobación por el Consejo Escolar y por al menos la mitad del claustro de profesores, nombrar un responsable del proyecto, buscar el entusiasmo por participar en el alumnado, introducir un espacio horario para poder realizar el programa de formación inicial y de reuniones posteriores, habilitar un espacio para poder reunirse con periodicidad, presentación del proyecto a las familias y creación de un equipo de profesores que trabaje directamente en el servicio e impulse su inclusión en la vida cotidiana de la escuela.

Para implantar los modelos en los centros, se deberán seguir una serie de pasos que permitan que todos los miembros de la comunidad educativa sean conocedores de los cambios que se están introduciendo en el centro, en materia de prevención de conflictos.

- Toma de Conciencia:

Normalmente uno o dos profesores se sienten motivados y convencidos de lo beneficioso y diferente del enfoque y son estos mismos los que impulsan el programa, aunque en ocasiones puede ser el equipo directivo o algún miembro del mismo o del departamento de orientación. Uno de los argumentos más convincentes es conocer o 
saber de otros centros educativos con características parecidas en los que la experiencia ha tenido éxito.

En el caso del alumno ayudante, se puede incorporar en los últimos grupos del último ciclo de primaria y de secundaria. Se conocen ejemplos de dichos modelos en centros de secundaria (Fernández y Orlandini, 2001), en el segundo ciclo de esta etapa educativa, aunque en este caso, existe menor interés por parte de los alumnos, motivo por el cual se sugiere su implantación en el rango de 10 a 15 años aproximadamente.

- El apoyo del equipo directivo:

La sensibilización en los niveles altos de la jerarquía escolar es de indudable relevancia. Cuando la implicación del equipo directivo con sus dotes de liderazgo sea muy alta se facilitará el mantenimiento del programa en fases posteriores.

- Implicación del profesorado:

El profesorado en su conjunto ha de conocer el objetivo del programa y las consecuencias que se prevén. El Plan de Acción Tutorial es el lugar privilegiado donde los conflictos interpersonales pueden ser abordados puesto que los tutores son en muchos casos conocedores de las necesidades personales de sus tutorados.

La selección de los alumnos ayudantes y la intervención son temas propios de la tutoría puesto que este alumnado actúa preferentemente dentro de su grupo aula, por ello la percepción, valoración y tratamiento que haga el tutor repercute directamente en el desarrollo del programa.

- Presentación en la comisión pedagógica y reuniones de tutores:

Resulta más adecuado que se presente la propuesta de un sistema de ayuda entre iguales en reuniones o comisiones en las que participe un amplio sector del profesorado antes de ser presentado al Consejo Escolar o al claustro.

- Presentación al claustro:

Si no se ha podido dar a conocer previamente en pequeños grupos la propuesta, se debería dar información por escrito antes del claustro.

- Presentación y aprobación del consejo escolar:

Dado que un programa de "ayuda entre iguales" tiene repercusión en el conjunto de la escuela debería ser aprobado por el Consejo Escolar para darle mayor apoyo institucional. Uno de los objetivos es que la figura del alumno ayudante y mediador se institucionalice y se convierta en parte de la organización de los grupos-clase. Su 
función es la de apoyo, lo que no inhibe que delegado y alumno ayudante y mediador puedan trabajar conjuntamente en problemas puntuales o en la organización de alguna actividad del grupo.

- Implicación del alumnado:

Hay que cuidar que los documentos informativos del centro como la agenda escolar, las circulares, etc., comuniquen y describan los objetivos y procedimientos del modelo. Esta información servirá tanto para el alumnado como para las familias. En el primer año de puesta en marcha del programa es conveniente hacer ver las ganancias que obtienen los propios alumnos ayudantes y mediadores: curso de formación en horario lectivo fuera del centro, formación del equipo, salidas del equipo, posibilidad de organización de actividades lúdicas, etc.

- Implicación e información a las familias:

A menudo no se da suficiente importancia a la implicación de las familias en esta propuesta. La familia deberá aprobar la participación de sus hijos/hijas como alumno ayudante y mediador. Se debe fijar una reunión con el AMPA para aclarar, informar y recoger sugerencias y resistencias, pero en todo caso se debe incluir información en los documentos oficiales, circulares que se envíen a las familias e incluirse como uno de los puntos de la reunión de presentación de los tutores con éstas.

De manera complementaria a todos estos pasos, se debe nombrar un equipo de profesionales del centro, que se encargue de la supervisión del programa, así como de la formación y apoyo de los alumnos que participen en dichos programas. Para ello será necesario decidir quienes van a componer dichos equipos, y definir las funciones $\mathrm{y}$ responsabilidades de los profesores encargados del equipo de ayuda o equipo de mediación, y del equipo de ayudantes o mediadores. A partir de ese momento, se tendrá que continuar con:

1. Elaboración del material para el uso del equipo de ayuda (tríptico explicando el sentido de la ayuda entre iguales, de la mediación, cartel anunciador, página web, etc.).

2. Diseño del plan de formación de los equipos de alumnos voluntarios.

3. Decisiones de infraestructura. Reuniones del equipo (contenido y periodicidad). 
4. Decisiones sobre los límites de la ayuda entre iguales (para qué, en qué casos, y a quién derivar los casos de riesgo).

5. Decisiones informativas: presentación del servicio de ayuda al claustro, alumnado, padres (plan de difusión).

6. Inserción en la organización del centro.

7. Vinculación con la Comisión de Convivencia.

Estos profesores, al igual que los propios alumnos voluntarios, formarán comisiones de convivencia preventivas al reunirse periódicamente y acabarán abordando un sinfín de conflictos de baja intensidad. También se debe contemplar que existe la necesidad de reunir a los alumnos de diferentes cursos en un mismo tiempo cada dos o tres semanas.

Y para hacer posibles al máximo, las horas y momentos de encuentro se aconseja que se sitúen las tutorías de un mismo nivel en un mismo bloque horario para crear la flexibilidad de la tutoría en la que los alumnos puedan dejar su grupo de procedencia para realizar la reunión periódica o puede ser el momento idóneo para abordar un conflicto en concreto.

Las maneras en que se pueden llevar a cabo estos programas de ayuda entre iguales pueden ser varias. Teniendo en cuenta la referencia de personas experimentadas que lo han implantado en sus centros (Fernández, Villaoslada y Funes, 2002), se puede introducir dentro del currículum y dar la oportunidad a todo el alumnado de practicar tanto las habilidades de escucha y resolución de conflictos como la posibilidad de ponerlo en práctica en situaciones reales. $\mathrm{O}$ bien hacer turnos rotativos para aquellos alumnos que quieran actuar en este sentido, promoviendo la mayor participación posible. Otra posibilidad es ampliar el servicio de forma periódica para que diferentes miembros de la comunidad puedan participar y formarse; mantener cursos periódicos de formación y profundización incitando nuevas incorporaciones e indagando sobre aspectos concretos dentro de la formación y crear subcomisiones de convivencia en las que participen alumnos de los servicios de ayuda con otros que no lo hacen.

En un estudio de Fernández, Villaoslada y Funes (2002), los ayudantes van rotando, y por tanto, llega un momento en el que los agresores también se convertirán en alumnos que ayudan. También en un estudio posterior de Menesini, Codecasa, Benelli y Cowie (2003), se comenta la posibilidad de que los agresores también se formen como alumnos ayudantes, ya que la formación que reciben y el hecho de estar del lado que 
ayuda y no del que agrede, es beneficioso para las víctimas y para ellos mismos. Esto no lo contempla Torrego (2006), ya que no concibe que un agresor sea a la vez quien proteja a las víctimas, por el riesgo que esto puede suponer para las propias víctimas. Por lo tanto, la solución más práctica para que los agresores participen en los programas pero no intervengan directamente con los alumnos que necesitan ayuda, sería crear un banco de posibles tareas en las que se dé cabida a un amplio número de perfiles. Por ejemplo el equipo de difusión, el grupo que cuenta a los demás el servicio, el grupo que organiza y cuida de una fiesta, etc. Y es por aspectos como estos, entre otros, por los que la intervención de los adultos, en distintos tiempos, lugares o modalidades, sigue siendo irreemplazable.

Según Taylor (1996), se deben tener en cuenta las siguientes precauciones cuando se vaya a poner en funcionamiento el programa de ayuda entre iguales. Es interesante dejar claro que los alumnos ayudantes no son en absoluto responsables de las acciones del alumno "ayudado" y que el contenido de las reuniones puede variar, en función de los temas tratados por los alumnos ayudantes, de manera que se debe tratar de conseguir que todos sus miembros se sientan cómodos en esa situación. Para que la información que se recoja por este medio sea relevante, deben tenerse en cuenta ciertas dimensiones, según Fernández, Villaoslada y Funes (2002):

a) Para los alumnos:

- El impacto y conocimiento en el centro de la figura del alumno ayudante: el grado de difusión del programa, como información determinante para su intervención.

- Los tipos de casos, su frecuencia y valoración de la intervención: casos en los que se interviene y cómo se valora su utilidad.

- La utilidad de la formación recibida: evaluación breve de la formación, indagación en torno a si el entrenamiento en técnicas de resolución de conflictos es útil para los casos en los que se interviene.

- Los lugares del centro en donde más se produce la intervención: en las aulas, pasillos, patios, etc.

- Las emociones y consecuencias para uno mismo: cómo se han sentido representando esa figura, si ha servido o no para el desarrollo personal, y qué tipo de consecuencias ha tenido para uno mismo. 
- Las reacciones de otros ante la intervención: de los compañeros y de los profesores, si se han sentido apoyados o no durante sus intervenciones.

- La valoración de la figura: cómo la perciben los demás, características personales que se consideran necesarias.

- Evaluación del programa: calificación y propuestas de mejora.

b) Para los profesores:

- Motivación: qué causas les han llevado a participar en el programa, implicación de los departamentos y equipos directivos.

- Expectativas iniciales: cambios o logros que se esperan obtener antes de la puesta en marcha del programa.

- Esfuerzo o implicación: coste personal, en tiempo y trabajo adicional que supone participar.

- Desarrollo del modelo: opiniones acerca de las diferentes fases de su funcionamiento y la participación que se ha producido en ellas, sobre la difusión en el centro, sobre la formación de apoyo al modelo desde el ámbito curricular, sobre el proceso de selección y la actuación de los alumnos ayudantes.

- Resultados: eficacia y utilidad del modelo y consecuencias para los alumnos, los profesores y los alumnos ayudantes.

- Perspectivas: del proyecto y de la intervención.

- Evaluación: calificación y propuestas de mejora.

El mantenimiento y supervisión del programa de ayuda entre iguales en el centro cuenta con algunas incidencias de las actuaciones de los alumnos ayudantes y mediadores. Puede ocurrir que los alumnos no actúen adecuadamente en un caso en particular, o que "metan la pata". Por ello, es imprescindible mantener un calendario de reuniones y supervisión y toma de acuerdos. Hay que tener precaución con el carácter manipulativo que puede darse en este modelo debido a que existe un problema ético importante, el convertir a esta figura en el confidente de los profesores. Se debe hacer hincapié sobre la diferencia de relación entre ayudante y ayudado y dos amigos, con el fin de evitar que el alumno ayudante se sobrecargue emocionalmente con los problemas de los alumnos ayudados. Finalmente, hay que derivar los casos si suponen para el alumno un sentimiento de estar sobrepasado o confuso en el modo de actuar ante un caso demasiado complejo para sus capacidades personales. 
En este sentido, Cowie y Wallace (2000) mantienen que se deben derivar los casos en los que los alumnos estén seriamente deprimidos y con dificultades psicológicas importantes; tengan problemas de embarazo o de educación sexual, en los que sea necesario el asesoramiento de un experto; cuando se den agresiones y/o amenazas físicas; enfermedades mentales e intentos de suicidio. A los anteriores, Fernández, Villaoslada y Funes (2002) añaden el maltrato familiar, el abuso sexual y la extorsión económica con amenaza.

La supervisión periódica es otro de los elementos claves para el buen funcionamiento del programa. Existen diversas razones que justifican la supervisión. La fundamental es que hay que asegurar el bienestar de los alumnos ayudantes y de los ayudados, ya que a través de la supervisión se sacan a la luz los casos sobre los que trabajar o con potencial de convertirse en conflictos serios. Además se hace difícil evaluar el desarrollo del programa y su impacto en el conjunto de la escuela pero la supervisión nos aporta la facultad de observar y valorar la eficacia del servicio. En el momento de la discusión y aclaración de formas de actuar se ayudan unos a otros en las propuestas de intervención. Este es el momento más importante para aclarar los límites de la intervención de los alumnos ayudantes y mediadores, puesto que en este proceso de narrar las intervenciones van apareciendo algunas que podrían encuadrarse dentro de los casos de derivación. La supervisión en grupo ahorra tiempo al profesorado encargado de llevar a cabo el seguimiento y se facilita el contraste de opiniones sobre las intervenciones incluso en las que no han salido bien.

Naylor y Cowie (1999) han desarrollado instrumentos específicos para llevar a cabo la evaluación de los casos y nos ofrecen información junto a los resultados de su implantación y desarrollo en el centro. Los datos, recogidos a partir de las reuniones de los participantes directos en el programa (alumnos y profesores implicados) y de sus beneficiarios (resto del alumnado del centro), permiten concluir con una evaluación positiva del sistema.

\subsubsection{Selección}

Las características que deben tener los alumnos que se presentan para ser ayudantes y mediadores básicamente son inspirar confianza, para poder contarle los problemas personales así como saber y querer escuchar. A su vez los alumnos que están dispuestos 
a ayudar a sus iguales deben tener la capacidad de recibir críticas y estar dispuesto y motivado para resolver conflictos.

Otro aspecto importante en la selección es el número ideal de participantes en este sistema de ayuda. Algunos autores como Fernández, Villaoslada y Funes (2002) y Torrego (2006), hablan de unos 25 ó 30 alumnos ayudantes para todo el centro escolar, aunque sería interesante tener en cuenta la cantidad de alumnado de cada centro, dependiendo de si es un centro pequeño, mediano o grande. En el caso de participar diferentes miembros de la comunidad educativa convendría equilibrar el número de alumnos y profesores, así como el de alumnas y alumnos, ya que existe una tendencia a contar con más alumnas voluntarias que alumnos.

Cada año los compañeros escogerán a los alumnos voluntarios de los grupos. Este proceso puede hacerse coincidir con la selección del delegado a finales de octubreprimeros de noviembre. Es interesante que se de la oportunidad a que se presenten voluntariamente quienes quieran actuar de esta forma y proceder a una votación por los propios compañeros. Por lo tanto, un aspecto importante sería que los alumnos que se presenten voluntariamente, hayan sido o no elegidos por sus compañeros.

El proceso de selección consta de las siguientes fases, según Fernández, Villaoslada y Funes (2002). En un primer momento, todos los alumnos del centro, a través de un cuestionario, citan a los compañeros de la clase que consideran más adecuados para contarles sus problemas personales. Todos disponen de un tríptico informativo en el que puede haber un pequeño formulario que deben rellenar, si desean ser alumnos ayudantes o alumnos mediadores, y colocarlo en un buzón habilitado para este fin. A continuación, los encargados del programa recogen todos los formularios y cotejan los nombres con los voluntarios, así como confeccionan la lista con todos los nombres coincidentes ordenados por número de elecciones. A partir de ese momento, se nombra a los alumnos más citados. El resto de los alumnos voluntarios, si lo hubiera, serán citados en el próximo curso de formadores. Y finalmente se comunica personalmente a los seleccionados mediante una convocatoria para la primera sesión del curso de formación. Cowie y Wallace (2006) admiten la posibilidad de que se decida no escoger a los alumnos voluntarios por medio de sus compañeros ni seleccionados por el profesorado y permitir que lo ejerzan todos los voluntarios. No es recomendable que salga elegido 
un alumno/a con problemas emocionales graves, alumnos con problemas graves de conducta o altamente violentos cuyo comportamiento en el transcurso del año sea lo opuesto a los objetivos del alumno ayudante. Los alumnos hiperactivos graves o que estén pasando por un momento de ruptura con toda norma y con grave necesidad de ser protagonistas pueden provocar dificultades en el propio equipo. En este sentido, Andrés y Barrios (2006) de los grupos de discusión realizados con estudiantes de centros de Educación Secundaria Obligatoria, proponen que se describa al alumno ayudante (o mediador) ideal, para elegir a los compañeros que mejoran encajan en el perfil, cuenten con ciertas competencias y puedan manejar destrezas que les permita intervenir con éxito, dejando al margen cuestiones de amistad.

Siguiendo de nuevo a Fernández, Villaoslada, Funes (2002), aunque el perfil recomienda que los alumnos ayudantes y mediadores sean alumnos reconocidos y valorados por sus propios compañeros, lo que se pretende, es favorecer la competencia social y las habilidades de comunicación y empatía en el conjunto del alumnado. Por lo tanto, se ha de dar oportunidad al mayor número de alumnos posible para que ejerzan estas funciones en el transcurso de su estancia en la Enseñanza Secundaria Obligatoria. Por este motivo se recomienda establecer dos turnos de alumnos ayudantes y mediadores por curso. Las demandas de un mediador son más puntuales, es decir sólo intervienen cuando se le pide que medie en algún conflicto, urge un caso de mediación o cuando es escogido como mediador o hay reuniones o actividades del equipo de mediación. De esta manera, el alumno está "en funciones" o "de turno" en tanto y en cuanto no exprese su deseo de interrumpir o finalizar su rol de mediador.

Como puede comprobarse, las funciones de los alumnos mediadores, están más acotadas a la resolución de conflictos, aunque indirectamente también se favorecen sus competencias sociales. Es conveniente que se forme a los mediadores y que éstos se reciclen anualmente, para que se renueven y actualicen los equipos.

\subsubsection{Formación}

La formación es similar, por no decir que idéntica en todos los casos para estos alumnos, sin importar que sea tutor, orientador, ayudante, mediador, etc., en cuanto a las capacidades requeridas para cumplir con las funciones de ayudante y mediador: 
- Asertividad: para expresar nuestras observaciones con claridad sin ofender a las personas que nos escuchan.

- Habilidades comunicativas y de escucha activa: para atender a las personas que nos asignen, con la mayor garantía de que no va a haber malentendidos, ni faltas de respeto en las conversaciones mantenidas.

- Autoconocimiento: ser capaces de reflexionar sobre nuestra persona y nuestra manera de ser, nuestras emociones, intereses, motivaciones, estados de ánimo, cualidades y limitaciones. Sólo conociéndonos a nosotros mismos podremos entender y ayudar a los demás.

- Equilibrio y consenso: Generar acuerdos básicos entre todos en referencia a aspectos como pautas de convivencia, intereses, expectativas y necesidades de los integrantes del grupo, y resolviendo las diferencias de opinión antes de tomar cualquier decisión. Todo ello basado en el diálogo y la validez de todas las opiniones.

- Liderazgo: Tener iniciativa para convencer, persuadir y despertar el trabajo en equipo.

- Empatía: Ser capaz de ponerse en el lugar del otro, para entender cómo se siente y cuales son sus motivaciones e intereses.

- Decisión: Ser capaz de proponer cambios para realizar el proceso, asumiendo el impacto que puede suponer, sin perder de vista la realidad del centro.

Dicho esto, cabe distinguir cómo se lleva a cabo la formación para los dos programas objeto de estudio: alumnos ayudante y alumno mediador. En el caso del programa alumno ayudante, el objetivo del curso de formación es enseñar las estrategias y habilidades necesarias para poder intervenir y mediar informalmente en conflictos, además el propio taller crea un ambiente socio afectivo que facilita la vivencia de relaciones interpersonales positivas. La metodología activa y participativa debe incluir un componente afectivo y experimental. En definitiva, es aprender en la "propia piel” el proceso de resolución de conflictos. Los objetivos de la formación según Fernández, Villaoslada y Funes (2002), son: crear el equipo de alumnos ayudantes; promover la ayuda y apoyo entre compañeros; capacitar a los alumnos en las habilidades de escucha y resolución de conflictos; identificar y acordar los valores y principios sobre los que se asienta el servicio de ayuda; favorecer la intervención de los alumnos ayudantes en los 
conflictos interpersonales en su grupo aula y aclarar la organización y procedimientos del servicio de ayuda.

Según estas autoras, la formación consta de 6 módulos en los que se desarrollan habilidades y técnicas necesarias. Cada módulo consta de la siguiente estructura:

- Fundamentación del módulo.

- Objetivos, contenidos, procedimientos y actividades.

- Esquema de la sesión.

- Explicación de las actividades y contenidos.

- Documentos de apoyo.

El programa de contenidos, según Fernández, Villaoslada y Funes (2002) y Torrego (2012), sería el siguiente:

1) Primer Módulo, constaría de una presentación, un módulo sobre las cualidades y habilidades del alumno ayudante, y otro sobre análisis de conflictos.

2) Segundo Módulo, recogería las funciones del alumno ayudante, por otra parte el conocimiento y práctica de las habilidades no verbales de la comunicación, y se cerraría el módulo trabajando la empatía.

3) Tercer Módulo, compuesto por el conocimiento de la escucha activa y práctica de las técnicas de la escucha activa.

4) Cuarto Módulo, se trabajarían la resolución de problemas y la planificación y toma de decisiones, para entrar en última instancia en el desarrollo de la creatividad.

5) Quinto Módulo: definición de principios y valores del alumno ayudante, revisión de funciones del alumno ayudante y organización del servicio de ayuda.

6) Sexto Módulo. Taller de ampliación. Derivación de casos. Y seguir profundizando en la asertividad.

Los módulos tienen un tiempo de dedicación aproximado de tres horas con un breve tiempo de recreo o de relajación a mitad de la sesión. De manera que la formación consta de 18 horas de duración. La temporalización está basada en un grupo estándar de alumnos de entre 12 y 14 años. La metodología es claramente participativa y salpicada con actividades donde los alumnos tienen que expresar sus sentimientos y puntos de vista. Según Cowie y Wallace (2006) se traduce en las siguientes claves: tener una experiencia activa $\mathrm{u}$ observar a otros cuando la tienen, reflexionar sobre dicha 
experiencia, y sacar conclusiones generales y volver a intentar la experiencia con la comprensión adquirida previamente.

El curso formativo debe desarrollarse de forma intensiva y fuera del centro escolar. A pesar de lo que algunos autores opinan sobre la posibilidad de parecer un castigo tener que "obligar" a los alumnos a ir a la formación fuera del horario escolar, y por lo tanto, en su tiempo libre, es necesario que no haya alteraciones propias de los centros como recreo, sonido de cambio de clase, tiempos lectivos de 50 minutos, etc. que puedan interferir, distraer o interrumpir dicha formación. También hay quienes opinan que se puede realizar la formación fuera del centro educativo, pero en horario lectivo. Y quienes organizan la formación a partir de los horarios de los alumnos con el fin de no interferir en el ritmo de aprendizaje ni en los horarios establecidos (Arró, Villanueva, y Traver, 2006). Sea como fuere, es importante trabajar la identidad de grupo de apoyo y crear un espacio y un tiempo único, donde se trabaje con las tensiones propias del aula, ya que se trata de crear grupo además de capacitar a los alumnos en las habilidades de escucha y resolución de conflictos.

Al realizarse fuera del centro escolar, tiene otro valor más cercano a sus vidas personales y pierden el carácter académico. Por ejemplo: salida a un albergue cuatro días, intercalando actividades campestres o incluso culturales... Pero lo que se puede encontrar entonces son una serie de problemas típicos de la edad y de la propia situación: salidas nocturnas, tendencia a la broma, etc. Esto sería interesante poderlo negociar con el ayuntamiento o centro cultural cercano en el que se pudiera realizar la formación durante un par de días. La formación no excederá más de 6 horas al día. Y puede realizarla el profesorado del centro y/o personas especializadas aunque tanto el formador externo como el interno son convenientes al principio de la experiencia.

En el caso del programa alumno mediador, Torrego (2006) indica que el programa de formación también consta de seis módulos de trabajo, al igual que en el caso de los alumnos ayudantes. En cada uno de ellos, se especifican los objetivos, contenidos, actividades y documentos necesarios para la formación de los mediadores. Se deben tratar temas como la concepción positiva del conflicto, el uso del diálogo, trabajar contextos cooperativos en las relaciones interpersonales, desarrollo de habilidades de autorregulación y autocontrol, favorecer una práctica de participación democrática y el 
desarrollo de actitudes de apertura, comprensión y empatía. A continuación se detalla una breve descripción de los módulos formativos:

- Módulo 1: Presentación e introducción al taller de mediación. Se pretende realizar una sensibilización sobre el trabajo en el taller de mediación y presentar de modo activo el enfoque y sentido del programa.

- Módulo 2: El conflicto y sus elementos. Se trabajarán los principales elementos que sirvan para entender el conflicto.

- Módulo 3: La mediación. Dar a conocer un proceso de mediación formal, sus fases, objetivos a tener en cuenta para su correcto desarrollo, etc.

- Módulo 4: Habilidades para una comunicación eficaz. Entrenar de modo aislado las principales habilidades que los mediadores tendrán que utilizar para mediar después en los conflictos.

- Módulo 5: Experimentar la mediación. Dirigido a entrenar el proceso de mediación en su conjunto, a través de casos seleccionados.

- Módulo 6: La mediación en marcha. Recoge recursos, orientaciones y sugerencias para iniciar y poner en marcha un proyecto de mediación en el centro.

La formación puede tener una duración entre 16 y 20 horas dependiendo de que se desarrollen íntegramente todas las actividades o no. La recomendación es que se trabaje fuera del horario lectivo, independientemente de que se lleve a cabo dentro o fuera del centro. Cada sesión debe tener una duración de no más de cuatro horas con la siguiente estructura:

Sesión 1: Módulos 1 y 2.

Sesión 2: Módulos 3 y 4.

Sesión 3: Módulos 4 y 5. Simulación de un caso de mediación.

Sesión 4: Simulación de un caso de mediación. Evaluación del caso.

Sesión 5: Simulación de un caso de mediación. Evaluación del caso. Revisión de expectativas y evaluación del curso de formación. 
Hay que distinguir entre la evaluación impacto del servicio de ayuda en el clima escolar, y la evaluación de la formación. La evaluación de la formación se centra en primer lugar en la satisfacción con la formación, en segundo lugar en la competencia en las técnicas adquiridas, para después centrarse en la percepción del clima socio-emocional del grupo y finalmente en la capacitación personal en los valores y las demandas de ayuda.

Finalmente, la formación debería ser continua durante todo el tiempo que los estudiantes forman parte del programa en el centro.

\subsubsection{Difusión}

Estos programas no son muy conocidos y/o utilizados en los centros de educación secundaria españoles. Por lo tanto, lo fundamental en este caso es crear cultura de centro, a través de la difusión del mismo. Todos deben conocer en qué consiste, cómo solicitarlo, dónde acudir para informarse, ventajas, etc. Por lo tanto, es imprescindible hacer difusión de dichos programa a dos niveles:

1. Para captar alumnos ayudantes y mediadores: explicando mediante dípticos y carteles por el centro, en qué consisten los Programas de Alumno Ayudante y Alumno Mediador, para que los alumnos se interesen y quieran participar.

2. Difusión de los programas, ofreciéndolos a toda la comunidad educativa. Una vez se ha seleccionado a los alumnos que van a ser ayudantes o mediadores, se difunde por el centro con pósters, reuniones en las aulas, etc., la existencia del programa para que el resto de los alumnos lo soliciten si están interesados.

En la fase de captación de alumnos, hay que realizar una formación en aspectos básicos que se detallan en el anterior apartado de formación. Una vez terminado el curso de formación, los alumnos se deben presentar ante sus compañeros formalmente como ayudantes o mediadores. Ésta es una buena actividad para la hora de tutoría. En esta fase se debería presentar al alumno ayudante del curso correspondiente, explicar el programa y las funciones de este alumno, tratar de aprovechar el momento para empatizar con los compañeros, explicar la organización del equipo y las futuras reuniones que van a tener lugar y aclarar posibles dudas. 
También es interesante que en esta fase, la información esté apoyada con material gráfico más visual que recuerde la puesta en marcha del programa, a través de pósters, folletos, tutorías y además puede ser una buena oportunidad para que los alumnos ayudantes estrechen vínculos y cooperen entre ellos, como indican Andrés y Barrios (2006), tras la puesta en marcha de grupos de discusión que evalúan la mejora de la convivencia tras la intervención.

\subsubsection{Temporalización}

Se considera recomendable, que los alumnos ejerzan su función de ayudantes o mediadores únicamente durante un curso académico, con el fin de que más estudiantes tengan la oportunidad de formarse para ayudar a los demás, y además mejorar las propias habilidades sociales, emocionales, de comunicación y empatía. También de este modo, se evita la sobrecarga emocional que supone para alumnos de la etapa de enseñanza secundaria obligatoria, trabajar con los problemas y dificultades de sus compañeros, de manera prolongada en el tiempo.

\subsubsection{Evaluación}

La puesta en marcha de un programa de mejora de la convivencia exige tener un conocimiento lo más riguroso posible del clima de centro y de aula previos a la intervención, ya que el objetivo general del programa es, conseguir la mejora del clima a través del desarrollo de las habilidades sociales del alumnado. Otros objetivos más concretos son disminuir la intensidad de los conflictos, y conseguir una mayor satisfacción del alumnado y las familias con la escuela. Para ello, se debe llevar a cabo una evaluación continua, en los dos programas.

En resumen, la evaluación que se puede llevar a cabo del programa de intervención, según Andrés (2001), contempla los siguientes objetivos:

- Evaluación del clima escolar y de aula.

- Evaluación de las habilidades sociales del alumnado.

- Valoración del programa de alumnos ayudantes y mediadores por alumnos y profesores. 
Los instrumentos de medida del clima que se han desarrollado tienen en cuenta un conjunto de factores. Por una parte, las representaciones que alumnos, profesores y familias tienen de las relaciones de convivencia en la escuela. A nivel de centro, se refiere a las relaciones e interacciones entre todos los miembros de la comunidad educativa, las reglas y los acuerdos sobre comportamientos entre ellos.

El concepto de clima escolar que parte originalmente de la psicología ecológica de Bronfenbrenner (1979), y de la sociología (Anderson, 1982), tiene que ver en gran medida con las percepciones, actitudes, normas y valores de alumnos y profesores. Este concepto de clima escolar, se ha construido en torno a los campos de gestión del aula, motivación y expectativas de logro y metodología de trabajo; información y participación en el aula y en el centro; relaciones interpersonales y conflictos y estrategias de resolución.

Algunos estudios que se han realizado para evaluar los sistemas de ayuda entre iguales han puesto de manifiesto, que el primer beneficio de estos modelos recae en los alumnos que participan en ellos de forma directa (Andrés, 2001; Naylor y Cowie, 1999; Salmivalli, 1999). En el programa, los alumnos que desempeñan el papel de alumnos ayudantes en cualquiera de sus modalidades, valoran la evolución de sus propias habilidades sociales. Se debe tener en cuenta que el cuestionario que se vaya a utilizar en dicha evaluación debe abarcar aspectos como la solución de problemas, la empatía, las habilidades de comunicación, eficacia emotiva y gestión del estrés, así como la prosocialidad y relaciones con los compañeros. En este sentido, se ha propuesto la utilización de una metodología cuantitativa que, siendo sencilla de aplicar, permite al mismo tiempo obtener y generalizar los resultados con gran rapidez. También es importante valorar la satisfacción que los alumnos y profesores implicados en el programa muestran con respecto a su funcionamiento. En esa valoración es preciso tener en cuenta distintos aspectos de la puesta en marcha del programa como las características concretas del proceso de implantación en el centro; las medidas de supervisión y seguimiento; los acuerdos para su posterior mantenimiento y como factor esencial, la confidencialidad. Para conseguirlo, se pueden utilizar distintos instrumentos de carácter cualitativo, como el diario de centro y los grupos de discusión.

A continuación se detallan las evaluaciones realizadas en cada uno de los dos programas de ayuda entre iguales, descritos. 
Dentro del programa de alumno ayudante, se llevan a cabo, diferentes tipos de evaluaciones, según Fernández, Villaoslada y Funes (2002):

1. Evaluación de la concepción y del diseño: se debe diseñar, a partir de las necesidades del centro, mediante entrevistas con el profesorado, así como a través de la realización de un cuestionario por parte de todos los alumnos y la observación directa, tanto en las aulas como en los espacios comunes. También es necesario partir de los recursos personales y materiales del centro, así como hacer una revisión teórica exhaustiva de la literatura sobre el tema para poder diseñar todos los protocolos necesarios para un funcionamiento fluido y eficaz.

2. Evaluación de la implementación: todas las acciones se deben organizar de forma cronológica y secuencial con el fin de alcanzar las metas previstas. Se debe informar a todos los miembros de la comunidad educativa de qué se va a incluir en el programa educativo del centro, detallando todas las actuaciones a llevar a cabo, y teniendo en cuenta el tiempo y los recursos disponibles, tanto materiales como humanos. Se deben tener en cuenta los costos, el uso y efecto del programa.

3. Evaluación de la ejecución: todas las actuaciones deben ir encaminadas a demostrar la efectividad del programa.

Algunos aspectos a tener en cuenta según estas autoras son informar y/o recordar periódicamente en las tutorías y siempre que la situación lo requiera, el uso de los alumnos ayudantes para lograr resolver los conflictos entre los alumnos; reestructurar los horarios del curso de formación siempre que la organización del centro lo permita; concienciar a toda la comunidad sobre la utilidad de la figura del alumno ayudante como medio para mejorar la convivencia del centro y modificar algunos materiales de formación, puesto que en algún momento pueden resultar un poco áridos, dependiendo de la edad de los alumnos.

En la evaluación de las tareas del alumno mediador, se propone realizar una valoración en distintos momentos de la misma: al inicio, a partir de una recogida de expectativas sobre el taller por parte de los asistentes al mismo; en su desarrollo, proponiendo situaciones de recogida de información durante su transcurso; y al final, de modo sumativo, utilizando un cuestionario. 
El clima del centro y las habilidades sociales se muestran, por lo tanto, como indicadores básicos para evaluar la incidencia de estos programas. En el día a día, el hecho de recoger las características específicas del proceso servirá para reflejar sus diferentes momentos y también debe recogerse, junto a la puesta en marcha del programa, la manera en la que se organiza la formación de los alumnos, cómo se realiza el seguimiento y qué medidas de apoyo se prevén a lo largo del curso. Por ello, el principal objetivo del diario de centro, debe ser recoger todas aquellas decisiones que puedan afectar a la implantación y desarrollo del programa.

Algunos de los instrumentos que se han utilizado en los centros en los que se ha desarrollado el programa de alumno ayudante y mediador, son los siguientes:

- Cuestionarios de clima de aula y de centro, para alumnos, profesores y padres.

- Cuestionario de habilidades sociales para los alumnos.

- Grupo de discusión con alumnos y profesores participantes en el programa.

Referente al diseño temporal de la evaluación, en un programa de dos cursos de duración, ésta se ha realizado en tres fases (Andrés, 2001). La primera, previa a la intervención, en donde se han distribuido los cuestionarios de clima a alumnos, profesores y familias, y el de habilidades sociales al alumnado. La segunda, a la mitad de desarrollo del proyecto, en donde se han distribuido los cuestionarios de clima solo al colectivo de alumnos, incorporando información sobre el grado de conocimiento del programa. La tercera, a realizarse al final de la intervención, en donde de nuevo se pregunta a los tres colectivos de alumnos, profesores y familias sobre el clima escolar, distribuyendo el cuestionario de habilidades sociales, por última vez, entre todo el alumnado del centro.

\section{Para resumir...}

Una vez finalizados todos los pasos necesarios para la implementación de ambos programas, se presentan dos tablas resumen, una con los aspectos comunes y otra con los aspectos diferenciadores entre los programas alumno ayudante y alumno mediador. 
Tabla 1: Resumen de aspectos comunes a los programas Alumno Ayudante y Alumno Mediador

\begin{tabular}{|c|c|}
\hline & Programas Alumno Ayudante y Alumno Mediador \\
\hline $\begin{array}{l}\text { Objetivos y } \\
\text { beneficios }\end{array}$ & $\begin{array}{l}\text { - Se incide en los aspectos socioemocionales del curriculum oculto. } \\
\text { - } \quad \text { Mejoran la integración social del alumnado en general. } \\
\text { - } \text { de mantan la colabora no violenta. } \\
\text { - } \text { Reducen los casos de maltrato entre iguales. } \\
\text { - } \text { Se favorece la participación directa del alumnado en la resolución de conflictos } \\
\text { - } \quad \text { Crean canales de comunicación entre alumnos y centro. } \\
\text { - Mejoran el clima afectivo y de convivencia del centro. } \\
\text { - } \quad \text { Disminución de medidas sancionadoras. } \\
\text { - Mayor satisfacción y mejora del centro. } \\
\text { Mejora de la autoestima de los alumnos y profesores que participan. }\end{array}$ \\
\hline $\begin{array}{l}\text { Consideraciones } \\
\text { previas e } \\
\text { implementación }\end{array}$ & 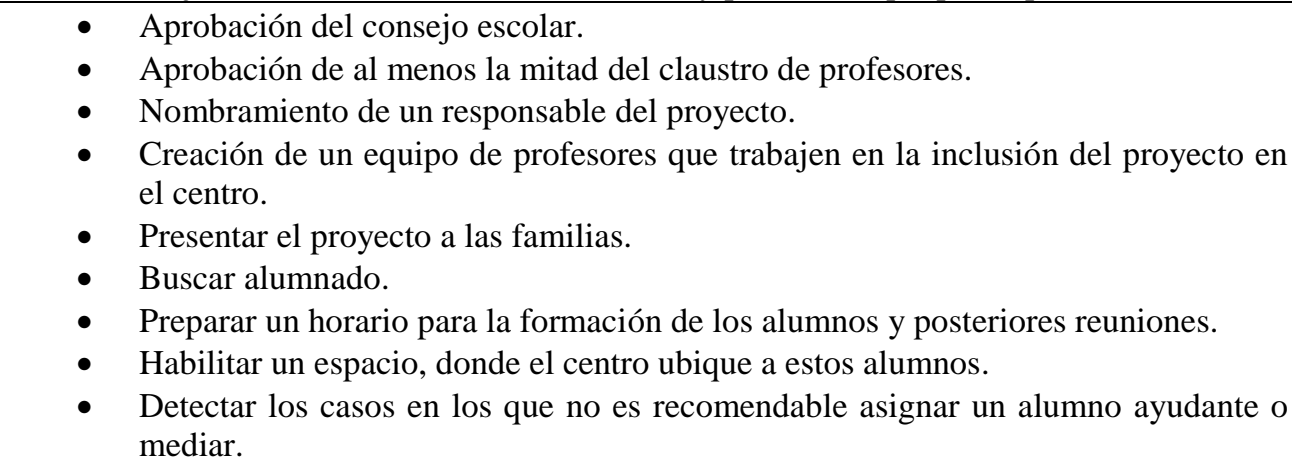 \\
\hline Selección & $\begin{array}{l}\text { - Los alumnos deben presentarse voluntariamente a formar parte de estos } \\
\text { programas. } \\
\text { - Estos alumnos preferiblemente deben cumplir una serie de características } \\
\text { personales: confianza, escucha activa, capacidad de recibir críticas y buena actitud } \\
\text { para resolver conflictos. } \\
\text { - Equilibrar el número de alumnos y profesores que participan, así como el género } \\
\text { de los participantes. } \\
\text { - Seleccionar a tres o cuatro alumnos por cada grupo. Tener entre } 25 \text { y } 30 \text { alumnos, } \\
\text { siempre teniendo en cuenta el volumen de alumnos del centro. }\end{array}$ \\
\hline Formación & $\begin{array}{l}\text { - Es recomendable que se lleve a cabo fuera del horario lectivo, independientemente } \\
\text { de que se lleve a cabo en el propio centro o fuera de él, con una duración entre } 16 \\
\text { y } 20 \text { horas en total. } \\
\text { - Cada sesión o módulo durará entre cuatro y seis horas, y nunca será superior a a } \\
\text { seis horas por día. }\end{array}$ \\
\hline Difusión & $\begin{array}{l}\text { A dos niveles: } \\
\text { 1. Para captar alumnos ayudantes y mediadores. Con dípticos y carteles explicando los } \\
\text { programas. } \\
\text { 2. Para ofrecer los programas a la comunidad educativa, con pósters, reuniones en las aulas } \\
\text { con la ayuda de los alumnos seleccionados. }\end{array}$ \\
\hline Temporalización & $\begin{array}{l}\text { La recomendación es que se pueda "ejercer" de alumno ayudante o mediador durante un } \\
\text { curso académico. }\end{array}$ \\
\hline Evaluación & $\begin{array}{l}\text { - Valoración de los programas de ayuda por parte de alumnos y profesores } \\
\text { implicados de manera subjetiva ya que es común que no se evalúen formalmente } \\
\text { estos programas. }\end{array}$ \\
\hline
\end{tabular}


Tabla 2: Resumen de diferencias de los programas Alumno Ayudante y Alumno Mediador.

\begin{tabular}{|c|c|c|}
\hline & Programa Alumno Ayudante & Programa Alumno Mediador \\
\hline $\begin{array}{l}\text { Objetivos y } \\
\text { beneficios }\end{array}$ & $\begin{array}{l}\text { - Se previenen los conflictos. } \\
\text { - La solución de ayuda está ligada al } \\
\text { alumno ayudante y al ayudado, } \\
\text { depende de los dos. }\end{array}$ & $\begin{array}{l}\text { - Se actúa ante los conflictos. } \\
\text { - Se enseña a los alumnos a buscar } \\
\text { soluciones autónomas y } \\
\text { negociadas. El alumno mediador } \\
\text { es neutral y no interviene en la } \\
\text { solución. }\end{array}$ \\
\hline $\begin{array}{c}\text { Consideraciones } \\
\text { previas a la } \\
\text { implementación }\end{array}$ & \\
\hline Selección & $\begin{array}{l}\text { Los agresores pueden formarse para ser } \\
\text { alumnos ayudantes. }\end{array}$ & $\begin{array}{l}\text { - No es recomendable que los alumnos } \\
\text { que son o han sido agresores sean } \\
\text { alumnos mediadores. }\end{array}$ \\
\hline Formación & $\begin{array}{l}\text { MÓDULO } 1 \\
\text { - Presentación, habilidades de este } \\
\text { alumno y análisis del conflicto. } \\
\text { MÓDULO } 2 \\
\text { - Funciones, habilidades no verbales } \\
\text { en la comunicación y empatía. } \\
\text { MÓDULO } 3 \\
\text { • Escucha activa. } \\
\text { MÓDULO } 4 \\
\text { - Resolución de problemas, toma de } \\
\text { decisiones, planificación y } \\
\text { creatividad. } \\
\text { MÓDULO } 5 \\
\text { - Principios, valores, funciones y } \\
\text { organización del servicio de ayuda. } \\
\text { MÓDULO } 6 \\
\text { - Taller de ampliación, derivación de } \\
\text { casos y asertividad. }\end{array}$ & $\begin{array}{l}\text { MÓDULO } 1 \\
\bullet \quad \text { Presentación. } \\
\text { MÓDULO } 2 \\
\bullet \quad \text { El conflicto y sus elementos. } \\
\text { MÓDULO } 3 \\
\bullet \quad \text { Mediación. } \\
\text { MÓDULO } 4 \\
\bullet \quad \text { Habilidades para una } \\
\quad \text { comunicación eficaz. } \\
\text { MÓDULO } 5 \\
\bullet \quad \text { Experimentar la mediación. } \\
\text { MÓDULO } 6 \\
\bullet \quad \text { La mediación en marcha. }\end{array}$ \\
\hline Difusión & \multicolumn{2}{|c|}{------ } \\
\hline Temporalización & \multicolumn{2}{|c|}{------} \\
\hline Evaluación & $\begin{array}{l}\text { Se evalúa de forma subjetiva: } \\
\text { - La concepción del diseño. } \\
\text { • La implementación. } \\
\text { • La ejecución. }\end{array}$ & $\begin{array}{l}\text { Se evalúa de forma subjetiva: } \\
\text { - El clima del aula y del centro por } \\
\text { parte de: alumnos, profesores y } \\
\text { padres. } \\
\text { Las habilidades sociales de los } \\
\text { alumnos. } \\
\text { - El final del proceso a través de } \\
\text { un grupo de discusión con } \\
\text { alumnos y profesores que han } \\
\text { participado en el programa. }\end{array}$ \\
\hline
\end{tabular}




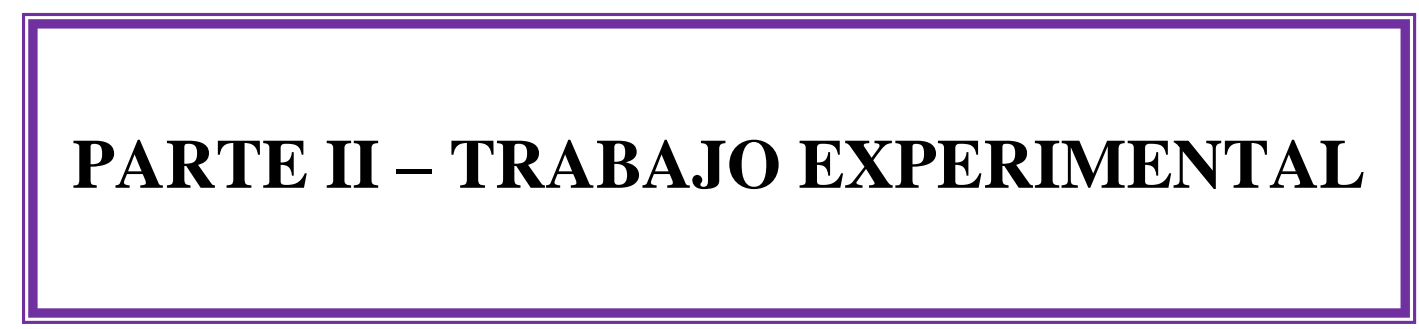



CAPÍTULO 3. ESTUDIOS DE LA TESIS 



\section{CAPÍTULO 3. ESTUDIOS DE LA TESIS}

\subsection{Justificación de las investigaciones}

Ámplia es la trayectoria a día de hoy, de los programas de ayuda entre iguales en los centros educativos, como medida de prevención de la violencia entre iguales. Aunque estos programas cuentan con mayor tradición en los centros de fuera de España, sobre todo ingleses, actualmente se dispone de datos y resultados procedentes de las investigaciones tanto de ámbito local, como autonómica y nacional, que reflejan un creciente interés por la convivencia escolar, y que permiten reflexionar sobre las características de las relaciones entre los diferentes colectivos que componen la comunidad educativa.

La presente tesis trata de dar respuesta a las limitaciones metodológicas encontradas en estudios anteriores, sobre el mismo tema de investigación, incorporando tres niveles diferentes de variables: individual (actitudes), grupal (roles) y organizativo (clima de centro). Tras la revisión bibliográfica, se hace patente que existen escasos estudios (sobre todo internacionales) en los que se haya tenido en cuenta la perspectiva de clima de centro, incluyendo diferentes niveles de variables (Azeredo et al., 2015; Cowie, 1998; Palladino, Nocentini y Menesini, 2012). De hecho, la prevención del acoso escolar es más eficaz cuando el programa tiene un enfoque global (Cowie, 2014). Así mismo, el hecho de que existan grupos de intervención y experimentales en el mismo centro, también se considera una limitación, puesto que los datos pueden contaminar los resultados, a consecuencia de las relaciones informales que se establecen de manera natural tanto entre el estudiantado, como el profesorado de todo el centro (Menesini, Codecasa, Benelli y Cowie, 2003).

Partiendo de las limitaciones comentadas, el primer artículo recoge las innovaciones en temas de convivencia escolar, que aportan los sitemas de ayuda entre iguales en los centros educativos, detallando las características de los programas alumno ayudante y alumno mediador. Por tanto puede decirse que este artículo es una guía de carácter más práctico para la implementación de los programas en un centro educativo. 
Tras este primer artículo, en el que se deja evidencia de los beneficios que pueden revertir en la comunidad educativa con el uso de los sistemas de ayuda entre iguales, se pretende conocer la eficacia de los mismos en los centros que los están utilizando. En este sentido, se realiza un segundo artículo, en el que se comparan dos centros de educación secundaria, uno de ellos cuenta con un programa alumno mediador de larga trayectoria en el centro, y otro en el que no se produce ningún tipo de intervención. En ambos casos se analizan los niveles sociogrupal e individual.

Los resultados apoyan una mejora en las actitudes províctima del centro con programa de mediación pero, no se produce una mejora de los roles, sino una prevención de la escalada negativa que parece darse en el centro sin programa de mediación. Como en éste artículo no se había tenido en cuenta la variable clima de centro, se procede a incorporar dicha variable organizacional en los dos artículos posteriores, puesto que los cambios en el ambiente del centro, son un indicador del efecto que tienen los programas de intervención.

En el tercer artículo se compara de nuevo en los mismos centros, cómo influye la puesta en marcha de estos programas no sólo en el estudiantado, sino que se incorpora la opinión del profesorado, así como un tercer nivel de análisis: el clima de centro. Los resultados de dicho artículo, apoyan mejoras en todas las variables analizadas, únicamente para el centro con programa de mediación. Sin embargo, existe discrepancia de opiniones entre los dos informantes (alumnado y profesorado). El alumnado percibe mayores mejoras que el profesorado respecto a lo que ha ocurrido en el centro tras la intervención (Hymel, McClure, Millar, Shumka y Trach, 2015).

Por último, el cuarto artículo pretende conocer si los programas que llevan poco tiempo funcionando en un centro, pueden producir cambios a diferentes niveles, de la misma forma que se ha confirmado en centros con larga trayectoria de implantación de estos programas. En este sentido diferentes autores indican que el tiempo medio para que se consoliden los programas de mediación y se perciban mejoras en el clima de centro, son dos o tres años (Boqué, 2004; Houlston y Smith, 2009). Quizás por el simple hecho de que exista en el centro un programa alumno mediador, como medida de prevención de las situaciones de acoso escolar, se piensa que mejorará el clima de centro. Pero de 
hecho, se produce el efecto contrario, y el clima de centro, empeora según los estudiantes, en el centro que cuenta con programa.

\subsection{Objetivos de la tesis}

Por tanto, en este trabajo se pretenden conocer los sistemas de ayuda entre iguales y si la aplicación de los mismos es eficaz para disminuir las situaciones de bullying que se dan en los centros de educación secundaria.

Para ello, se plantean los siguientes objetivos específicos:

A. Exponer las características y fases a tener en cuenta para la implantación de un sistema de ayuda entre iguales en los centros de Enseñanza Secundaria Obligatoria.

B. Conocer la eficacia del programa alumno mediador en los centros de secundaria, a partir de las variables individuales (actitudes), sociogrupales (roles) y organizativas (clima de centro).

C. Comparar las opiniones de los alumnos y profesores sobre la eficacia de los programas basados en la ayuda de iguales.

D. Analizar el impacto del factor tiempo de implementación de un programa en un centro, sobre la eficacia de los sistemas de ayuda.

A continuación se representa la correspondencia entre los objetivos específicos y los artículos de la tesis.

\begin{tabular}{cc}
\hline Objetivos específicos & Artículos \\
\hline Objetivo A & Artículo 1 \\
Objetivo B & Artículo 2, 3 y 4 \\
Objetivo C & Artículo 3 \\
Objetivo D & Artículo 4 \\
\hline
\end{tabular}





\section{CAPÍTULO 4. ARTÍCULOS SOBRE LA INVESTIGACIÓN}





\section{ARTÍCULO 1}

\section{Sistemas de ayuda entre iguales: programas de innovación educativa en la convivencia escolar.}

Usó, I, Górriz, A.B., Villanueva, L., y Adrián, J.E. (2011). Sistemas de ayuda entre iguales: programas de innovación educativa en la convivencia escolar. Quaderns Digitals.

http://www.quadernsdigitals.net/datos/hemeroteca/r_75/nr_819/a_11063/11 063.html 


\title{
SISTEMAS DE AYUDA ENTRE IGUALES: PROGRAMAS DE INNOVACIÓN EDUCATIVA EN LA CONVIVENCIA ESCOLAR
}

\section{Resumen:}

La convivencia escolar y todo lo que le acontece es un tema que preocupa mucho en la actualidad. El hecho de que los conflictos en las aulas sean cada vez más frecuentes, nos obliga a buscar alternativas pacíficas e innovadoras, que fomenten la participación democrática para resolver dichas situaciones, y además que beneficien no sólo a los implicados, sino al conjunto de todo el centro educativo.

Una de las alternativas propuestas es la utilización de los sistemas de ayuda entre iguales. Pero estos programas ¿son eficaces?, ¿cómo se aplican en los centros?, ¿quién debe desarrollarlos?... Estas son algunas de las preguntas a las que se va a dar respuesta en las siguientes líneas. De este modo se plantea una reflexión en torno a la necesaria formación en valores y actitudes, en aspectos como el autocontrol, la asunción de responsabilidad por parte de los alumnos en la resolución de sus propios conflictos, en definitiva en la necesidad de que este tipo de programas colaboren en la mejora educativa, no solo fomentando unos mejores alumnos en nuestros centros, sino también unos mejores ciudadanos.

Palabras clave: mejora e innovación educativa, participación democrática, mejores alumnos, mejores ciudadanos, ayuda entre iguales, convivencia entre iguales.

\section{SYSTEMS PEER SUPPORT: INNOVATION SCHOOL EDUCATION IN COEXISTENCE}

\begin{abstract}
:
School life and everything that happens is a matter of great concern today. The fact that conflicts in the classroom are becoming more frequent, compels us to seek peaceful alternatives and innovative, to foster democratic participation to resolve such situations, and also that benefit not only those involved, but the set of all school.

One of the proposed alternatives is the use of peer support systems. But how effective are these programs, how they apply in schools? Who should develop them? .Here are some of the questions to be answer in the following lines. This would pose a reflection on the necessary training in values and attitudes in areas such as self-control, accountability for the students to resolve their own conflicts, in short the need for this
\end{abstract}


type programs assist in improving education, fostering not only a best student in our schools, but also a better citizen.

Keywords: educational improvement and innovation, democratic participation, better students, better citizens, peer support, co-existence between equals.

\section{Introducción}

El deterioro de la convivencia en los centros educativos y la aparición de manifestaciones de violencia han provocado que, en la actualidad, la convivencia escolar haya generado especial interés en el sistema educativo, siendo cada vez más numeroso el volumen de estudios e informes que tratan de indagar en esta problemática (Defensor del Pueblo-UNICEF, 2006; Iborra, Rodríguez, Serrano y Martínez, 201; López, Gil, Moreno, Comas, Funes y Parella, 2008; OCDE, 2009).

Desde el análisis de las relaciones interpersonales que se producen dentro de la comunidad educativa, se trata de profundizar en el carácter y la calidad de estas relaciones, sobre todo en las que se dan entre los propios alumnos y sus iguales. No se debe olvidar que la escuela constituye un importante agente socializador responsable de la transmisión de pautas de comportamientos y valores, así como de la formación de capacidades y destrezas de resolución de conflictos que les ayudarán a enfrentarse con éxito a los problemas de convivencia del día a día.

Asimismo, en los centros educativos se debe proporcionar a los menores las oportunidades necesarias para aprender y adquirir responsabilidades como las que se les exigirán en la vida adulta. De este modo, los estudiantes deben tomar decisiones sobre sus propios conflictos personales, teniendo en cuenta aspectos como el autocontrol, la disciplina y el respeto a los demás como máximas de la vida en sociedad.

Por todo ello, en los últimos años han aparecido múltiples propuestas de intervención para la mejora del clima en las aulas, para una convivencia pacífica y democrática. Estas propuestas tienen en cuenta tanto a los estudiantes directamente implicados como al grupo en cuyo seno han ocurrido este tipo de agresiones (Barrios, Andrés y Granizo, 2010; Smith, Pepler y Rigby, 2004).

Así, una forma de intervenir en los centros es la propuesta por Fernández, Villaoslada y Funes (2002) con la utilización de los sistemas de ayuda entre iguales. Esta iniciativa tiene como base la actuación dentro del medio escolar, donde se potencia la comunicación y negociación de los conflictos dando voz y espacio, para que toda la 
comunidad educativa pueda manifestar sus necesidades personales, creando situaciones de aprendizaje en el medio escolar en las que los alumnos se escuchan entre sí, se preocupan unos por los otros y se ayudan. Y lo más importante, supone el aprovechamiento de un gran recurso humano: el propio alumnado.

El objetivo de este artículo es analizar las principales características de los sistemas de ayuda entre iguales orientados a la prevención de los conflictos y el acoso escolar en los centros de secundaria. En concreto, se pretende dar a conocer los modelos de alumno ayudante y de alumno mediador, teniendo en cuenta los perfiles y funciones de los alumnos participantes, las fases de las que consta la implantación de este tipo de iniciativas en los centros escolares, así como su eficacia.

\section{Sistemas de ayuda entre iguales}

Tal y como sugiere Fernández (2003), “el concepto de "educación entre iguales" arranca de la idea básica de que los propios iguales son fuente de conocimiento y miembros activos que impulsan la acción educativa en los centros escolares. La participación de los alumnos en sus propios conflictos recoge la dimensión práctica de la formación cívica para la ciudadanía sobre la que se asienta esta propuesta y se constituye como una clave imprescindible para la educación en valores".

En los últimos años han surgido experiencias (Arró, Villanueva y Traver, 2006; Avilés, Torres y Vian, 2008; Fernández y Orlandini, 2001; Naylor y Cowie, 1999; Smith, Talamelli, Cowie, Naylor y Chauhan, 2002, 2004) en las que se involucra a los propios alumnos en la toma de decisiones y mejora diaria de la convivencia en los centros escolares, a través de sistemas de ayuda entre iguales. Estos sistemas pueden involucrar a los estudiantes, profesores, personal de administración y servicios, familias, etc., en definitiva, a todos los implicados en la comunidad educativa para combatir sutilmente por ejemplo, situaciones de acoso y victimización en el contexto entre iguales.

Pero, ¿cuáles son las características del acoso escolar? Tomando como referencia la definición planteada por Olweus (1993) se trata de "aquellas conductas de persecución física, verbal y/o psicológica que realiza un estudiante contra otro, al que elige como víctima de repetidos ataques. Esta acción, negativa e intencionada, sitúa a las víctimas en posiciones de las que difícilmente pueden salir por sus propios medios. La continuidad de estas acciones provoca en las víctimas efectos claramente negativos: descenso de la autoestima, estados de ansiedad e incluso cuadros depresivos, etc., lo que 
dificulta su integración en el medio escolar y el desarrollo normal de los aprendizajes" (pág. 9). Así mismo, hay una serie de características que siempre están presentes en este tipo de situaciones (Olweus, 1983; Ortega y Mora-Merchán, 2000): estabilidad en el tiempo, naturaleza variada de la agresión, diferencia de poder entre agresor y víctima e intención del agresor de hacer daño.

Tal y como plantean Connell, Pepler y Craig (1999), durante los episodios de intimidación, el 75\% de los iguales (los testigos de la agresión), suelen proporcionar un refuerzo positivo al agresor para intimidar y no ayudan a la víctima. Por lo tanto, la eficacia de las intervenciones de los sistemas de ayuda entre iguales deberá tener dos componentes. En primer lugar, es importante hacer ver a los compañeros testigos la importancia de aspectos como la responsabilidad y la necesidad de empatía por la víctima. En segundo lugar, es necesario establecer estrategias de intervención eficaces para los niños, y así animarles a resistir la dinámica del grupo de iguales. En combinación, estas estrategias podrían influir en la mayoría silenciosa y animarles a actuar en contra de la intimidación.

Si bien es difícil concretar que se entiende por educación entre pares de una manera rigurosa con el objeto de planificar una intervención, sí está claro, según diferentes autores (Avilés, 2002; Ortega y Mora-Merchán, 2000; Rigby, 2008; Shariff, 2008), las dificultades que tienen las víctimas de acoso para expresar y contar lo que les pasa. Por este motivo y aprovechando la similitud con la relación espontánea de amistad, estos programas pueden cubrir nuestras expectativas en la puesta en práctica en los centros educativos. Tanto las estrategias de ayuda entre iguales y de mediación, como los servicios que éstos generan dentro de la escuela en su puesta en práctica, inciden directamente en la creación de valores en acción (Bolivar, 1995). Se favorece la reflexión moral desde una perspectiva inclusiva donde se crea sentido de pertenencia y cohesión al grupo, fomentando el "nosotros" como preocupación compartida y promoviendo su sentido de conciencia común y colaborativa que es lo que se necesita para hacer frente a un problema como el acoso.

\subsection{Características y funciones de los alumnos participantes}

El rol de ayuda se describe como el de un compañero que ampara, escucha y ayuda a sus iguales cuando surge un conflicto o se sienten desvalidos, tristes, solos, etc., con un marcado carácter preventivo, dado que se reducen las posibilidades de situaciones 
violentas y de sufrimiento y favorece una mejor integración social del alumnado en su conjunto.

Según Fernández, Villaoslada y Funes (2002), las características de este sistema de ayuda ente iguales son las siguientes:

- Los alumnos intervienen desde la neutralidad buscando el equilibrio entre las partes sin aportar juicios de valor ni soluciones, adoptando una posición de escucha y receptividad de las necesidades de los otros.

- Dichos alumnos pueden intervenir en la resolución de conflictos en el aula sin la necesidad de intervención directa del profesor tutor, ya que la posición de iguales repercute en una mayor credibilidad ante sus compañeros.

- Los programas de ayuda deben convertirse en cultura de centro para proporcionar oportunidades reales de participación y de toma de decisiones de sus propios conflictos.

- Cuando los alumnos adoptan un papel de ayuda, mejora su autoestima y se consigue llevar a cabo un adecuado comportamiento y actitudes.

- Es muy importante la selección de los alumnos que participan en los programas y de la formación para su puesta en práctica y desarrollo personal.

- El carácter voluntario y altruista de estos modelos supone trabajar codo con codo, tanto con los alumnos a quien se ayuda como con el resto de compañeros que cumplen funciones parecidas.

- Se fomenta la capacidad de tomar decisiones y responsabilidades con adultos, profesores, e implicados en el servicio, en situación de homogeneidad.

- Se obtienen beneficios para el propio alumno ayudante, pues hay una clara mejora de sus potencialidades personales e imagen social, y por otro lado, su puesta en práctica crea una red de apoyo y colaboración para el centro en su conjunto.

Por tanto, las funciones tanto de un alumno ayudante, como de uno mediador son entre otras, ser la persona que da confianza, que le gusta escuchar e intenta ayudar a sus iguales, que además conoce los recursos del centro para resolver problemas graves, informa de su existencia y contenido a quienes lo necesiten, y deriva los problemas que superan su capacidad de actuación para que los resuelvan otras personas adultas, con mayor experiencia o recursos. 


\subsection{Fases del proceso}

Todos los sistemas de resolución pacífica de conflictos pueden presentar dificultades en su desarrollo tanto desde la perspectiva de la organización escolar como desde el modo en que se trabajan los valores y se gestionan los conflictos. Y es por esto que no todos los centros educativos muestran predisposición a incluir en sus proyectos educativos la educación entre iguales, ya que hay una serie de aspectos y limitaciones a tener en cuenta para la implementación de estos programas en los centros.

Por tanto, antes de implantar unos de estos programas hay que realizar un análisis de las necesidades del centro y el propio centro debe estar concienciado de lo que implican estos programas (Cowie y Wallace, 2000, 2006). También es recomendable considerarlo un modelo integrador, en el que funcionen paralelamente estos sistemas y las medidas correctoras.

Los sistemas de ayuda entre iguales no se deben concebir únicamente como instrumentos para hacer frente a las dificultades, sino que están pensados para favorecer la convivencia. Una vez puesta en marcha esta experiencia, se deben tener en cuenta en todo momento, la confidencialidad de los hechos y las personas involucradas, por ello, se debe realizar una buena selección de alumno ayudante o mediador. Asimismo, se corre el riesgo de crear jerarquías de alumnos "buenos", que generen envidia y repulsa, por tanto, cuantos más alumnos puedan participar en la educación entre iguales, más exitosa será la experiencia y más habrá penetrado en el tejido social del centro, la filosofía de base.

Respecto a las fases del proceso de implementación de estos programas, en primer lugar se debe contar con el apoyo del equipo directivo y a continuación se debe buscar la implicación del profesorado y el apoyo de la comisión pedagógica así como la de los tutores. Posteriormente deberá ser aprobado por el consejo escolar y al menos por la mitad del claustro de profesores. A partir de ahí, se puede crear el equipo de profesores que va a llevar a cabo el proyecto, presentarlo a las familias, pensar cómo presentar el programa a los alumnos y establecer un lugar donde localizar a los alumnos ayudantes y mediadores en el centro, así como determinar los casos que no se podrán tratar a través de estos programas.

Resumiendo, cuando el sistema no es aceptado por los alumnos y los profesores, si existen actitudes negativas de algunos profesores respecto al programa, o si 
participan pocos usuarios, la ejecución de este tipo de propuestas presentará grandes dificultades.

\subsection{Tipos de sistemas entre iguales}

Son muchas los posibles tipos de ayuda entre iguales, desde ser tutor en materias académicas o guía de actividades colectivas, a ser orientador en cuanto a expectativas académicas, por ejemplo. Pero, todas estas modalidades de ayuda pueden agruparse en tres (Cowie y Sharp, 1998):

a) Agrupaciones de alumnos basadas en interacciones de amistad: adecuadas en primaria al desarrollarse en los recreos de manera informal, no requiere una formación específica.

b) Sistemas de apoyo que brindan orientación a compañeros con necesidad de comunicar su malestar personal: requieren formación específica y supervisión adulta a la hora de brindar apoyo a los compañeros. En esta modalidad estarían los programas de alumnos ayudantes (Cowie y Wallace, 2000; Fernández y Orlandini, 2001), en los que se profundizará en las próximas líneas.

c) Mediadores escolares y sistemas de resolución de conflictos: los alumnos mediadores (Torrego, 2000, 2006; Uranga, 1998, 2000) actúan como tercera parte neutral en conflictos interpersonales, requiriendo también formación específica.

De cualquier modo, la ayuda entre iguales se ha expresado tradicionalmente en los programas de alumno ayudante y de alumno mediador, por lo que a continuación se centra la atención en ambos, a través de su descripción, análisis y comparación.

\subsubsection{Objetivos y Beneficios}

Por una parte, el objetivo del programa alumno ayudante es la prevención de los conflictos, siendo el alumno ayudante quien interviene directamente en la búsqueda de soluciones a los problemas planteados, es decir, la solución la aporta el alumno ayudante. Mientras, en el programa alumno mediador, la intervención se produce ante el conflicto emergente y el papel del mediador en la búsqueda de soluciones es neutral, limitándose a facilitar estrategias que lleven a las partes a alcanzar una solución satisfactoria, para ambas.

Sin embargo, en los dos programas se obtienen beneficios comunes, como la mejora de los aspectos socio-emocionales del currículum oculto, la integración social, la 
convivencia y la autoestima, aumenta la colaboración y participación en la resolución pacífica de los conflictos, y algo muy importante, se reducen los casos de maltrato entre iguales así como las medidas sancionadoras.

\subsubsection{Selección de los alumnos voluntarios}

Para los dos programas se ofrecen diferentes posibilidades, según autores: pueden ser los tutores del curso los que recomienden a los alumnos que consideren más cualificados para participar en el programa o también se les puede pasar un cuestionario a los alumnos preguntándoles qué compañero de la clase se ajusta mejor al papel del programa explicado.

Un aspecto común, es que tanto para ser ayudante como mediador, es recomendable que los alumnos acepten voluntariamente el ejercer dicha función. Este es el momento en el que además se sebe tratar de equilibrar el número de alumnos voluntarios en función del género, ya que suelen ser las chicas las que se presentan para participar mayoritariamente en este tipo de programas debido a las características de prosocialidad y altruismo que generalmente las caracterizan.

Según autores como Fernández, Villaoslada y Funes (2002) y Torrego (2006), el número de alumnos voluntarios ideal son entre tres y cuatro por grupo, por lo tanto la recomendación sería contar con unos veinticinco o treinta alumnos voluntarios en el centro, manteniendo esta proporción como referencia en función del volumen total de alumnos matriculados en cada centro.

La diferencia más significativa entre estos programas respecto a la selección, es que en el programa alumno ayudante, los agresores pueden llegar a convertirse en ayudantes, según Menesini, Codecasa, Benelli y Cowie (2003), pero si se tiene en cuenta que los alumnos agresores pueden ser alumnos mediadores, la situación cambia, ya que Torrego (2006), asegura que la formación recibida para ser mediadores no es suficiente como para que estos alumnos ayuden en el futuro al resto de sus compañeros.

\subsubsection{Formación}

Aunque la duración de la formación de los voluntarios es prácticamente la misma (entre 16 y 20 horas), y está distribuida en seis módulos, los contenidos son diferentes. Al alumno ayudante se le da una formación más generalista sobre escucha activa, habilidades sociales, etc., y al alumno mediador, la formación se centra más en las partes de la mediación y en su desarrollo. 
Tampoco existe consenso si nos referimos al momento y lugar en el que se puede llevar a cabo esta formación, pero la mayoría de los centros que lo han puesto en marcha optan por hacerlo fuera del horario lectivo, salvo que se pueda incorporar al currículum como recomiendan las autoras Fernández, Villaoslada y Funes (2002), ofertando esta formación como una asignatura optativa.

El lugar en el que se lleve a cabo la formación es de menor controversia: dentro o fuera del centro escolar, según consideren los responsables del programa.

\subsubsection{Temporalización}

La recomendación es que se ejerza de alumno ayudante o mediador durante un curso académico, y que se forme a nuevos grupos de ayudantes y mediadores cada año, de manera rotatoria, ya que es un modelo democrático y su objetivo no es crear una élite de alumnos voluntarios, sino el ofrecer a todos los estudiantes la posibilidad de enriquecerse y recibir formación para mejorar también sus propias habilidades sociales. Además, de este modo, se evita que los alumnos se sobrecarguen emocionalmente con los problemas de los compañeros durante períodos muy lagos de tiempo.

\subsubsection{Evaluación}

Son muy pocas las evaluaciones que se llevan a cabo en estos programas, de manera que lo único que se han obtenido son valoraciones no estandarizadas de los propios participantes. Las mayores diferencias entre ambos programas es que cada uno tiene en cuenta aspectos diferentes para determinar si se han conseguido o no los objetivos fijados en la puesta en marcha del modelo. En el modelo alumno ayudante se valora el proceso a través del diseño, la implementación y la ejecución del mismo. Y en el alumno mediador se evalúa el resultado de la puesta en marcha del programa, considerando las mejoras en el clima del aula y del centro, así como las habilidades sociales adquiridas por los participantes.

\subsection{Eficacia de los sistemas de ayuda entre iguales}

Actualmente, no hay estudios que se hayan llevado a cabo y que acrediten que los sistemas de resolución de conflictos en los centros implican un mejor aprendizaje, ya que es complicado vincular la mejora del clima escolar en la convivencia y la mejora del rendimiento escolar, pero sí es verdad que los menores aprenden más y mejor cuando se sienten valorados, escuchados y respetados y ésto apoya la necesidad de desarrollar su puesta en práctica. Además, son muchos los trabajos que han analizado 
los beneficios para los participantes de programas como el de alumnos ayudantes (Cowie, 1998; Del Barrio, Barrios, Granizo, van der Meulen, Andrés y Gutiérrez, 2011; Naylor y Cowie, 1999; Smith, Talamelli, Cowie, Naylor y Chauhan, 2004). A través de entrevistas a alumnos y profesores en las que se les preguntaba por los beneficios del programa, ambos colectivos coincidieron en que habían obtenido beneficios personales debido a su participación. En general, valoraban desde el incremento de la autoconfianza y seguridad en sí mismos, el sentimiento de responsabilidad y creencia de que estaban contribuyendo positivamente al desarrollo diario de la escuela, hasta comentarios referentes a que gracias al entrenamiento recibido, habían adquirido y mejorado sus habilidades sociales e interpersonales, sobre todo, la escucha activa, así como el sentimiento de interés de unos hacia otros dentro de la escuela. Incluso algunos de estos participantes comentaron que les había influido positivamente, les había llevado a descubrir su vocación y les había ayudado a elegir para sus estudios universitarios una profesión asistencial, de ayuda y cuidados hacia los demás.

De cualquier manera, queda claro el aumento de emociones positivas por parte de los usuarios del programa y de autoestima para los ayudantes, pero las víctimas, es decir, aquellos que acuden al servicio, también valoraban lo que la escuela estaba haciendo por ellos, proporcionándoles un ayudante-amigo que les ayudaba a superar los problemas, les escuchaba y les atendía si lo precisaban, lo que suponía para ellos un alivio emocional. Tal y como encontraron en sus trabajo Naylor y Cowie (1999), Cowie y Olafsson (2000) o Arellano (2008), los métodos de ayuda entre iguales no redujeron la incidencia del acoso escolar en los centros, pero aún así los usuarios se sentían tan satisfechos que consideraron que la puesta en marcha de sistemas de ayuda entre iguales redujo el impacto negativo del acoso que estaban sufriendo e hizo más aceptable para ellos informar sobre el mismo. Así, aumentó el número de víctimas que contaban su sufrimiento a un profesor o amigo y encontraron útil la protección y seguridad que les daba la presencia de alumnos ayudantes en la escuela, porque entendían que era un centro que se preocupaba por ellos.

Por su parte, del estudio de Smith y Watson (2004), se desprende que casi el 90\% de los participantes lo calificó como "bastante útil" o "útil”, y los profesores comentaron una notable reducción en la ocurrencia de pequeños incidentes de acoso, consiguiendo que a su vez, se aumentara la concienciación de los estudiantes más vulnerables, para solicitar la participación en este programa. 
Respecto a los posibles avances en el clima social del centro escolar, en un estudio longitudinal realizado por Smith et al. (2002), se demostró que el hecho de haber implantado un sistema de ayuda entre iguales en un centro había mejorado el clima social, propiciando un medio donde era aceptado compartir problemas con otras personas, aunque no fuera necesariamente un ayudante. En un estudio más reciente, Del Barrio et al. (2011) en el que se ha realizado la valoración de la aplicación de un programa de ayuda entre iguales en un centro de secundaria de la comunidad de Madrid, han observado que los estudiantes consideran beneficioso el programa para prevenir e intervenir en los casos de conflictividad y acoso entre iguales. Un aspecto destacable de este estudio es que todos los participantes, tanto directos como indirectos, destacan el aumento de emociones positivas tras aplicar el sistema de ayuda entre iguales, que se traduce en alivio para los usuarios del programa, y en autoestima para los ayudantes, así como la mejora en general de la convivencia.

El estudio español de Avilés, Torres y Vian (2008) compara dos centros, uno con un programa de ayuda entre iguales y el otro no. En el que se ha aplicado el programa, se ha detectado que en toda la comunidad educativa se han reforzado las habilidades sociales y comunicativas de los alumnos que han participado activamente, considerando dicho programa como una buena medida de prevención que no les importaría seguir teniendo en el centro.

Por nuestra parte, Usó (2010) trató de analizar la repercusión real de la aplicación de los sistemas de ayuda entre iguales en los centros de Educación Secundaria de la provincia de Castellón. Para ello se contó con la participación de ocho orientadores y orientadoras de los centros de diferentes localidades de la provincia de Castellón. De los ocho orientadores entrevistados, seis trabajaban en centros públicos y dos en concertados. En todos los casos, se trataba de profesionales con una larga trayectoria y experiencia en los centros en los que ejercen sus funciones día tras día. Para recabar la información se utilizó una entrevista semiestructurada en la que entre otras cuestiones se preguntaba en torno a los programas de alumno ayudante y alumno mediador. Así, a la pregunta sobre si sabían en qué consistía el primero de estos programas, el 50\% aseguraron conocerlo, mientras que el resto no sabían ni a qué se refería concretamente ni qué funciones tenía ese alumno. Sin embargo, en todos los casos conocían el programa alumno mediador, incluso hacían referencia a materiales y autores reconocidos. Respecto a la aplicación en su centro de estos programas, dos de los centros sí que estaban llevando a cabo el programa Alumno Mediador. Los seis centros restantes, no trabajaban con ningún 
programa de prevención de la violencia y promoción de la convivencia. Finalmente, ante la cuestión de si tenían previsto aplicar alguno de estos programas en su centro en el futuro, la respuesta de los orientadores de estos seis centros fue que si se les facilitase un protocolo de implementación no tendrían ningún inconveniente en presentarlo en sus centros por si les pareciese de utilidad.

\section{Conclusiones}

A lo largo de este artículo se han analizado los sistemas de ayuda entre iguales orientados a la prevención de los conflictos y el acoso escolar en los centros de secundaria. Dado que este tipo de propuestas se ha expresado tradicionalmente en los programas de alumno ayudante y de alumno mediador, se ha centrado la atención en la comparación entre ambos. Para ello se han desarrollado sus características principales, los perfiles y funciones de aquellos que participan en estos programas, las fases de las que consta su implantación para finalizar analizando su eficacia.

A modo de resumen comentar que si bien ambos programas tienen rasgos comunes también se observan matices diferenciales. De este modo, en cuanto a los objetivos e intervención, en el programa del alumno ayudante la solución la aporta el propio ayudante, con el principal objetivo de prevenir conflictos; sin embargo, el papel del alumno mediador es neutral, la solución la ponen las partes en conflicto y dicha intervención se produce ante el conflicto ya emergente. Respecto a la formación de los alumnos voluntarios para ser ayudantes o mediadores, ésta también es diferente. Al alumno ayudante se le da una formación más generalista sobre escucha activa, habilidades sociales, etc., mientras que la formación del alumno mediador está más centrada en las fases y desarrollo de la mediación.

De cualquier manera, dadas las nuevas necesidades que la gestión de la convivencia en los centros está poniendo en evidencia, la educación entre iguales parece contribuir a la asunción de responsabilidades por parte del alumnado sobre sus conflictos personales y estos métodos que se han venido desarrollando en estas páginas pueden atender a demandas personales, a facilitar las relaciones entre los grupos, incluso a mejorar el clima social de los centros educativos simplemente por las actitudes prosociales que promueven. No quiere decir que los métodos tradicionales de gestión de conflictos no sean útiles y necesarios, pero hoy en día parecen incluso más necesarios métodos innovadores que ayuden en la resolución de estos conflictos que diariamente ocurren en las aulas. Son muchas las ocasiones en las que los estudiantes se quejan de que los 
adultos no cuentan con ellos en la toma de decisiones, pues bien, con estas actuaciones se promueven el proceso natural de responsabilidad hacia los otros, se fomentan soluciones empáticas y asumidas por los propios alumnos y lo más importante para ellos quizás es que estas soluciones no son impuestas por las figuras de autoridad.

Estos tipos de procesos innovadores provocan muchas veces recelos en la propia institución escolar, siendo todavía escasos los centros que los están implementando. Sin embargo, se considera que la comunidad educativa ya está sensibilizada ante los problemas de convivencia y quizás con mayor difusión de este tipo de medidas, así como formación al profesorado la puesta en marcha de estas iniciativas sería una realidad generalizada en los centros de secundaria.

\section{Referencias bibliográficas}

Arellano, N. (2008). Violencia entre pares escolares (bullying) y su abordaje a través de la mediación escolar y los sistemas de convivencia. Informe de Investigaciones Educativas, Vol. XXII, $N^{o} 2$.

Arró, M., Villanueva, L., y Traver, J. (2006). El alumno-amigo: un sistema de ayuda entre iguales. Ponencia presentada en las Jornadas de Fomento de la Investigación. Universitat Jaume I.

Avilés, J.M. (2002). La intimidación entre iguales (bullying) en la Educación Secundaria Obligatoria. Validación del Cuestionario CIMEI y estudio de incidencia. Tesis doctoral no publicada. Universidad de Valladolid.

Avilés, J.M., Torres, N., y Vian, M.V. (2008). Equipos de Ayuda, Maltrato entre Iguales y convivencia Escolar. Revista Electrónica de Investigación Psicoeducativa. 16, 6(3), 863-886.

Barrios, A., Andrés, S. y Granizo, L. (2010). El asesoramiento para la mejora de la convivencia El Clima de Centro. En E. Martín y J. Onrubia (Coords.). Orientación Educativa: Procesos de innovación y mejora de las enseñanzas. Vol. 3. Barcelona: Graó, en prensa.

Bolivar, A. (1995). La evaluación de valores y actitudes. Madrid: Aluda. Anaya.

Conell, P., Pepler, D., y Craig, W. (1999). Peer involvement in bullying: Insights and challenges for intervention. Journal of Adolescence, 22, 437-452. 
Cowie, H. (1998). Perspectiva of teachers and pupils on the experience of peer support against bullying. Educational Research and Evaluation, 4, 108-125.

Cowie, H., y Sharp, S. (1998). Counselling and supporting children in distress. London: Sage Publications.

Cowie, H., y Olafsson, R. (2000). The role of peer support in helping the victims of bllying in a school with high levels of aggression. School Psychology International, 21, 79-95.

Cowie, H., y Wallace, P. (2000, 2006). Peer Support in action. From standing by to stand by. Londres: Sage Publication.

Defensor del Pueblo y UNICEF (2006). Informe "Violencia Escolar: El Maltrato entre iguales en la Educación Secundaria Obligatoria 1999-2006”. Documentos Defensor del Pueblo: Madrid.

Del Barrio, C., Barrios, A., Granizo, L., van der Meulen, K., Andrés, S., y Gutiérrez, H. (2011). Contribuyendo al bienestar emocional de los compañeros: evaluación del Programa Compañeros Ayudantes en un instituto madrileño. European Journal of Education and Psychology, 4, 5-17.

Fernández, I., y Orlandini, G. (2001). La ayuda entre iguales. Cuadernos de Pedagogía, 304, 97-100.

Fernández, I., Villaoslada, E., y Funes, S. (2002). Conflicto en el centro escolar. Ell modelo de alumno ayudante como estrategia de intervención educativa. Madrid: Catarata

Fernández, I. (2003). La educación entre pares. El modelo del alumno ayudante. En: J. E. Adrián y R. A. Clemente (coord.), Convivencia escolar en secundaria. Valencia: Cefire.

Iborra, I., Rodríguez, A., Serrano, A., y Martínez, P. (2011). Informe Situación del menor en la Comunidad Valenciana: víctima e infractor. Serie 18 documentos. VIU (Valencian International University). Valencia: Centro Reina Sofía y Generalitat Valenciana.

López, A., Gil, G., Moreno, A., Comas, D., Funes, M.J., y Parella, S. (2008). Informe Juventud en España, 2008. Madrid: Instituto de la Juventud. 
Menesini, E., Codecasa, E., Benelli, B., y Cowie, H. (2003). Enhancing children's responsability totake actin against bullying: Evaluation of a befriending intervention in Italian middle schools. Aggressive Behavior, 29, 1-14.

Naylor, P., y Cowie, H. (1999). The effectiveness of peer support systems in challenging school bullying: The perspectives and experiences of teachers and pupils. Journal of Adolescent, 22, 1-13.

OCDE, 2009. Estudio Internacional sobre la Enseñanza y el Aprendizaje (TALIS). OCDE.

Olweus, D. (1983). Low school achievment and aggressive behavour inadolescent boys. En D. Magnusson y V. Allen (Eds.), Human development. An interactional perspective (pp. 353-365). New York: Academic Press.

Olweus, D. (1993). Bullying at school. What we know and what we can do. Oxford: Blackwell.

Ortega, R., y Mora-Merchán, J.A. (2000). Violencia escolar: Mito o realidad. Sevilla: Mergablum, Edición y Comunicación.

Rigby, K. (2008). Children and bullying. Victoria: Blackwell Publishing.

Shariff, S. (2008). Cyber-bullying. New York: Routledge.

Smith, P.K., y Watson, D. (2004). Evaluation oh the CHIPS (ChildLine in Partnership with Schools) programme. Reasearch repport RR570. Nottingham: DfES publications.

Smith, P.K., Pepler, D., y Rigby, K. (Eds.). (2004). Bullying in schools. How successful can interventions be? Cambridge: Cambridge University Press.

Smith, P.K., Talamelli, L., Cowie, H., Naylor, P., y Chauhan, P. (2002, 2004). Profiles of no-victims, escaped victims, continuing vitims and new victims of school bullying. British Journal of Educational Psychology, 74, 565-581.

Torrego, J.C. (Coord.) (2000). La mediación en instituciones educativas. Madrid: Narcea.

Torrego J.C. (2006). Modelo integrado de mejora de la convivencia. Estrategias de mediación y tratamiento de conflictos. Barcelona: Graó. 
Uranga, M. (1998, 2000). Mediación, negociación y habilidades para el conflicto en el marco escolar. En Casamayor, G. (Coord.), Cómo resolver conflictos. La disciplina en la enseñanza secundaria (pp. 143-159). Barcelona: Aljibe.

Usó, I. (2010). Prevención de la violencia y promoción de la convivencia en las aulas de secundaria: Programas Alumno Ayudante y Alumno Mediador. Trabajo de Investigación de Master en Intervención y Mediación Familiar. Universitat Jaume I de Castellón. 



\section{ARTÍCULO 2}

Los programas de mediación entre iguales: una herramienta eficaz para la convivencia escolar.

Villanueva, L., Usó, I., y Adrián, J.E. (2013). Los programas de mediación entre iguales: una herramienta eficaz para la convivencia escolar. Apuntes de Psicología, 31(1), 165-171. 


\title{
LOS PROGRAMAS DE MEDIACIÓN ENTRE IGUALES: UNA HERRAMIENTA EFICAZ PARA LA CONVIVENCIA ESCOLAR
}

\section{Resumen}

A pesar de las ventajas de los sistemas de mediación entre iguales, todavía son escasos los estudios que incorporan una evaluación científica del impacto de estos programas. Por ello, el objetivo de este estudio era el de analizar el impacto de los programas de mediación entre iguales en Educación Secundaria, a través de los roles que adoptaban los menores ante los conflictos, así como de sus actitudes províctima.

Para lograr este objetivo, se compararon dos centros públicos de Educación Secundaria, de similares características, uno de ellos con programa de mediación entre iguales, y el otro, sin programa de mediación. En ambos centros, se administró la Escala de Roles “Adivina Quién”, a 323 alumnos de 12-15 años, tanto en tiempo 1 (situación inicial), como en tiempo 2 (tras la aplicación del programa).Los resultados muestran, en el centro sin programa de mediación escolar, fundamentalmente un incremento de las actitudes províctima, lo cual apunta hacia una mejora explícita en el centro con mediación.

Palabras clave: programas mediación, iguales, convivencia escolar, roles, actitudes.

\begin{abstract}
Although the advantages of peer mediation systems are outstanding, few studies have included a longitudinal design and a scientific measure of the impact of these programs. In this sense, the objective of this study was to analyse the impact of peer mediation programs in high school education, throughout the roles adopted in the conflict, and the attitudes pro-victim.

In order to attain this goal, two public high schools, with similar characteristics, were compared: one developing a peer mediation program, and one not developing it. The Role Scale Nominations, was administered to 323 students from 12-15 years old, in time 1 (baseline), and time 2 (after program development). Results showed mainlythe increase of the attitudes pro-victim in the school with mediation program, indicating a clear improvement due to these type of programs.
\end{abstract}

Key words: mediation programs, peers, school bullying, roles, attitudes. 


\section{Introducción}

En el Estudio Internacional sobre Enseñanza y Aprendizaje (Teaching and Learning International Survey, TALIS) de 2009 de la OCDE, se ofrece la primera comparación internacional de 23 países, sobre las condiciones de enseñanza y aprendizaje. Centrándonos en el factor de intimidación verbal y abuso a compañeros, España cuenta con un porcentaje de $40.6 \%$, ocupando el séptimo lugar en el ranking de los 23 países evaluados. Esta cifra llama la atención, puesto que la media internacional se ha fijado en $34.6 \%$ y aunque la diferencia numérica no sea muy elevada, el porcentaje que tiene Islandia, en el último lugar del listado con un $11.1 \%$ da que pensar sobre la situación española. Por otra parte, se puede considerar que existe poca diferencia en comparación con México, que es el país que cuenta con el mayor porcentaje de bullying en las aulas con un $61.2 \%$.

Derivado de estos datos, se entiende que el bullying es un tema que se necesita tratar con cierta urgencia, ya que continúa suscitando malestar en los centros, y las medidas adoptadas hasta el momento no han conseguido erradicar el problema. En este sentido, medidas internas al centro y no invasivas, como la puesta en marcha de sistemas propios de mediación entre iguales por parte de la comunidad escolar, podrían ser una solución. Por ello, en los últimos años, han surgido experiencias en el territorio español en las que se involucra a los propios alumnos en la toma de decisiones y mejora diaria de la convivencia en los centros escolares, a través de sistemas de ayuda entre iguales (Arró, Villanueva, y Traver, 2006; Avilés, Torres y Vian, 2008; Del Barrio, Barrios, Granizo, van der Meulen, Andrés y Gutiérrez, 2011; Fernández y Orlandini, 2001).

En estos sistemas de mediación/ayuda entre iguales los alumnos intervienen desde la neutralidad buscando el equilibrio entre las partes sin aportar juicios de valor ni soluciones. Además, su posición de iguales repercute en una mayor credibilidad ante sus compañeros (Fernández, Villaoslada y Funes, 2002).Por todo ello, las ventajas globales de los sistemas de mediación entre iguales son evidentes: fomento de la autonomía y de las habilidades sociales del alumnado, mejora de las relaciones sociales, del clima de centro, tasas de reducción del acoso y de la victimización entre el 20-50\%, etc. (Cowie, 1998; Smith, 2011). Sin embargo, al mismo tiempo, podemos encontrar diferentes estudios y metaestudios que no hallaron diferencias significativas entre centros que utilizaban estos programas con iguales y centros que no los utilizaban 
(Cowie, Hutson, Oztuga y Myersa, 2008; Cowie y Olafsson, 2000; Ttofi y Farrington, 2011).

En el fondo de esta contradicción o resultados encontrados, parece existir una diferente concepción metodológica. Por un lado, muchos de los estudios están basados en impresiones personales de estudiantes y profesores y análisis descriptivos de los resultados obtenidos. Sin embargo, otros estudios han seguido evaluaciones más sistemáticas, que han apuntado varias ventajas de la ayuda entre iguales. Aún así, entre aquellos estudios que sí encontraron resultados positivos, todavía son escasos los que incorporan diseños longitudinales y una evaluación científica del impacto de estos programas (Kmitta, 1999).

Por el momento, las principales ventajas encontradas se agrupan en tres aspectos: beneficios en los propios alumnos mediadores, en las relaciones de agresores y víctimas, y en el clima social del centro escolar (Avilés, Torres y Vian, 2008; Menesini, Codecasa, Benelli y Cowie, 2003; Naylor y Cowie, 1999). Y dentro de estos tres niveles, existen también diferencias substanciales. En comparación con los resultados positivos encontrados en el nivel individual (propios alumnos mediadores y usuarios directos del programa), el resto de niveles más sociales (roles participantes, clima escolar, etc.), se presentan con resultados más ambiguos (Fernández, Villaoslada y Funes, 2002; Ttofi y Farrington, 2011). Por todo ello, en este trabajo se pretende analizar el impacto de este tipo de programas de mediación entre iguales, no en los usuarios directos del mismo, sino en todos los implicados en las situaciones de acoso, a nivel grupal. Es decir, se trataría de analizar el nivel sociogrupal del problema del acoso, expresado a través de los roles que los menores adoptan ante el problema, así como las actitudes que los menores presentan ante la víctima.Si se asume que las actitudes pueden no correlacionar necesariamente con la conducta real de los menores ante el grupo (Salmivalli, Lagerspetz, Björkqvist, Österman y Kaukiainen, 1996), ambos niveles resultan ser complementarios e informativos.

El enfoque o perspectiva sociogrupal tiene como principal interés conocer qué papel adoptan los miembros de un grupo ante la victimización de un compañero (Salmivalli, et al., 1996). Desde esta perspectiva, es importante el papel de agresores y víctimas, pero también la pasividad del público o audiencia, la actuación del defensor de la víctima, o la del ayudante del agresor. Como parte del problema, los iguales tienen también en sus manos la solución, a través de los programas de mediación entre iguales. 
Según las palabras de Salmivalli et al. (1996), si el acoso es un problema grupal, la contribución del grupo en la intervención, es fundamental. Diversos autores han destacado este enfoque del acoso basado en la red de iguales como unidad de análisis, en el que tienen lugar diferentes procesos grupales, como por ejemplo, el rechazo entre iguales o el esquema de dominio-sumisión (Monks, Palermiti, Ortega y Costabile, 2011; Ortega y Mora-Merchán, 2008).

Existen escasos estudios (principalmente de carácter internacional) que hayan tenido en cuenta esta perspectiva sociogrupal o de clima de centro, incluyendo diferentes niveles de variables. Cowie (1998) obtuvo resultados en este sentido: el programa de alumno ayudante había afectado positivamente al clima social de la escuela. Por su parte, también Palladino, Nocentini y Menesini (2012), constataron una disminución del bullying en el grupo experimental, tras un programa de intervención liderado por iguales. Pero sin duda, el estudio más cercano a un análisis sociogrupal es el de Menesini, Codecasa, Benelli y Cowie (2003), quienes informan de cambios tanto en los roles participantes de los menores ante el acoso como en las actitudes províctima, tras un programa de intervención con iguales. En concreto, en los grupos control (sin intervención), los roles negativos y el público se incrementaron, mientras decrecieron las actitudes províctima. No obstante, las propias autoras destacaron como una limitación del estudio el hecho de que existían grupos de intervención y experimentales en el mismo centro, lo cual podía contaminar los resultados por las relaciones informales que se establecen entre alumnado y profesorado en todo el centro.

Por lo tanto, el objetivo general del trabajo aquí presentado era el de analizar, en población española, el impacto de los programas de mediación entre iguales en dos centros escolares diferentes, y a través de dos tipos de variables: los roles que adoptan los menores ante los conflictos y las actitudes províctima. En este sentido, las hipótesis formuladas fueron las siguientes: en primer lugar, se esperaba una disminución de los roles negativos y un aumento de los roles positivos frente al acoso, en el centro con programa de mediación entre iguales. En segundo lugar, se hipotetizó que las actitudes províctima aumentarían en el centro con programa de mediación entre iguales. 


\section{Método}

\section{Participantes}

La población estaba compuesta por 323 estudiantes de dos centros de Educación Secundaria Obligatoria de primer curso de E.S.O. $(179$ estudiantes $=55.11 \%)$ y de tercero $(144$ estudiantes $=44.89 \%)$. De los cuales 170 eran chicos $(52.63 \%)$ y 153 eran chicas $(47.37 \%)$, con un rango de edad entre 12.07 y 14.23 (media = 13.43).

Los dos centros de Educación Secundaria en los que se han recogido los datos, presentaban características similares en cuanto a ubicación y zona geográfica (ámbito urbano), número de alumnado y profesorado, así como en oferta académica (ESO, Bachillerato y FP). Ambos eran centros públicos de nivel socioeconómico predominantemente medio. Sin embargo, el primer centro contaba con un programa de mediación entre iguales desde hace 4 años (PM), mientras que el segundo centro no contaba con este programa (SPM), (ver tabla 1).

Tabla 1: Distribución de los participantes en los grupos con programa de mediación (PM) y sin programa de mediación (SPM).

\begin{tabular}{cccc}
\hline Programa & Chicos & Chicas & Total \\
\hline SPM & 85 & 67 & 152 \\
PM & 85 & 86 & 171 \\
Total & 170 & 153 & 323 \\
\hline
\end{tabular}

\section{Instrumentos}

Escala de roles “Adivina Quién” (Salmivalli, Lagerspetz, Bjorkqvist, Österman y Kaukiainen, 1996), adaptada por Sutton y Smith (1999).

Se trata de un cuestionario de 21 ítems que a través de la pregunta "Adivina quien" pretende conocer cuál es la reacción y conducta de los iguales en situaciones de bullying. Cada ítem se relaciona con las conductas que se asocian a cada uno de los seis roles participantes de agresor, animador, ayudante del agresor, defensor, público y víctima. En este caso, cada estudiante debe nominar al compañero o compañera que se ajuste más a la descripción que está leyendo, siguiendo el método de nominaciones de Goossens, Olthof y Dekker (2006) y Camodeca y Goossens (2005). El método consiste en identificar a los estudiantes en un rol determinado, siempre que la puntuación estandarizada de los ítems que hacen referencia a ese roles es más alta que la media de 
la clase y más alta que en ningún otro rol. La única excepción la constituye el role de víctima, donde un alumno pertenece si es nominado por al menos el $20 \%$ de la clase. Diversos autores (Sutton y Smith, 1999), agrupan a los ayudantes y animadores del agresor en un nuevo role, los seguidores. Esta agrupación se ha realizado también en este trabajo.

Escala de actitudes províctima (Rigby y Slee, 1991).

Esta escala de autoinforme se utiliza para evaluar las actitudes hacia las víctimas (defensa de la víctima, no justificación de la agresión, etc.). La versión abreviada consta de 10 ítems, en los que los estudiantes deben marcar una de las tres alternativas que se les plantean como posibles respuestas: "de acuerdo", "no lo sé", "en desacuerdo. Con un rango de 1 a 30, las altas puntuaciones indican una actitud en defensa de la víctima.

\section{Procedimiento}

La investigación cuenta con dos momentos: tiempo 1 (T1) y tiempo 2 (T2), con el fin de conocer la evolución de las variables en los dos centros a lo largo de un curso académico. Los datos del primer pase (T1) se recogieron en el propio centro escolar, durante el mes de Diciembre del curso académico 2010/11, mientras que los datos del segundo pase (T2) se recogieron durante el mes de Junio del mismo curso académico. Completado el cuestionario de forma colectiva, en todo momento se aseguró al alumnado que sus respuestas serían confidenciales. Los cuestionarios se contrabalancearon en las distintas aulas para evitar el efecto del cansancio.

El programa de mediación entre iguales que se ha desarrollado en uno de los dos centros sigue la siguiente estructura:

1. Consideraciones previas: concienciación de la comunidad educativa sobre la convivencia y mediación escolar, y difusión del programa para crear compromiso para su implementación.

2. Selección de los participantes: participación voluntaria del profesorado, y realización de un listado de alumnado de $2^{\circ}$ y $3^{\circ}$ ESO que se consideran adecuados para ser mediadores, después de pasar por el programa de Habilidades Sociales, obligatorio para todos los estudiantes del centro en el primer curso. Tras la aceptación por parte de los alumnos y los padres, se inicia el proceso. 
3. Formación del profesorado a través del Seminario de Formación continua como Mediadores, del CEFIRE. La formación del alumnado se realiza a través de una asignatura optativa, en la que se les ofrecen diferentes módulos de trabajo.

4. Difusión mediante posters y dípticos informativos por las instalaciones del centro, y en horas de tutorías. También a las familias en las reuniones de inicio de curso, y al personal docente y de administración y servicios del centro.

5. Temporalización: Al inicio de curso se realiza la difusión, en todo el centro, enfatizando la presencia en los cursos de primero. A partir de ese momento, desarrollo del programa, en el que actúan como mediadores los alumnos que se forman desde el curso anterior. En las primeras mediaciones, los alumnos están respaldados y supervisados por alguno de los profesores mediadores.

6. Evaluación: Finalmente, se tiene en cuenta el nivel de satisfacción que tienen tanto las partes implicadas y el grado de consecución de los acuerdos pactados, a través de un cuestionario de satisfacción.

\section{Resultados}

En primer lugar, con el fin de comparar la evolución de los roles en ambos centros, se llevaron a cabo la prueba $C h i^{2}$ para las diferencias intergrupos y el test McNemar, en las diferencias intragrupo (T1 y T2). En segundo lugar, se presenta el análisis de pruebas $T$ con muestras relacionadas para la variable actitudes.

\section{Diferencias intergrupos en roles}

En el tiempo 1, del número inicial de participantes en cada grupo, ha podido clasificarse en uno de los cinco roles (agresor, seguidor, defensor, público o víctima), a 48 menores (28\%) en el centro sin programa de mediación (SPM) y a 57 menores (37.5\%) en el centro con programa de mediación (PM). El resto de participantes serían los menores "sin role" (71.3\% y 62.5\%, respectivamente), y los menores víctima-agresor $(0.6 \%$ y $0 \%$, respectivamente), que no se han tenido en cuenta en los análisis.

La tabla 2 muestra los porcentajes y las frecuencias que cada rol participante en el acoso mostraba en el tiempo 1 en ambos centros: sin programa de mediación (SPM), y con programa de mediación (PM). En ambos centros, los roles más numerosos corresponden a los seguidores, público y defensor, mientras que los roles menos numerosos corresponden a agresor y víctima. Sin embargo, esta comparación no arroja diferencias 
significativas $\left(C h i^{2}=2.5 ; p=0.64\right)$, indicando que la distribución inicial de roles en el $\mathrm{T} 1$ en ambos centros es equivalente.

Tabla 2: Porcentajes y frecuencias (entre paréntesis) de los participantes en cada role en ambos centros en el tiempo 1.

\begin{tabular}{ccc}
\hline ROLES & T1 $(\mathrm{SPM})$ & T1 $(\mathrm{PM})$ \\
\hline Agresor & $10.4(5)$ & $19.3(11)$ \\
Seguidor & $31.3(15)$ & $31.6(18)$ \\
Defensor & $20.8(10)$ & $22.8(13)$ \\
Público & $31.3(15)$ & $22.8(13)$ \\
Víctima & $6.3(3)$ & $3.5(2)$ \\
Total & $100(48)$ & $100(57)$
\end{tabular}

SPM: centro sin programa de mediación; PM: centro con programa de mediación.

En el tiempo 2, del número inicial de participantes en cada centro, ha podido clasificarse en uno de los cinco roles (agresor, seguidor, defensor, público o víctima), a 68 menores (39.7\%) en el centro sin programa y a 88 menores $(57.8 \%)$ en el centro con programa. El resto de participantes serían los menores "sin role" (58.5\% y 42.1\%, respectivamente), y los menores víctima-agresor (1.8\% y 0\%, respectivamente).

En lo que se refiere a la distribución de roles en ambos centros en el tiempo 2, la tabla 3 muestra los porcentajes y las frecuencias obtenidas. Aunque se aprecia un mayor número de seguidores y un menor número de público en el centro sin programa (SPM), frente al centro con programa (PM), de nuevo los resultados no muestran diferencias significativas $\left(C h i^{2}=8.2 ; p=0.08\right)$, indicando que la distribución final de roles en el T2 en ambos centros continúa siendo equivalente. 
Tabla 3: Porcentajes y frecuencias (entre paréntesis) de los participantes en cada rol en ambos centros en el tiempo 2.

\begin{tabular}{ccc}
\hline ROLES & T2 $(\mathrm{SPM})$ & T2 $(\mathrm{PM})$ \\
\hline Agresor & $5.9(4)$ & $10.2(9)$ \\
Seguidor & $51.5(35)$ & $33(29)$ \\
Defensor & $16.2(11)$ & $14.8(13)$ \\
Público & $19.1(13)$ & $36.4(32)$ \\
Víctima & $7.4(5)$ & $5.7(5)$ \\
Total & $100(68)$ & $100(88)$
\end{tabular}

SPM: centro sin programa de mediación; PM: centro con programa de mediación.

\section{Diferencias intragrupos en roles}

Si se analizan las diferencias intragrupos dentro del centro sin programa de mediación (SPM), pueden encontrarse los siguientes resultados. En la tabla 4 pueden observarse los porcentajes y las frecuencias de los menores que permanecían, en ambos tiempos (T1 y T2), en cada role participante en el acoso, dentro del centro sin programa de mediación (SPM). Esta comparación entre ambos tiempos arroja diferencias significativas (McNemar $\left.C h i^{2}=9.8 ; p=0.04\right)$. En concreto, puede decirse que en el centro sin programa, aumenta el doble el número de menores seguidores, mientras que disminuye a la mitad el número de menores defensores y de menores en rol de público. En menor medida, también disminuye ligeramente el número de agresores.

Tabla 4: Porcentajes y frecuencias (entre paréntesis) de los participantes en cada rol en el centro SPM en el tiempo 1 y tiempo 2.

\begin{tabular}{ccc}
\hline ROLES & T1 (SPM) & T2 (SPM) \\
\hline Agresor & $10.3(3)$ & $3.4(1)$ \\
Seguidor & $24.1(7)$ & $62.1(18)$ \\
Defensor & $27.6(8)$ & $13.8(4)$ \\
Público & $34.5(10)$ & $17.2(5)$ \\
Víctima & $3.4(1)$ & $3.4(1)$ \\
Total & $100(29)$ & $100(29)$ \\
\hline
\end{tabular}


Por último, la tabla 5 muestra los porcentajes y las frecuencias de los menores que permanecían, en ambos tiempos (T1 y T2), en cada rol participante en el acoso, dentro del centro con programa de mediación (PM). En esta ocasión, los resultados no señalan diferencias significativas (McNemar $C h i^{2}=9.8 ; p=0.27$ ), indicando que la distribución de roles permanece estable del tiempo 1 al tiempo 2.

Tabla 5: Porcentajes y frecuencias (entre paréntesis) de los participantes en cada rol en el centro PM en el tiempo 1 y tiempo 2.

\begin{tabular}{ccc}
\hline ROLES & T1 $(\mathrm{PM})$ & T2 $(\mathrm{PM})$ \\
\hline Agresor & $25.6(10)$ & $7.7(3)$ \\
Seguidor & $28.2(11)$ & $28.2(11)$ \\
Defensor & $20.5(8)$ & $20.5(8)$ \\
Público & $20.5(8)$ & $33.3(13)$ \\
Víctima & $5.1(2)$ & $10.3(4)$ \\
Total & $100(39)$ & $100(39)$ \\
\hline
\end{tabular}

Diferencias integrupos e intragrupos en actitudes

Respecto a las diferencias intergrupos, las diferencias de medias entre centros en el tiempo 1 (T1), no mostraron diferencias significativas $(p=.85)$, (tabla 6). Ambos centros parecían partir del mismo nivel de actitudes províctima. Sin embargo, en el postest $(\mathrm{T} 2)$, si aparecen diferencias significativas $(p=.001)$, ya que después de la intervención el centro con programa de mediación, muestra una media mayor en actitudes províctima, que el centro que no lleva a cabo ningún tipo de intervención. Por su parte, las diferencias intragrupos mostraron un aumento significativo de las actitudes províctima en el centro con programa de mediación (PM), del tiempo 1 (T1) al tiempo 2 (T2), mientras que en el centro sin intervención, las medias de actitudes se mostraron estables. 
Tabla 6: Medias y desviaciones típicas en ambos centros para la variable actitudes

\begin{tabular}{cccccccccccc}
\hline \multicolumn{4}{c}{ Centro PM } & \multicolumn{4}{c}{ Centro SPM } & \multicolumn{3}{c}{$\mathrm{p}$} \\
\hline \multicolumn{2}{c}{ Pretest } & \multicolumn{2}{c}{ Postest } & \multicolumn{2}{c}{ Pretest } & \multicolumn{2}{c}{ Postest } & \multicolumn{2}{c}{ Intergrupo } & \multicolumn{2}{c}{ Intragrupo } \\
\hline M & DT & M & DT & M & DT & M & DT & Pretest & Postest & PM & SPM \\
\hline 25.53 & 3.47 & 26.68 & 3.10 & 25.59 & 3.15 & 25.48 & 3.34 & 0.856 & 0.001 & 0.001 & 0.566 \\
\hline
\end{tabular}

\section{Discusión}

El objetivo general de este estudio era el de analizar en población española, el impacto de los programas de mediación entre iguales en dos centros escolares diferentes, incorporando dos niveles de variables: los roles conductuales que adoptan los menores ante los conflictos, así como las actitudes que muestran ante la víctima de estos conflictos. En este sentido, la primera hipótesis planteaba una disminución de los roles negativos y un aumento de los roles positivos frente al acoso, en el centro con programa de mediación entre iguales. Sin embargo, esta hipótesis no ha podido ser confirmada tal como estaba planteada.

En primer lugar, cabe destacar que la distribución inicial de roles sociogrupales ante el acoso en el tiempo 1 en ambos centros es equivalente, tal como demuestran los análisis intergrupos. Tras la intervención en el centro con programa de mediación, no se apreciaron diferencias significativas en los roles antes y después del programa. Pero lo que sí pudo comprobarse es, cómo en el centro donde no existió esta intervención, se duplicó de forma significativa el número de seguidores del agresor (aunque los agresores disminuyeron ligeramente), mientras que disminuyó en la mitad el número de defensores y de público. Estos resultados, aunque modestos, parecen implicar que, ante la ausencia de intervención parece existir un desplazamiento de menores del role de defensor de la víctima y del público hacia posicionamientos más negativos, como es apoyar explícitamente al agresor. El caso del role de público es especialmente significativo, ya que de una posición pasiva ante el acoso (observar la agresión, no detenerla ni comunicarla a adultos, etc.) estarían cambiando a una estrategia activa ante el mismo: ocultar la agresión, retener a la víctima, etc. Es decir, en este caso no se habría podido detener la llamada "conspiración del silencio" ante las situaciones de acoso. En el rol de víctima, no parece haberse producido ningún cambio sustancial, 
aunque esto no reste que sí se hubieran producido mejoras cualitativas autoinformadas, como hallaron otros estudios (Avilés, Torres y Vian, 2008; Naylor y Cowie, 1999).

Por lo tanto, los efectos de la intervención en el centro con programa de mediación no parecen estar indicando una mejora sustancial en este centro, sino acaso una prevención de la escalada negativa que se suele producir en estas edades con el tema del acoso escolar (Defensor del Pueblo y Unicef, 2006; Rigby y Slee, 1991). Estos datos refuerzan los resultados encontrados por Menesini et al. (2003) en su estudio con clases experimentales y controles dentro del mismo centro escolar.

La segunda hipótesis predecía el aumento de las actitudes províctima en el centro con programa de mediación. En este caso, los datos parecen apoyar la hipótesis planteada, ya que, partiendo de niveles similares, el centro con programa de mediación muestra mejores actitudes províctima en el postest, que el centro que no lleva a cabo ningún tipo de intervención. Mientras en el centro sin intervención las actitudes permanecieron estables, el centro con programa de mediación experimentó una mejora de las actitudes províctima del tiempo 1 al tiempo 2. De nuevo, estos resultados apoyan aquellos estudios que validan los efectos de este tipo de programas (Cowie, 1998; Menesini et al. 2003; Palladino et al. 2012).

En definitiva, los resultados parecen apoyar la eficacia de los programas de mediación entre iguales, principalmente desde el punto de vista de las actitudes que los menores ostentan hacia la víctima. Los resultados respecto a los roles son modestos, pero en el caso de las actitudes (en donde la conducta no se ve necesariamente implicada) son más robustos. Estos resultados pueden parecer de pequeño tamaño si se comparan con el ingente esfuerzo que supone poner en marcha programas globales que implican a toda la comunidad escolar, máxime si tenemos en cuenta que la media para la consolidación de un programa de mediación escolar es de 3 años (Boqué, 2004). No obstante, se trata en cualquier caso, de crear cultura participativa y democrática ante el acoso escolar; sólo así, desde los propios implicados, se podrá combatir el problema.

Finalmente, se pueden comentar algunas limitaciones del estudio. En primer lugar, hubiera sido interesante realizar un seguimiento adicional de los efectos encontrados, para observar la estabilidad de los mismos, aspecto frecuentemente olvidado una vez que se han encontrado efectos positivos a corto plazo (Smith, 2011). Por otra parte, de cara a futuras investigaciones sobre el impacto de estos programas, se deben integrar de 
forma conjunta, diferentes niveles de comprobación de los efectos, es decir, nivel de usuarios directos del programa, nivel actitudinal, nivel sociogrupal, nivel global de clima de centro, etc. En esta línea, se ha comprobado la efectividad de las intervenciones que afectan a todo el centro escolar (programas globales que se diseñan de acuerdo con la naturaleza sociocultural y multinivel del problema del acoso), frente a intervenciones meramente curriculares o de habilidades sociales (Vreeman y Carroll, 2007).

A pesar de estas limitaciones, el presente estudio subraya la validez de los programas de mediación entre iguales principalmente a la hora de fomentar las actitudes províctima, y en menor medida ante los roles. En general, estos resultados apoyan la necesidad de implantar este tipo de programas en los centros escolares de Educación Secundaria, como procedimiento preventivo de los problemas de acoso escolar.

\section{Referencias}

Arró, M., Villanueva, L., y Traver, J. (2006). El Alumno-Amigo: Un sistema de ayuda entre iguales. Ponencia presentada en las Jornadas de Fomento de la Investigación.Universitat Jaume I.

Avilés, J.M., Torres, N., y Vian, M.V. (2008). Equipos de ayuda, maltrato entre iguales y convivencia escolar. Revista Electrónica de Investigación Psicoeducativa, 16, 863-886.

Boqué, M.C. (2004). Mediación escolar: unidos ante el conflicto. Perspectiva CEP, 8, 55-69.

Camodeca, M., y Goossens, F. A. (2005). Children's opinions on effective strategies to cope with bullying: The importance of bullying role and perspective. Educational Research, 47, 93-105.

Cowie, H. (1998). Perspectiva of teachers and pupils on the experience of peer support against bullying. Educational Research and Evaluation, 4, 108-125.

Cowie, H., y Olafsson, R. (2000). The role of peer support in helping the victims of bullying in a school with high levels of aggression.School Psychology International, 21, 79-95. 
Cowie, H., Hutson, N., Oztug, O., y Myers, C. (2008) The impact of peer support schemes on pupils' perceptions of bullying, aggression and safety at school, Emotional and Behavioural Difficulties, 13,63-71.

Del Barrio, C., Barrios, A., Granizo, L., van der Meulen, K., Andrés, S., y Gutiérrez, H. (2011). Contribuyendo al bienestar emocional de los compañeros: evaluación del Programa Compañeros Ayudantes en un instituto madrileño. European Journal of Education and Psychology, 4, 5-17.

Defensor del Pueblo y UNICEF (2006). Informe Violencia Escolar: El Maltrato entre iguales en la Educación Secundaria Obligatoria 1999-2006. Documentos Defensor del Pueblo: Madrid.

Goossens, F.A., Olthof, T., y Dekker, P.H. (2006). New participant role scales: Comparison between various criteria for assigning roles and indications for their validity. Aggressive Behavior, 32, 343-357.

Instituto de Evaluación del Ministerio de Educación. TALIS (OCDE). Estudio Internacional sobre la Enseñanza y el Aprendizaje. Informe español 2009. Madrid.

Fernández, I., y Orlandini, G. (2001). La ayuda entre iguales. Un proyecto de innovación que implica a toda la comunidad. Cuadernos de Pedagogía, 304, 97100.

Fernández, I., Villaoslada, E. y Funes, S. (2002). Conflicto en el centro escolar. El modelo de alumno ayudante como estrategia de intervención educativa. Madrid: Catarata.

Kmitta, D. (1999). Pasado y futuro de la evaluación e los programas de resolución de conflictos escolares. En F. Bradoni (Comp.) Mediación escolar (pp. 275-300). Buenos Aires: Paidós.

Menesini, E., Codecasa, E., Benelli, B., y Cowie, H. (2003). Enhancing children's responsibility totake action against bullying: evaluation of a befriending intervention in Italian middle schools.Aggressive Behavior, 29, 1-14.

Monks, C.P., Palermiti, A., Ortega, R., y Costabile, A. (2011). A cross-national comparison of aggressors, victims and defenders in preschools in England, Spain and Italy. The Spanish Journal of Psychology, 14, 133-144. 
Naylor, P., y Cowie, H. (1999). The effectiveness of peer support systems in challenging school bullying: The perspectives and experiences of teachers and pupils. Journal of Adolescent, 22, 1-13.

Ortega, R. y Mora-Merchán, J. (2008). Las redes de iguales y el fenómeno del acoso escolar: explorando el esquema dominio-sumisión. Infancia y Aprendizaje, 31, 515-528.

Palladino, B.E., Nocentini, A., y Menesini, E. (2012). Online and offline peer led models against bullying and cyberbullying. Psicothema, 24, 634-639.

Rigby, K., y Slee, P.T. (1991). Bullying among Australian school children: Reported behavior and attitudes toward victims.The Journal of Social Psychology, 131, 615-627.

Salmivalli, C., Lagerspetz, K., Björkqvist, K., Österman, K., y Kaukiainen, A. (1996). Bullying as a group process. Participant roles and their relations to social status within the group.Aggressive Behavior, 22, 1-15.

Smith, P.K. (2011). Why interventions to reduce bullying and violence in schools may (or may not) succeed: Comments on this Special Section. International Journal of Behavioral Development, 35, 419-423.

Sutton, J., y Smith, P.K. (1999). Bullying as a group process: An adaptation of the participant role approach.Aggressive Behavior, 25, 97-111.

Ttofi, M., y Farrigton, D.P. (2011). Effectiveness of school-based programs to reduce bullying: A systematic and meta-analytic review. Journal of Experimental Criminology, 7, 27-56.

Vreeman, R.C., y Carroll, A.E. (2007). A systematic review of school-based interventions to prevent bullying. Archives of Pediatrics and Adolescent Medicine, 161, 78-88. 


\section{ARTÍCULO 3 \\ Impact of peer mediation programs to prevent bullying behaviours in secondary schools}

Usó, I., y Villanueva, L. (en revisión). Impact of peer mediation programs to prevent bullying behaviours in secondary schools. Enviado a Infancia y Aprendizaje. 


\title{
IMPACT OF PEER MEDIATION PROGRAMS TO PREVENT BULLYING BEHAVIOURS IN SECONDARY SCHOOLS
}

\begin{abstract}
The aim of the study was to determine the impact of peer mediation programmes at a secondary school, as compared to another centre that did not have any such programme. The impact would be evaluated by means of three levels of variables: pro-victim attitudes, the roles adopted by the youngsters, and the school climate (this last item was analysed from two perspectives: that of the pupils and that of the teachers). In order to attain this goal, students from 12-14 years old $(\mathrm{N}=323)$, and 17 teacher-tutors were administered different questionnaires in time 1 (baseline, prior to intervention), and time 2 (after program intervention). Results highlight the validity of peer mediation programmes when it comes to fostering pro-victim attitudes, preventing the increase of negative roles, and improving the school climate.
\end{abstract}

\section{Introduction}

According to a number of national reports (Defensor del Pueblo and Unicef, 2006; Oñate and Piñuel, 2006) the percentages of the bullying that takes place among pupils attending secondary schools stand somewhere between $23 \%$ and $32 \%$. Similarly, in Spanish schools the rate of verbal intimidation and harassment is $41 \%$, thereby ranking it seventh in the list of 23 countries that were evaluated (TALIS Report, 2009). These data appear to show that bullying is an issue that needs to be dealt with quite urgently, since it continues to give rise to problems and unrest in schools and in families. Hence, internal measures taken by the schools themselves, such as implementing their own peer mediation systems, could be a very appropriate solution. In fact, Lee, Kim and Kim (2013) found that the most effective anti-bullying programmes were those that involved the help of peers and establishing global strategies in the school.

In peer mediation systems pupils themselves play a significant role in the day-to-day decision-making and improvements affecting daily life in schools. Their usefulness is essentially based on the closeness, age and status of the pupils mediating between the victim and the bully, together with their knowledge of the complex network of social relationships within the peer group (Cowie, 2014). The implementation of mediation programmes in Spanish schools is not compulsory at present. When the day comes and 
it is made obligatory, however, it will be interesting to be able to rely on a series of methodologically tested procedures that can be transferred to different contexts within the world of education. The Evidence-Based Programmes (EBP) approach offers the possibility of evaluating both the application under routine conditions (effectiveness) and the large-scale implementation (efficiency) needed to achieve a global educational approach to harmonious relations at school (Becker and Domitrovich, 2011).

The advantages of peer mediation systems are obvious (Cowie, 1998; Cowie and Smith, 2010; Smith, 2011). Yet different studies and meta-studies found no significant differences between centres that use these programmes and others that did not use them (Cowie, Hutson, Oztug and Myers, 2008; Cowie and Olafsson, 2000; Ttofi and Farrington, 2011). Underlying this contradiction there seems to be a difference in methodological conception (Azeredo, Rinaldi, de Moraes, Levy and Menezes, 2015; Chalamandaris and Piette, 2015). While some studies are based on the participants' personal impressions, others have followed more systematic evaluations. Nevertheless, studies that incorporate longitudinal designs and a scientific evaluation of the scope of these programmes are still very few in number (Houlston and Smith, 2009; Kmitta, 1999). Consequently, this research intends to analyse the impact of this kind of programme on all those involved in situations where bullying occurs, at the group and contextual levels. To do so, an analysis by levels is performed, including variables of an individual (attitudes towards the victim) and group nature (roles adopted by the youngsters), as well as others related to the school climate (frequency of violent acts or relationships among classmates).

Of all these variables, attitudes seem to be the ones that are influenced most by the intervention, rather than behaviour (Merrell, Gueldner, Ross and Isava, 2008). In fact, following different anti-bullying interventions, pro-victim attitudes showed significant increases in roles such as those of defender of the victim and the bystander (Salmivalli, Kaukiainen and Voeten, 2005; Salmivalli and Voeten, 2004), although other studies have not noted this increase (Ellis, Marsh and Craven, 2005). Although there seems to be a relationship between anti-bullying attitudes and behaviour (Eslea and Smith, 2000), this does not mean that attitudes always have their equivalent at the behavioural level. Attitudes can sometimes be inconsistent with respect to behaviour or even contradict it. In fact only $20 \%$ of students seem to actively intervene in the victims' favour, despite presenting prosocial attitudes (Salmivalli and Voeten, 2004). Therefore, it is assumed 
that there may not necessarily be a correlation between attitudes and the actual behaviour of the youngsters in the presence of the group (Salmivalli, Lagerspetz, Björkqvist, Österman and Kaukiainen, 1996), then the two levels (individual and group) are found to be complementary and informative.

On the other hand, the main interest of the social group approach is to determine the role adopted by members of a group when faced with the victimisation of a classmate: bully, follower, victim, defender or bystander (Salmivalli, et al., 1996). In this sense, several studies have reported changes in the participating roles following the antibullying intervention. Frey, Hirschstein, Edstrom and Snell (2009) and Andreou, Didaskalou and Vlachou (2008) reported a decline in the bystander role in the experimental group, while that of the reinforcer, who "eggs on" the bully, increased in the control group. These authors speak of a negative increase in the group without intervention and of a possible end to the conspiracy of silence in the experimental group. Similarly, following an intervention with a peer mediation programme, Menesini, Codecasa, Benelli and Cowie (2003) found that both the negative and the bystander roles increased in the control groups, whereas pro-victim attitudes decreased. Yet the foregoing studies highlighted as one of their limitations the fact that there were intervention and experimental groups at the same school, which might contaminate results due to the informal relationships that are established between pupils and teachers throughout the school. Furthermore, none of the studies incorporated variables regarding the climate within the school.

In research carried out on the effectiveness of programmes designed to deal with bullying, the most commonly used variables have traditionally been attitudes, beliefs and behaviours (Jiménez, Ruiz, Llor and Pérez, 2012), but this has not been the case with the variable school climate (Azeredo et al., 2015). And yet systems providing peer mediation apparently seem to work better in a whole school approach (Cowie, 2014). This variable school climate is taken into account increasingly more often (Ortega-Ruiz, Casas and Del Rey, 2014), since interventions that affect the whole school have been shown to be more effective than those that only have an impact on curricula or social skills (Vreeman and Carroll, 2007). Several studies have found that after intervention with peer mediation programmes, the school climate was more positive and secure (Cowie, 1998; Lane-Garon and Richardson, 2003), while the frequency and intensity of the bullying diminished (Palladino, Nocentini and Menesini, 2012), as did the number 
of disciplinary actions (administrative suspensions and expulsions) (Bell, Coleman, Anderson and Whelan, 2000; Burrell, Zirbel and Allen, 2003).

In view of the foregoing, the aim of the study was to determine the impact of peer mediation programmes at a secondary school, as compared to another centre that did not have any such programme. The impact would be evaluated by means of three levels of variables: pro-victim attitudes, the roles adopted by the youngsters, and the school climate (this last item was analysed from two perspectives: that of the pupils and that of the teachers). Accordingly, a follow-up of the possible effects was conducted over a period of six months. Hence, the aim of this study is to contribute with the following aspects: a longitudinal analysis of the possible effects of these programmes, including different levels of measures (individual, group and contextual) and different sources of information (self-report, peers and teachers), as well as incorporating a control group from a context that is totally different from that of the intervention group.

In accordance with previous studies, it was hypothesised that in the intervention group, all the measures analysed would show an improvement from T1 (pre-intervention) to T2 (post-intervention), as compared to the control group. This improvement could be less obvious in the behavioural variables (roles) than in the attitudinal variable, since it has been shown that attitudes are more easily influenced by the effect of interventions (Fox, Elder, Gater and Johnson, 2010; Merrell et al., 2008; Salmivalli et al., 2005). The perception of the possible improvement will be different depending on the informant (pupils versus teachers), given the discrepancies between the two (De Los Reyes and Kazdin, 2005; Youngstrom, Loeber and Stouthamer-Loeber, 2000).

\section{Method}

\section{Participants}

Participants were 323 students from two secondary schools and their teacher-tutors $(\mathrm{N}=17)$. Of the pupils that participated, 170 were boys $(52.63 \%)$, with ages that ranged between 12.07 and 14.23 years (mean $=13.4$ ). Pupils were studying the first year of ESO (Educación Secundaria Obligatoria - compulsory secondary education) (179 pupils $=55.11 \% ; 11-12$ years old $)$ and the third year of ESO (144 pupils $=44.89 \%$; 13-14 years old). Only these two age brackets were chosen because the school explicitly requested that the 12-13 year olds not be included (due to the overload of exams and assessments they had before them) and because those aged 11-12 are the ones who seem 
to benefit from this type of programmes more than older pupils (Houlston and Smith, 2009; Pepler, Smith and Rigby, 2004). The home countries of the youngsters were $83 \%$ Spanish and Latin American, 11\% Romanian, 5\% Arab and 1\% Asian.

Of the total number of participating pupils, $171(53 \%)$ belonged to the school with the mediation programme (school A) and $152(47 \%)$ belonged to school B (without a mediation programme). On comparing the two centres, it can be seen how the distribution by gender does not show any significant differences $\left(\chi^{2}=1.24 ; p=.15\right)$, and neither did age (mean at school $\mathrm{A}=13.5$; mean at school $\mathrm{B}=13.3 ; \mathrm{t}=-1.21$; $\mathrm{p}=.22)$ or nationality $\left(\chi^{2}=2.86 ; \mathrm{p}=.41\right)$.

Seventeen teacher-tutors from each of the participating classes also took part in the study ( $\mathrm{N}=7$ at school $\mathrm{A} ; \mathrm{N}=10$ at school $\mathrm{B})$. The general mean age was 44.2 years and $53 \%$ of them were women. On the other hand, the mean length of their experience as teachers was 16.7 years, while the mean length of time spent working at the schools in the study was 6 years. On analysing the possible differences between teachers from each school, it can be seen that the distribution by gender is almost the same $\left(\chi^{2}=.08\right.$; $\mathrm{p}=.58$ ) and the mean age is also similar (mean school $\mathrm{A}=42.5$; mean school $\mathrm{B}=45.5$; $\mathrm{t}=.7, \mathrm{p}=.45)$. Yet, they do present significant differences in terms of work experience ( school $\mathrm{A}=11$; school $\mathrm{B}=20.7 ; \mathrm{t}=2.2, \mathrm{p}=.04$ ) and as regards the number of years spent working at their current school ( $\operatorname{school} \mathrm{A}=3.14$; school $\mathrm{B}=8.1 ; \mathrm{t}=2.2, \mathrm{p}=.04$ ). That is to say, school B (with no mediation programme) had teachers with longer overall teaching experience, as well as more teaching experience at their current school.

\section{Instruments}

The Questionnaire on Harmonious Relations at School (Ortega and Del Rey, 2003).

This questionnaire comprises 14 items that allow a general view of the status of life in the school community, including factors such as relationships with classmates and with teachers, disputes between teachers and pupils, lack of understanding between teacher and pupil, failure to comply with the rules, insults and fights, and pupils who are not integrated or are unmotivated. Both pupils and teachers have to use a scale ranging from 0-3 points to rate the degree or frequency of the behaviours outlined above. In all cases, a higher score indicated a higher presence of that behaviour.

The "Guess Who" role scale (Salmivalli et al., 1996), adapted by Sutton and Smith (1999). 
This questionnaire contains 21 items that seek to use the question "Guess who" to determine the behaviour adopted by peers in situations of bullying. At the beginning of the session, participants were provided with a common definition of bullying. Each of the 21 items is related with the behaviours associated to each of the six participant roles, i.e. bully, reinforcer, bully's assistant, defender, bystander and victim. Some authors (Sutton and Smith, 1999) put the bully's assistants and reinforcers together in a new role: followers. This grouping has also been used in this study. In this case, each pupil must nominate the classmate who best fits the description that is being read. This method consists in identifying youngsters in a particular role, provided that the standardised score of the items that refer to that role is higher than the average for the class and higher than in any other role. The only exception is the role of victim, which a pupil belongs to if nominated by at least $20 \%$ of his or her classmates.

Pro-victim attitudes scale (Rigby and Slee, 1991).

This 10-item self-report scale is used to evaluate attitudes towards the victims ("Nobody should pick on someone weaker than themselves", "A bully is really a coward", "It makes me angry when I see someone being picked on without reason"). Pupils must mark one of the three alternatives they are given: "agree", "unsure" or "disagree". With a range from 1 to 30 , the high scores indicate an attitude of defending the victim.

\section{Procedure}

Data were collected at two times: Time 1 (month of December in the academic year 2010/11) and Time 2 (month of June of the same year). Pupils filled in the three questionnaires in a collective one-hour session during school time, while teachers only filled in the Questionnaire of Living Together at School. Instruments were counterbalanced in the different classrooms in order to avoid the effect of tiredness. Pupils were assured at all times that their answers would be confidential. Necessary consents from the local government, university ethical commission, schools and parents were requested and obtained before beginning the study.

The peer mediation programme that has been carried out at school A for the last five years (by the teachers' team) has the structure proposed by Torrego (2005). 


\section{Analysis of results}

T-test analyses with paired samples were performed for the intragroup differences and with independent samples for the intergroup differences, both for the variable pro-victim attitude and for the different aspects of living together in the school community. In these cases, the effect size was calculated, in accordance with Cohen (1988). The small number of teachers participating in the study led to non-parametric tests being conducted (Mann-Whitney U tests for paired and independent samples). In the case of the participating roles, $\chi^{2}$ tests were carried out for the intergroup differences and the McNemar test for the intragroup differences (T1 and T2).

\section{Results}

\section{Intergroup and intragroup differences on attitudes}

As regards intergroup differences, i.e. the differences between the means of the schools at Time 1 (T1), no significant differences were observed $(\mathrm{p}=.85)$ (Table 1). Both schools set out from the same level of pro-victim attitudes. Yet in the post-test (T2), significant differences did appear $(\mathrm{p}=.001)$, as following the intervention the school with the mediation programme shows a higher mean on pro-victim attitudes than the school that does not carry out any kind of intervention. The intragroup differences, in contrast, showed a significant increase in the pro-victim attitudes at the school with the mediation programme (A) from Time 1 to Time $2(\mathrm{p}=.001)$, whereas at the school without interventions, the means of the attitudes remain stable $(p=.56)$. The effect size in all cases was low (in intergroup differences, Cohen's $D=.33, r=.16$; in intragroup differences, Cohen's D = -.33, r = -.16).

Table 1: Means and standard deviations for the variable attitudes.

\begin{tabular}{|c|c|c|c|c|c|c|c|c|c|c|c|}
\hline \multicolumn{4}{|c|}{ School A } & \multicolumn{4}{|c|}{ School B } & \multicolumn{4}{|c|}{$\mathrm{p}$} \\
\hline \multicolumn{2}{|c|}{ Pre-test } & \multicolumn{2}{|c|}{ Post-test } & \multicolumn{2}{|c|}{ Pre-test } & \multicolumn{2}{|c|}{ Post-test } & \multicolumn{2}{|c|}{ Intergroup } & \multicolumn{2}{|c|}{ Intragroup } \\
\hline $\mathrm{M}$ & SD & $\mathrm{M}$ & $\mathrm{SD}$ & M & $\mathrm{SD}$ & $\mathrm{M}$ & $\mathrm{SD}$ & Pre-test & Post-test & A & B \\
\hline 25.53 & 3.47 & 26.68 & 3.10 & 25.59 & 3.15 & 25.48 & 3.34 & .856 & .001 & .001 & .566 \\
\hline
\end{tabular}




\section{Intergroup differences in roles}

At Time 1, 48 youngsters (28\%) at the school with no mediation programme (B) and 57 youngsters $(37.5 \%)$ at the school with a mediation programme (A) were classified into one of the five roles (bully, follower, defender, bystander or victim). The other participants would be youngsters "without a role" (71.3\% and 62.5\%, respectively) and the victim-bully youngsters $(0.6 \%$ and $0 \%$, respectively), who have not been taken into account in the analyses. This comparison between the two schools did not yield any significant differences $\left(\chi^{2}=2.5 ; p=.64\right)$, thus indicating that the initial distribution of roles at $\mathrm{T} 1$ at the two schools is equivalent.

At Time 2, 68 youngsters (39.7\%) at the school with no mediation programme (B) and 88 youngsters $(57.8 \%)$ at the school with a mediation programme (A) were classified into one of the five roles (bully, follower, defender, bystander or victim). The other participants would be youngsters "without a role" (58.5\% and $42.1 \%$, respectively) and the victim-bully youngsters $(1.8 \%$ and $0 \%$, respectively). As far as the distribution of roles is concerned at the two schools at Time 2, although a higher number of followers and a lower number of bystanders can be seen at the school without a programme (B) as compared to the centre with a programme (A), again the results do not show any significant differences $\left(\chi^{2}=8.2 ; p=.08\right)$, thereby indicating that the final distribution of roles at $\mathrm{T} 2$ in the two schools continues to be equivalent.

\section{Intragroup differences in roles}

On analysing the percentages and the frequencies of the youngsters that remained in each role at both times ( $\mathrm{T} 1$ and $\mathrm{T} 2$ ), in the school with a mediation programme (A) it can be seen how the results fail to show any significant differences $\left(\mathrm{McNemar} \chi^{2}=9.8\right.$; $\mathrm{p}=.27$ ), thus indicating that the distribution of roles remains stable from Time 1 to Time 2.

Lastly, Table 2 shows the percentages and the frequencies of the youngsters who remained, at both times ( $\mathrm{T} 1$ and $\mathrm{T} 2$ ), in each of the roles participating in the bullying at the school with no mediation programme (B). This comparison between the two times yields significant differences (McNemar $\chi^{2}=9.8 ; \mathrm{p}=.04$ ). In particular, it can be said that at the school with no mediation programme, the number of followers increases 
twofold, whereas the number of defenders and bystanders drops by half. Although to a lesser extent, the number of bullies also went down.

Table 2: Percentages and frequencies of the roles at Time 1 and Time 2.

\begin{tabular}{ccc}
\hline & T1 (B) & T2 (B) \\
\hline & $\%(\mathrm{~N})$ & $\%(\mathrm{~N})$ \\
\hline Bully & $10.3(3)$ & $3.4(1)$ \\
Follower & $24.1(7)$ & $62.1(18)$ \\
Defender & $27.6(8)$ & $13.8(4)$ \\
Bystander & $34.5(10)$ & $17.2(5)$ \\
Victim & $3.4(1)$ & $3.4(1)$ \\
Total & $100(29)$ & $100(29)$ \\
\hline \multicolumn{2}{c}{ B: school with no mediation programme }
\end{tabular}

\section{Intragroup differences in harmonious relations at school}

According to the pupils' perception and on analysing the results of the T-tests for paired samples, it can be seen that at the school without a mediation programme no significant differences were obtained between $\mathrm{T} 1$ and $\mathrm{T} 2$ on different items regarding the school climate. One notable point is the fact that two tendencies towards statistical significance were obtained on the items "Disputes between pupils and the teacher" (Mean T1 = 1.01; Mean $\mathrm{T} 2=1.22 ; \mathrm{t}=-1.85 ; \mathrm{p}=.06$ ) and "Pupils insult each other" (Mean $\mathrm{T} 1=1.65$; Mean $\mathrm{T} 2=1.86 ; \mathrm{t}=-1.84 ; \mathrm{p}=.06$ ). In both cases, negative behaviours increased from T1 to T2. On the other hand, only one significant difference was obtained at the school with a mediation programme on the item "Pupils fight each other" (Mean T1 = 1.13; Mean T2 $=.88 ; \mathrm{t}=3.21 ; \mathrm{p}=.002$; Cohen's $\mathrm{D}=1.64, \mathrm{r}=.63)$. In this case, the negative behaviour of fighting among pupils went down from T1 to T2. According to the report by teachers, both at school $\mathrm{A}$ and school B, there were no significant differences between T1 and T2 on the different items dealing with living together (Mann-Whitney U tests for paired samples).

\section{Intergroup differences in harmonious relations at school}

At Time 1, according to the pupils' self-reports, there were significant differences between the two schools on the $\mathrm{T}$ test for independent samples (see Table 3). More specifically, at the school with the mediation programme the pupils report that teachers think only of themselves and do not understand the pupils to a greater extent than in the centre without a mediation programme. In the other aspects concerning the school 
climate, both centres present similar levels. According to Cohen (1988), the effect size would range between low and medium.

Table 3: Means and standard deviations of the variable harmonious relations at school, at Time 1.

\begin{tabular}{ccccccc}
\hline T1 & $\mathrm{A}$ & $\mathrm{B}$ & $\mathrm{t}$ & $\mathrm{p}$ & $\mathrm{D}$ & $\mathrm{r}$ \\
\hline $\begin{array}{c}\text { Teachers think only of } \\
\text { themselves }\end{array}$ & $1.29(1.0)$ & $.81(.94)$ & -4.22 & .000 & .49 & .24 \\
$\begin{array}{c}\text { Teachers do not } \\
\text { understand pupils }\end{array}$ & $1.92(.93)$ & $1.57(.99)$ & -3.22 & .001 & .36 & .17 \\
\hline
\end{tabular}

A: school with a mediation programme; B: school with no mediation programme. Size effect values: Cohen's D and r.

At Time 2, a number of significant differences between the two schools are obtained, as can be seen in Table 4. On the one hand, following the intervention at the school with the mediation programme, better scores were obtained on the items "Get on well with classmates" and on "Classmates' opinion of you" than at the school without a mediation programme. Likewise, following the intervention, at this school there are fewer pupilteacher disputes and fewer fights than at the school without a mediation programme. Nevertheless, as regards the item "The teachers think only of themselves", the school with the mediation programme continues to have higher scores than the school without the mediation programme, as occurred at Time 1 . In this case, the effect size ranges between low and medium.

Table 4: Means and standard deviations of the variable harmonious relations at school, at Time 2.

\begin{tabular}{ccccccc}
\hline T2 & $\mathrm{A}$ & $\mathrm{B}$ & $\mathrm{T}$ & $\mathrm{p}$ & $\mathrm{D}$ & $\mathrm{r}$ \\
\hline $\begin{array}{c}\text { Get on well with } \\
\text { classmates }\end{array}$ & $2.78(.43)$ & $2.66(.64)$ & -1.91 & .05 & .19 & .09 \\
$\begin{array}{c}\text { Classmates' opinion of } \\
\text { you }\end{array}$ & $2.47(.57)$ & $2.27(.71)$ & -2.71 & .007 & .31 & .15 \\
$\begin{array}{c}\text { Pupil-teacher disputes } \\
\text { Pupils fight each other }\end{array}$ & $.92(.75)$ & $1.19(.95)$ & 2.82 & .004 & -.31 & -.15 \\
$\begin{array}{c}\text { Teachers think only of } \\
\text { themselves }\end{array}$ & $1.33(.97)$ & $1.26(.98)$ & 4.15 & .000 & -.46 & -.22 \\
\hline
\end{tabular}

A: school with a mediation programme; B: school with no mediation programme. Size effect values: Cohen's D and r.

At Time 1, and according to the teachers' perception, there are no significant differences between the two centres (Mann-Whitney $U$ tests for independent samples) as regards different aspects of harmonious relations at school, which means it can be 
said that the two schools set out from a similar situation. At Time 2 there is only one tendency towards significance on the item "Disputes between pupils and teachers" (mean at school $\mathrm{A}=.57$; mean at school $\mathrm{B}=1.20 ; \mathrm{p}=.08$ ), which indicates a lower presence of this kind of conflict at the school with the mediation programme.

\section{Discussion}

The general aim of this study was to analyse the impact of peer mediation programmes at a school, with the incorporation of three levels of variables: the attitudes shown by the youngsters towards the victim, the behavioural roles that they adopt when faced with bullying behaviours, and the school climate. Thus, the first hypothesis posited an improvement at all these levels of measurement from T1 (pre-intervention) to T2 (postintervention), in comparison to the control group. The results obtained support this hypothesis, since positive effects of the peer mediation programme were found. Specifically, at the school with the mediation programme, after the follow-up, attitudes of defending the victim increased and the school climate improved, whereas at the school without a mediation programme the negative role of the bully's follower increased and the positive role of the victim's defender diminished.

As regards pro-victim attitudes, it was seen that, despite setting out from similar levels, the school with the mediation programme displayed better pro-victim attitudes in the post-test than the school that did not carry out any kind of intervention. Whereas at the school without intervention the attitudes remained stable, the school with the mediation programme pro-victim attitudes improved from T1 to T2. These results support the group of studies that found improvements in pro-victim attitudes after intervention (Menesini et al., 2003; Salmivalli et al., 2005; Salmivalli and Voeten, 2004).

If the roles played in instances of bullying are analysed, it must be pointed out that the initial distribution of the roles at Time 1 at the two schools is equivalent, as shown in the intergroup analyses. One interesting change that could be confirmed is how the number of followers of the bully underwent a significant twofold increase (although the number of bullies went down slightly), while the number of defenders and bystanders dropped to half the original number at the school with no intervention. This drop in the number of bystanders following the intervention can be found in a number of different studies (Frey et al., 2009), as can the increase in the number of followers (Andreou et 
$a l ., 2008)$. Yet what seems to be a finding in favour of the efficiency of the programme becomes somewhat less clearly so in the study by Andreou et al. (2008), since it cannot be confirmed whether the youngsters who were bystanders before the intervention have become defenders of the victim after the intervention. In the case of this study, at T2 at the school without intervention not only can a decrease in the number of bystanders (and of defenders) be observed, but also an increase in the number of followers of the bully. This could be indicating that not only do youngsters who stop being bystanders not go on to become defenders but may even join up with the bully to help him harass the victim.

With regard to the school climate, significant changes were reported by the pupils at the school with a mediation programme, following the intervention. Specifically, at this centre, the number of fights and pupil-teacher disputes decreased at Time 2, while the opinion held by classmates about pupils improved, as did the relationships among companions. Teachers' reports, although not significant, also showed a noteworthy trend around the decrease of pupil-teacher disputes. That is to say, the school climate or life in the school community improved substantially as a result of the intervention, thereby confirming previous studies (Andrés, 2007). It should be noted, however, that there is one aspect of harmonious relations at school that did not undergo any kind of improvement after the intervention, namely the item "teachers think only of themselves", which may be revealing a certain lack of communication between teachers and pupils. This could be suggesting the need to emphasise the components of the intervention that focus on this aspect of the teacher-pupil relationship, as also suggested by Hymel, McClure, Miller, Shumka, and Trach (2015).

The second hypothesis posited that the possible improvement attained after intervention could be less obvious in the behavioural variables (roles) than in attitudes. The findings seem to support this hypothesis, since the significant differences in the variable attitudes can be found both in the intragroup comparison and the intergroup comparison. Likewise, whereas attitudes have improved at the school with intervention, the distribution of the behavioural roles seems to have deteriorated at the school without intervention. These results could be corroborating the fact that the intervention might be preventing the negative escalation that usually occurs at these ages with the topic of bullying (Menesini et al., 2003; Rigby and Slee, 1991). As has been mentioned above, perhaps pro-victim attitudes are necessary but not sufficient to develop into behaviours 
such as a defender of the victim, as suggested by Fox et al. (2010). What do seem to predict whether the youngster will intervene or not may be variables such as selfefficacy (Gini, Albiero, Benelli and Altoe, 2008) or popularity within the peer group (Vannini et al., 2011). Thus, future studies on the impact of these programmes should perhaps incorporate variables such as those we have just cited.

Lastly, and in relation to the type of informant providing the information about possible improvements, it was hypothesised that there would be discrepancies between the two sources (teachers and pupils), as has indeed been shown by the results of this study. In agreement with previous studies (De Los Reyes and Kazdin, 2005; Youngstrom et al., 2000), teachers did not perceive the improvements that have taken place in the school climate, although they were perceived by pupils. Several studies have shown how the teachers' reports did not reflect any improvement after applying the different interventions, for example, in comparison to the parents' reports, where improvements were perceived (Langberg, Epstein and Becker, 2012), or in comparison to objective measures (decreased of pupils's suspensions), (Bell et al., 2000). On other occasions the teaching staff under- or over-estimated the number of pupils frequently involved in episodes of bullying (Bradshaw, Sawyer and O'Brennan, 2007; Waasdorp, Pas, O'Brennan and Bradshaw, 2011). Nevertheless, this absence of any differences between the pre-test and the post-test after the intervention reported by teachers could be accounted for by the low number of teachers surveyed, or the fact that only the variable harmonious relations at school has been explored and not the variables attitudes or roles.

In sum, all the effects found at the school with a mediation programme run in the same direction. That is, there is consistency not only in the effects found in the different outcome variables but also through the different informants (self-reports and peer reports), with the exception of the teachers' reports. These findings offer support for those studies that validate the positive effect of this kind of peer mediation programmes (Andrés, 2007; Cowie, 1998; Menesini et al., 2003; Palladino et al., 2012).

Finally, mention should be made of some limitations of the study. Firstly, it would have been interesting to carry out a long-term follow-up of the effects that were found in order to observe their stability, which is an aspect that is often neglected once shortterm positive effects have been found (Smith, 2011), although they seem to disappear in the long term (Andreou et al., 2008). On the other hand, with regard to future research 
on the impact of these programmes, and in line with an ecological approach to the problem, assessment of the school climate needs to be reinforced in an attempt to capture all its nuances, as well as covering a greater number of informants, such as the non-teaching staff at the school or the pupils' families. Despite these limitations, this study highlights the validity of peer mediation programmes when it comes to fostering pro-victim attitudes, preventing the increase of negative roles, and improving the school climate.

\section{References}

Andreou, E., Didaskalou, E., and Vlachou, A. (2008). Outcomes of a curriculum based anti-bullying intervention program on students' attitudes and behavior. Emotional and Behavioural Difficulties, 13, 235-248.

Andrés, M.S. (2007). Los sistemas de ayuda entre iguales como instrumentos de mejora de la convivencia en la escuela: evaluación de una intervención. (Tesis doctoral). Universidad Autónoma de Madrid. Madrid.

http://redined.mecd.gob.es/xmlui/handle/11162/83871

Azeredo, C.M., Rinaldi, A.E.M., de Moraes, C.L., Levy, R.B., and Menezes, P.R. (2015). School bullying: A systematic review of contextual-level risk factors in observational studies. Aggression and Violent Behavior, 22, 65-76.

Becker, K.D., and Domitrovich, C.E. (2011). The conceptualization, integration and support of evidence-based interventions in the schools. School Psychology Review, 40, 582-589.

Bell, F.K., Coleman, J.K., Anderson, A., Whelan, J.P., and Wilder, C. (2000). The effectiveness of peer mediation in a low-SES rural elementary school. Psychology in the Schools, 37, 505-516.

Bradshaw, C.P., Sawyer, A.L., and O’Brennan, L.M. (2007). Bullying and peer victimization at school: Perceptual differences between students and school staff. School Psychology Review, 36, 361-382. 
Burrell, N.A., Zirbel, C., and Allen, M. (2003). Evaluating peer mediation outcomes in educational settings: A meta-analytic review. Conflict Resolution Quarterly, 21, 7-26.

Chalamandaris, A.G., and Piette, D. (2015). School-based anti-bullying interventions: Systematic review of the methodology to assess their effectiveness. Agression and Violent Behavior, 24, 131-174.

Cohen, J. (1988). Statistical power analysis for the behavioral sciences ( $2^{\text {nd }}$ ed). Hillsdale, NJ: Lawrence Earlbaum Associates.

Cowie, H. (1998). Perspectiva of teachers and pupils on the experience of peer support against bullying. Educational Research and Evaluation, 4, 108-125.

Cowie, H. (2014). Understanding the role of bystanders and peer support in school bullying. The International Journal of Emotional Education, 6, 26-32.

Cowie, H., Hutson, N., Oztug, O., and Myers, C. (2008). The impact of peer support schemes on pupils' perceptions of bullying, aggression and safety at school. Emotional and Behavioural Difficulties, 13, 63-71.

Cowie, H., and Olafsson, R. (2000). The role of peer support in helping the victims of bullying in a school with high levels of aggression. School Psychology International, 21, 79-95.

Cowie, H., and Smith, P.K. (2010). Peer support as a means of improving school safety and reducing bullying and violence. In B. Doll, W. Pfohl and J. Yoon (Eds.), Handbook of Youth Prevention Science (pp. 177-193). New York: Routledge.

Defensor del Pueblo and UNICEF (2006). Informe Violencia Escolar: El Maltrato entre iguales en la Educación Secundaria Obligatoria 1999-2006. Documentos Defensor del Pueblo: Madrid.

Del Rey, R. y Ortega, R. (2001). El programa de ayuda entre iguales en el proyecto Sevilla Antiviolencia Escolar. Revista de Educación, 326, 297-310.

De Los Reyes, A., and Kazdin, A.E. (2005). Informant discrepancies in the assessment of childhood psychopathology: A critical review, theoretical framework, and recommendations for further study. Psychological Bulletin, 131, 483-509. 
Ellis, L.A., Marsh, H.W., and Craven, G.R. (2005). Navigating the transition to adolescence and secondary school. Newfrontiers for Self-Research, 2, 329-355.

Eslea, M., and Smith, P.K. (2000). Pupil and parent attitudes towards bullying in primary schools. European Journal of Psychology in Education, 15, 207-219.

Fox, C.L., Elder, T., Gater, J., and Johnson, E. (2010). The association between adolescents' beliefs in a just world and their attitudes to victims of bullying. British Journal of Educational Psychology, 80, 183-198.

Frey, K.S., Hirschstein, M.K., Edstrom, L.V., and Snell, J.L. (2009). Observed reductions in school bullying, nonbullying aggression, and destructive bystander behavior: A longitudinal evaluation. Journal of Educational Psychology, 101, 466-481.

Gini, G., Albiero, P., Benelli, B., and Altoe, G. (2008). Determinants of adolescents' active defending and passive bystanding behavior in bullying. Journal of Adolescence, 31, 93-105.

Informe TALIS (OCDE) (2009). Estudio Internacional sobre la Enseñanza y el Aprendizaje. Madrid: Instituto de Evaluación del Ministerio de Educación.

Houlston, C., and Smith, P.K. (2009). The impact of a peer counselling cheme to address bullying in an all-girl London secondary school: A short-term londitudinal study. British Journal of Educational Psychology, 79, 69-86.

Hymel, S. McClure, R., Miller, M., Shumka, E., and Trach, J. (2015). Addressing school bullying: Insights from theories of group processes. Journal of Applied Developmental Psychology, 37, 16-24.

Jiménez, J.A., Ruiz, J.A., Llor, B., and Pérez, M. (2012). Effectiveness of antibullying school programmes: A systematic review by evidence levels. Children and Youth Services Review, 34, 1646-1658.

Kmitta, D. (1999). Pasado y futuro de la evaluación e los programas de resolución de conflictos escolares. In F. Bradoni (Comp.), Mediación escolar (pp. 275-300). Buenos Aires: Paidós.

Lane-Garon, P.S., and Richardson, T. (2003). Mediator mentors: Improving school climate, nurturing student disposition. Conflict Resolution Quarterly, 21, 47-67. 
Langberg, J.M., Epstein, J.N., and Becker, S.P. (2012). Evaluation of the homework, organization and planning skills (HOPS) intervention for middle school students with attention deficit hyperactivity disorder as implemented by school mental health providers. School Psychology Review, 41, 342-364.

Lee, S., Kim, Ch.J., and Kim, D.H. (2013). A meta-analysis of the effect of schoolbased anti-bullying programs. Journal of Child Health Care, 3, 1-18.

Menesini, E., Codecasa, E., Benelli, B., and Cowie, H. (2003). Enhancing children's responsibility to take action against bullying: evaluation of a befriending intervention in Italian middle schools. Aggressive Behavior, 29, 1-14.

Merrell, K.W., Gueldner, B.A., Ross, S.W., and Isava, D.M. (2008). How effective are school bullying intervention programs? A meta-analysis of intervention research. School Psychology Quarterly, 23, 26-42.

Oñate, A., and Piñuel, I. (2006). Informe Cisneros X "Acoso y violencia escolar en España”. Madrid: Instituto de Innovación Educativa y Desarrollo Directivo.

Ortega, R., and del Rey, R. (2003). La violencia escolar: estrategias de prevención. Barcelona: Graó.

Ortega-Ruiz, R., Casas, J.A., and del Rey, R. (2014). Towards the construct of cyberconvivencia/Hacia el constructo ciberconvivencia. Infancia y Aprendizaje, $37,602-628$.

Palladino, B.E., Nocentini, A., and Menesini, E. (2012). Online and offline peer led models against bullying and cyberbullying. Psicothema, 24, 634-639.

Pepler, D., Smith, P.K., and Rigby, K. (2004). Looking back and looking forward: Implications for making interventions work effectively. In P. K. Smith, D. Pepler, and K. Rigby (Eds.), Bullying in schools: How successful can interventions be? (pp. 307-335). United Kingdom: Cambridge University Press.

Rigby, K., and Slee, P.T. (1991). Bullying among Australian school children: Reported behavior and attitudes toward victims. The Journal of Social Psychology, 131, 615-627.

Salmivalli, C., Lagerspetz, K., Björkqvist, K., Österman, K., and Kaukiainen, A. (1996). Bullying as a group process. Participant roles and their relations to social status within the group. Aggressive Behavior, 22, 1-15. 
Salmivalli, C., and Voeten, M. (2004). Connections between attitudes, group norms, and behaviour in bullying situations. International Journal of Behavioral Development, 28, 246-258.

Salmivalli, C., Kaukiainen, A., and Voeten, M. (2005). Anti-bullying intervention: Implementation and outcome. British Journal of Educational Psychology, 75, 465-487.

Smith, P.K. (2011). Why interventions to reduce bullying and violence in schools may (or may not) succeed: Comments on this Special Section. International Journal of Behavioral Development, 35, 419-423.

Sutton, J., and Smith, P.K. (1999). Bullying as a group process: An adaptation of the participant role approach. Aggressive Behavior, 25, 97-111.

Torrego, J.C. (2005). Mediación de conflictos en instituciones educativas: manual para la formación de mediadores. Madrid: Narcea.

Ttofi, M., and Farrigton, D.P. (2011). Effectiveness of school-based programs to reduce bullying: A systematic and meta-analytic review. Journal of Experimental Criminology, 7, 27-56.

Vannini, N. et al. (2011). "FearNot!": A computer-based anti-bullying-programme designed to foster peer intervention. European Journal of Psychology in Education, 26, 21-44.

Vreeman, R.C., and Carroll, A.E. (2007). A systematic review of school-based interventions to prevent bullying. Archives of Pediatrics and Adolescent Medicine, 161, 78-88.

Youngstrom, E., Loeber, R., and Stouthamer-Loeber, M. (2000). Patterns and correlates of agreement between parent, teacher, and male adolescent ratings of externalizing and internalizing problems. Journal of Consulting and Clinical Psychology, 68, 1038-1050.

Waasdorp, T.E., Pas, E.T., O’Brennan, L.M., and Bradshaw, C.P. (2011). A multilevel perspective on the climate of bullying: Discrepancies among students, school staff, and parents. Journal of School Violence, 10, 115-132. 



\section{ARTÍCULO 4 \\ ¿Son eficaces para prevenir el acoso escolar los programas de ayuda entre iguales de reciente implantación?}

Usó, I., y Villanueva, L. ¿Son eficaces los programas de ayuda entre iguales de reciente implantación? Enviado a Revista de Educación. 


\section{¿SON EFICACES PARA PREVENIR EL ACOSO ESCOLAR LOS PROGRAMAS DE AYUDA ENTRE IGUALES DE RECIENTE IMPLANTACIÓN?}

\section{Resumen}

En el presente estudio, se analiza la eficacia de los sistemas de ayuda entre iguales como una posible medida para prevenir las situaciones y conductas de acoso escolar en los centros de Enseñanza Secundaria, teniendo en cuenta el tiempo de implantación en el centro. Para ello se comparan dos centros, uno con programa de mediación (desde hace un curso) y el otro sin programa de intervención, en dos momentos temporalmente diferentes: antes del programa y después del programa. Las variables analizadas posibles indicadoras de cambios se tienen en cuenta a tres niveles: individual (actitudes), grupal (roles) y organizacional (clima de centro). Los participantes fueron 331 estudiantes, de los cursos de $1^{\circ}$ y $3^{\circ}$ de ESO.

Tras la puesta en marcha del programa, los resultados indican que no hay diferencias entre ambos centros para las variables roles y actitudes províctima. Por otro lado, tampoco se produce ninguna mejora del clima de centro para el centro con programa de intervención. La variable tiempo de implementación de un programa de intervención parece tener una influencia directa sobre la ausencia de resultados positivos.

Palabras clave: acoso escolar, ayuda entre iguales, tiempo implementación, roles, actitudes, clima de centro. 


\section{Introducción}

Cada vez más, se demanda información, formación, prevención y soluciones, a las situaciones de conflicto y bullying que se dan en los centros educativos. Los medios de comunicación informan de manera periódica de noticias relacionadas con situaciones de bullying en los institutos. Y según fuentes nacionales, se debe tener en cuenta que existe entre el $23 \%$ y el $32 \%$ de alumnos y alumnas que se encuentran en situaciones de acoso (Defensor del Pueblo y UNICEF, 2006; Informe TALIS, 2009; Oñate y Piñuel, 2006). El hecho de que exista victimización en todos los implicados, es una razón más que suficiente para que se realicen acciones contra la intimidación.

Según diferentes estudios, las víctimas sufren por el acoso al que son sometidos por sus iguales, en términos de desarrollo social, emocional, académico y físico (Cook, Williams, Guerra, Kim y Sadek, 2010; Copeland, Wolke, Lereya, Shanahan, Worthman, y Costello, 2014; Reijntjes, Kamphuis, Prinzie, y Telch, 2010; Reijntjes et. al., 2011; Tofti, Farrington, Losël, y Loeber, 2011), mientras que los agresores, adquieren conductas antisociales, que pueden implicar consecuencias negativas para el resto de sus vidas (Cerezo y Méndez, 2013). Por último, se puede afirmar que datos epidemiológicos recientes muestran una gran variedad de efectos perjudiciales de la intimidación, no sólo para las víctimas, sino también para los jóvenes que intimidan y los testigos del acoso escolar (Bradshaw, 2015). Al tiempo, se producen efectos negativos tanto en el clima de centro como en los profesionales de la educación, en particular, y en toda la comunidad educativa en general (Gázquez, Cangas, Padilla, Cano y Pérez, 2005).

Con los programas de prevención del bullying, como los sistemas de ayuda entre iguales en general, y los sistemas de mediación en particular, se establecen estrategias globales que permiten conocer las relaciones que mantienen los estudiantes e intervienen en sus habilidades sociales y salud emocional (Bradshaw, 2014; Cowie, 2014; Lee, Kim y Kim, 2013; Olweus et al., 2007), De esta manera se consigue reducir el impacto de los conflictos más habituales de convivencia y con el desarrollo moral y social, se promueve que el alumnado se involucre en la participación del programa, de forma directa (Andrés, 2007). Estos programas, además cuentan con una buena eficacia en los primeros cursos de la Educación Secundaria Obligatoria, (Yeager, Fong, Lee y Espelage, 2015), puesto que el paso a esta nueva etapa educativa, sobre todo entre los 11 y los 13 años, está marcado por la mayor utilización del maltrato relacional directo e 
indirecto, la persecución psicológica y las formas más indirectas de maltrato (Björkqvist, Lagerspetz, y Kaukiainen, 1992; Díaz-Aguado, Martínez y Martín, 2013; Evans, Fraser y Cotter, 2014; Olweus, 1993), y es donde más sentido tiene que la ayuda entre iguales se establezca de modo formal en los centros. También han mostrado su eficacia en las redes sociales (Banerjee, Robinson y Smalley, 2012) o mediante la prestación de asesoramiento en grupos de discusión sobre qué hacer ante el acoso cibernético cuando ocurre (DiBasilio, 2008).

La resolución de conflictos no se aprende sólo con dedicarle una hora a la semana, sino que se trata de un trabajo permanente, por ello, los programas de prevención tienen un proceso de implantación, consolidación e institucionalización de los mismos. Y para saber el grado de eficacia conseguido, existen tres niveles de variables indicadoras de posibles cambios: individual (actitudes), grupal (roles), y organizacional (clima de centro).

Según diferentes estudios, existe relación entre las conductas de desarrollo moral y las actitudes adoptadas en los diferentes grupos, que pueden explicar los roles que se asumen en las situaciones de bullying. Resulta interesante, poder clasificar el papel que adoptan los diferentes estudiantes, en relación a la victimización de uno de sus compañeros, asumiendo uno de los roles descritos por Salmivalli, Lagerspetz, Björkqvist, Österman y Kaukiainen (1996), agresor, animador o ayudante del agresor, víctima, defensor de la víctima, y público o espectador. No todos los estudiantes adoptan un papel fijo en las situaciones de bullying, de hecho, tras las intervenciones de prevención o intervención, se pueden producir cambios en estas clasificaciones. También tras la intervención con programas de ayuda entre iguales, las actitudes en favor de la víctima pueden verse aumentadas, así como los roles de defensor de la víctima y espectador (Salmivalli, Kaukiainen y Voeten, 2005; Salmivalli y Voeten, 2004). Pero puede que no se produzca una correlación entre las actitudes de un estudiante y el comportamiento real que adopta en presencia del grupo (Salmivalli, et al., 1996). Menesini, Codecasa, Benelli y Cowie (2003) describieron la asunción de roles tanto en el grupo control como experimental. Después de la intervención de un programa de ayuda entre iguales y en el grupo control, los roles negativos y público se habían incrementado, mientras que las actitudes províctima, disminuían. Del mismo modo, en un estudio más reciente (Usó y Villanueva, en revisión), comparando un centro con programa alumno mediador, con una trayectoria de implantación de cuatro 
cursos, y un centro sin programa de intervención, encontraron, que tras la intervención, en el centro con programa, las actitudes de defensa de la víctima aumentaron, y mejoró el clima escolar, mientras que en el centro sin programa, el rol negativo de seguidor/aayudante del agresor aumentó y el rol positivo de defensor de la víctima disminuyó.

No han sido pocos, los estudios que han concluido que tras la intervención con programas de mediación entre iguales, el clima de centro se percibe de manera más positiva y segura (Cowie, 1998; Lane-Garon y Richardson, 2003; Usó y Villanueva, en revisión), y además la frecuencia y la intensidad de la intimidación disminuye (Palladino, Nocentini y Menesini, 2012). Pero se debe tener en cuenta que cambiar el clima de centro cuando se percibe como negativo, es una tarea compleja que permite obtener resultados a medio y largo plazo, y en pocas ocasiones se obtienen evidencias inmediatas. Además, conseguir este propósito requiere un esfuerzo y compromiso de toda la comunidad educativa y también de las familias (Rigby y Slee, 2008).

La mayoría de los estudios se han centrado en comprobar la eficacia e implicaciones de los sistemas de ayuda entre iguales, y lo han hecho en centros con larga trayectoria de implantación de los programas y que ya cuentan con la institucionalización y conocimiento de los mismos por parte de todos los miembros de la comunidad educativa (Andrés, 2007; Andrés y Gaymard, 2014; Sharp y Cowie, 1998; Usó y Villanueva, en revisión). Pero en el caso de los centros que se deciden a implementar estos programas en sus centros ¿cuánto tiempo debe transcurrir para apreciar el impacto de los mismos en la comunidad educativa? Torrego y Galán (2008) plantean que es necesario un cambio de mentalidad en el tratamiento de los conflictos, ya que su resolución es una cuestión lenta, que requiere tiempo para que realmente se noten y consoliden los efectos de los programas. En este sentido, algunos autores han indicado que para la consolidación de un programa de mediación escolar, la media es de tres años (Boqué, 2004) y otros, han apuntado que los programas con menos de dos años de trayectoria en los centros, tienen pocas probabilidades de contribuir de forma completa a mejorar el clima de centro (Houlston y Smith, 2009). Incluso algunos autores, han indicado que puede haber un aumento de los conflictos en las primeras etapas de implementación de los programas en los centros (Cowie, 1998; Cowie, Naylor, Tallamelli, Chauhan y Smith, 2002; Houlston, Smith y Jessel, 2009; Naylor, Cowie y Del Rey, 2001; Ortega, Del Rey y Mora-Merchán, 2004; Smith, 2003). 
A partir de todas estas consideraciones, el presente estudio tiene como objetivo conocer si existen cambios en las diferentes variables implicadas en los conflictos entre el centro en el que se desarrolla de manera reciente, el programa alumno mediador (en su segundo año), respecto al centro en el que no se realiza ninguna intervención directa de mejora de la convivencia.

Para ello, se plantean las siguientes hipótesis. En el centro con programa de mediación, las puntuaciones en roles positivos o defensores de la víctima aumentarán, al tiempo que se producirá una mejora en las actitudes províctima. Finalmente, modificar el clima de centro es una tarea difícil y costosa en el tiempo, por tanto, dada la poca trayectoria del programa de intervención entre iguales, en esta variable se espera no encontrar cambios significativos entre los centros.

\section{Método}

\section{Participantes}

Los participantes fueron 331 alumnos de dos centros de Educación Secundaria Obligatoria, de la misma localidad. Los centros se han elegido porque presentan características similares, tanto a nivel geográfico, como socioeconómico, y de oferta académica. En segundo lugar, porque uno de ellos no cuenta con ningún programa de ayuda entre iguales (centro A) con $152(45,9 \%)$ estudiantes, y el otro estaba instaurando en el centro por segundo año consecutivo, un programa de alumno mediador (centro B), con $179(54,1 \%)$ estudiantes.

En cada centro se recogieron datos de alumnos de $1^{\circ}$ y $3^{\circ}$ curso de la ESO distribuidos de la siguiente manera (ver tabla 1). En el centro A, donde no hay intervención 80 $(52.6 \%)$ estudiantes eran de primer curso, mientras que $72(47.4 \%)$ se encontraban cursando $3^{\circ}$ de la ESO. En el centro B, $80(44.7 \%)$ estudiantes pertenecían a los cursos de $1^{\circ}$ ESO, mientras que los $99(55.3 \%)$ restantes a $3^{\circ}$ de ESO. Se escogieron los estudiantes de primero y tercero, puesto que los de segundo curso contaban con una gran carga de exámenes tanto internos como externos.

Al comparar los dos centros, se puede observar que no hay diferencias en la distribución por sexo $\left(\chi^{2}=1.76 ; \mathrm{p}=.18\right)$, (172 chicos y 159 chicas $)$, ni en la edad media de los estudiantes (media del centro $\mathrm{A}=13.5$, media del centro $\mathrm{B}=13.4 ; \mathrm{t}=1.037 ; \mathrm{p}=.300$ ). 
Tabla 1. Distribución de la muestra total, por centros

\begin{tabular}{cccc}
\hline & \multicolumn{2}{c}{ Centro } & \multirow{2}{*}{ TOTAL } \\
\cline { 2 - 3 } & Sin programa (A) & Con programa $(\mathrm{B})$ & \\
\hline Estudiantes & $152(45.9 \%)$ & $179(54.1 \%)$ & 331 \\
Estudiantes de primer curso & $80(52.6 \%)$ & $72(47.4 \%)$ & $160(48.3 \%)$ \\
Estudiantes de tercer curso & $80(44.7 \%)$ & $99(55.3 \%)$ & $171(51.7 \%)$ \\
Chicos & $85(25.7 \%)$ & $87(26.3 \%)$ & $172(52 \%)$ \\
Chicas & $67(20.2 \%)$ & $92(27.8 \%)$ & $159(48 \%)$ \\
Media de edad & 13.5 años & 13.4 años & 13.4 años \\
\hline
\end{tabular}

\section{Instrumentos}

Escala de Roles “Adivina Quién” (Salmivalli, Lagerspetz, Bjorkqvist, Österman y Kaukiainen, 1996), adaptada por Sutton y Smith (1999). Es un cuestionario compuesto por 21 ítems, que tiene por objetivo conocer cuál es la reacción y conducta de los iguales en situaciones de conflicto. El estudiante debe nominar siguiendo el método propuesto por Goossens, Olthof y Dekker (2006) y Camodeca y Goossens (2005). Hay que identificar a través de la pregunta ¿Adivina quién? qué estudiantes de la clase encajan en cada rol, siempre que la puntuación estandarizada de los ítems que hacen referencia a ese rol sea más alta que la media de la clase y más alta que en ningún otro rol. La única excepción la constituye el rol de víctima, donde un alumno pertenece si es nominado por al menos el 20\% de la clase. Diversos autores (Sutton y Smith, 1999), agrupan a los ayudantes y animadores del agresor en un nuevo rol, los seguidores. Esta agrupación se ha realizado también en este trabajo. Los roles son los siguientes: El "agresor" es la persona que realiza las acciones de humillación y maltrato contra la víctima ("empieza a atacar o a molestar"), el "animador" indica acciones para que el agresor le haga a la víctima ("le dice cosas al agresor como demuéstrale quien manda aquí"), el "ayudante" reforzando la conducta del agresor ("llama a otros para que vean la agresión”), el "defensor" apoya a la víctima y trata de parar el acoso ("le cuenta a una adulto que se están metiendo con alguien"); “espectador”, observan la agresión, y colaboran con el acoso, por no denunciarlo a los adultos ("finge no darse cuenta de lo que pasa”), y por último "víctima" (“siempre se meten con él/ella”).

Escala de Actitudes Províctima (Rigby y Slee, 1991). En esta escala, se evalúan las actitudes províctima. Los estudiantes, deben responder a una de las tres alternativas "de acuerdo", "no sé”, “en desacuerdo", según las afirmaciones que se plantean a través de 
los 10 ítems que representan situaciones de acoso. Cada respuesta tiene asociada una puntuación que puede ser de 1, 2 ó 3 puntos, que se asignan según el ítem sea directo o inverso. La puntuación total oscila de 10 a 30 puntos, siendo las puntuaciones más elevadas, las que demuestran una actitud más favorable en defensa de la víctima. Algunos de los ítems que se plantean son los siguientes: "Es gracioso ver cómo se ofenden algunos chicos cuando les molestan", "los chicos blandos me ponen enfermo", "me gusta cuando alguien se pone de parte de los chicos que son molestados/agredidos".

Cuestionario sobre Clima de Centro (Ortega y Del Rey, 2003). El instrumento permite conocer la opinión de los estudiantes sobre problemas de convivencia en el centro, las relaciones que mantienen los compañeros, el profesorado y cómo ven la participación de las familias en la vida del centro. Algunos ejemplos de ítems son “¿Cómo te llevas con tus compañeros?”, “Qué opinión crees que tienen de ti tus profesores?”, "Hay enfrentamientos alumno-profesor" ó "Los alumnos se pelean". Los estudiantes deben indicar si las situaciones se dan en el centro "nada", "poco", "regular" o "mucho" Las respuestas de alternativa múltiples, se cuantifican en puntuaciones de 0 a 4 , siendo positivas las puntuaciones más elevadas, en los ítems directos, mientras que cuando el ítem sea inverso, se considerarán como positivas las puntuaciones en las que se obtenga poca puntuación.

\section{Procedimiento}

Para realizar este estudio, se solicitó permiso a la Conselleria de Educación, informando del objetivo de la investigación, así como del procedimiento a seguir. Se les facilitaron a los tutores de todos los grupos de primero y tercer curso de ESO, autorizaciones para que los padres y madres que lo consideraran oportuno, dieran el consentimiento para que sus hijos e hijas participaran en el estudio.

A los alumnos autorizados, se les explicó el objetivo de la investigación, el significado de "maltrato entre iguales e intimidación" y el procedimiento para responder a los tres cuestionarios, así como el principio de confidencialidad de sus respuestas. Los cuestionarios se administraron en la clase de tutoría, de manera grupal. Para poder comparar los resultados, se recabó información en dos momentos: Tiempo 1 (en el mes de diciembre) y Tiempo 2 (mes de junio, tras la intervención con el programa de ayuda 
entre iguales). Cabe decir que la intervención con el programa de ayuda entre iguales fue coordinada y realizada por el equipo directivo y claustro de profesores del centro.

\section{Análisis de datos estadísticos}

Se ha utilizado para los análisis intergrupo, el Análisis Multivariado de la Varianza (MANOVA) con la variable centro (con o sin intervención) como variable independiente y las variables roles, actitudes y clima de centro, como variables dependientes. Para los análisis intragrupo, se han realizado pruebas T-Student para muestras relacionadas. En dichos casos de calculó el tamaño del efecto, según Cohen (1988).

\section{Resultados}

\section{Análisis Intergrupo}

En el tiempo 1, para las variables roles y actitudes províctima, el efecto de la variable centro (con o sin intervención) no tuvo resultados significativos (Traza de Pillai $=.025$, $\mathrm{p}=.139)$. Y por tanto, se apoya la afirmación de que los dos centros parten de una situación parecida, sin diferencias en las variables analizadas. Esto permitirá conocer los cambios que se han producido en el segundo tiempo.

También para el tiempo 1 se analizó el efecto de la variable centro (con o sin intervención) sobre el clima de centro, y en este caso sí aparecían diferencias significativas $($ Traza de Pillai $=.220, \mathrm{p}=.000)$. Por tanto, al comparar el primer tiempo en ambos centros, se asumen situaciones iniciales diferentes respecto al clima de centro (ver tabla 2). En el centro sin programa de mediación, los compañeros se llevan mejor entre ellos y existen menos diferencias en las normas de clase de los profesores. Sin embargo, en el centro con programa de mediación, los padres participan más en las actividades del centro, se respetan más las normas, los profesores van menos "a lo suyo" y tratan de entender más a los alumnos. Asimismo, los estudiantes del centro con programa de mediación, indican con mayor frecuencia maltratos por parte de los compañeros que en el centro sin programa de mediación. 
Tabla 2. Efecto de la variable centro (con o sin programa) en la variable clima de centro en tiempo 1

\begin{tabular}{ccccc}
\hline \multirow{2}{*}{ Clima de centro en tiempo 1 } & \multicolumn{2}{c}{$\mathrm{M}(\mathrm{SD})$ en Centro } & \multirow{2}{*}{$\mathrm{F}(1,330)$} & $\mathrm{p}$ \\
\cline { 2 - 5 } & Sin programa & Con programa & \\
\hline Cómo te llevas con los compañeros & $2.69(.591)$ & $2.85(.480)$ & 7.410 & $.007^{* *}$ \\
Hay diferentes normas en clasesegún el profesor & $1.00(.503)$ & $1.25(.754)$ & 11.663 & $.001^{* *}$ \\
Los padres participan en las actividades del centro & $1.42(.867)$ & $1.80(.851)$ & 15.638 & $.000^{* *}$ \\
No se respetan las normas & $1.86(.825)$ & $1.63(.820)$ & 6.389 & $.012^{* *}$ \\
Los profesores van a lo suyo & $1.28(1.084)$ & $1.04(1.024)$ & 4.228 & $.041^{*}$ \\
Los profesores no entienden a los alumnos & $1.91(.938)$ & $1.66(1.028)$ & 5.444 & $.020^{*}$ \\
Cúantas veces te han maltratadocompañeros & $.17(.412)$ & $.32(.536)$ & 8.072 & $.005^{* *}$ \\
\hline
\end{tabular}

$*$ Nivel de significación $<.05 * *$ Nivel de significación $<.01$

Tras los análisis realizados en el segundo tiempo, se puede comprobar que no existen diferencias significativas de la variable centro (con o sin intervención) sobre los roles y las actitudes províctima (Traza de Pillai $=.013, \mathrm{p}=.515$ ).

Sin embargo, también en este segundo tiempo, aparece el efecto significativo de la variable centro (con o sin intervención) sobre el clima de centro, como se muestra en la tabla 3 (Traza de Pillai $=.323, \mathrm{p}=.000$ ). En el centro con programa de mediación, tras la intervención el clima de centro no mejora, puesto que los estudiantes piensan que continúan existiendo diferencias en las normas de clase según los profesores, más enfrentamientos entre alumno-profesor, más alumnos que se insultan, se pelean y dicen malas palabras en clase. Los estudiantes sienten que los compañeros los maltratan con mayor frecuencia que en el centro sin intervención, al igual que reciben más ciberbullying e intimidaciones. Por último, en el centro sin programa, los estudiantes continúan pensando que los profesores los entienden menos, que en el centro con programa de mediación. 
Tabla 3: Efecto de la variable centro (con o sin programa) en la variable clima de centro en tiempo 2

\begin{tabular}{|c|c|c|c|c|}
\hline \multirow[b]{2}{*}{ Clima de centro en tiempo 2} & \multicolumn{2}{|c|}{ M (SD) en Centro } & \multirow[b]{2}{*}{$\mathrm{F}(1,330)$} & \multirow[b]{2}{*}{$\mathrm{p}$} \\
\hline & $\begin{array}{c}\text { Sin } \\
\text { programa }\end{array}$ & $\begin{array}{c}\text { Con } \\
\text { programa }\end{array}$ & & \\
\hline Hay diferentes normas en clase según profesor & $1.00(.503)$ & $1.37(.678)$ & 31.386 & $.000 * *$ \\
\hline Hay enfrentamientos alumno-profesor & $.92(.753)$ & $1.43(.867)$ & 31.873 & $.000 * *$ \\
\hline Hay malas palabras en clase & $1.81(.867)$ & $2.02(.909)$ & 4.228 & $.041 *$ \\
\hline Los alumnos se insultan & $1.65(.957)$ & $1.99(.896)$ & 11.310 & $.001 * *$ \\
\hline Los alumnos se pelean & $.84(.825)$ & $1.53(1.029)$ & 43.946 & $.000 * *$ \\
\hline Los profesores no entienden a los alumnos & $1.99(.894)$ & $1.72(.972)$ & 6.604 & $.011 *$ \\
\hline Cúantas veces te han maltratado compañeros & $.16(.433)$ & $.33(.549)$ & 9.573 & $.002 * *$ \\
\hline Has recibido ciberbullying & $.02(.140)$ & $0.08(.326)$ & 4.186 & $.042 *$ \\
\hline Frecuencia con que se dan intimidaciones en el centro & $1.02(5.35)$ & $1.28(.583)$ & 18.251 & $.000 * *$ \\
\hline
\end{tabular}

$*$ Nivel de significación $<.05 * *$ Nivel de significación $<.01$

\section{Análisis Intragrupo}

A continuación se muestran los análisis intragrupo, para las variables roles, actitudes y clima de centro, con el fin de conocer las posibles diferencias en cada centro, de un tiempo a otro. Si se toman los análisis para la variable Roles, ni en el centro A, ni en el centro B, existen diferencias significativas en la distribución de roles participantes, de un tiempo al otro (obteniendo significaciones que oscilan entre .33 y .97).

Respecto a la variable actitudes, tampoco en ninguno de los dos centros, existen diferencias significativas del tiempo 1 al tiempo 2 (centro A, M1 = 25.59; M2 = 25.48, $\mathrm{p}=.566$. Centro $\mathrm{B}, \mathrm{M} 1=26.37 ; \mathrm{M} 2=26.49, \mathrm{p}=.669$ ).

Por último, dentro de la variable clima de centro, los resultados indican que en el centro A (sin programa de mediación), se han obtenido diferencias significativas entre el tiempo 1 y 2 en los ítems que se detallan en la tabla 4, todos ellos, con un pequeño tamaño del efecto (Cohen, 1988). Los estudiantes consideran que pasado el curso, sus compañeros tienen una mejor opinión de ellos mismos, y que los padres participan más en las actividades del centro respecto al tiempo 1. Incluso, aún sin intervención, se produce una mejora respecto a los enfrentamientos entre alumnos y profesores, los alumnos se pelean menos, y disminuyen las situaciones de ciberbullying y la frecuencia de las intimidaciones. 
Tabla 4: Diferencias intragrupo del tiempo 1 al 2 en los ítems en Clima de Centro para el centro A (sin programa de mediación)

\begin{tabular}{ccccccc}
\hline \multirow{2}{*}{ Centro A } & tiempo 1 & tiempo 2 & & & & \\
\cline { 2 - 4 } & $\mathrm{M}(\mathrm{SD})$ & $\mathrm{M}(\mathrm{SD})$ & $\mathrm{T}$ & $\begin{array}{c}\mathrm{p} \\
\text { intragrupo }\end{array}$ & $\mathrm{D}$ & $\mathrm{r}$ \\
\hline Qué opinión crees que tienen de tí tus & $2.31(.712)$ & $2.47(.574)$ & -2.164 & $.032 *$ & -.039 & -.019 \\
$\begin{array}{c}\text { compañeros } \\
\text { Los padres participan en la vida del centro }\end{array}$ & $1.42(.865)$ & $1.70(.631)$ & -3.245 & $.001 * *$ & -.369 & -.181 \\
Hay enfrentamientos alumnos professores & $1.18(.831)$ & $.92(.751)$ & 3.163 & $.002 * *$ & .328 & .167 \\
Los alumnos se pelean & $1.24(.919)$ & $.84(.823)$ & 4.429 & $.000 * *$ & .458 & .223 \\
Has recibido ciberbullying & $.08(.294)$ & $.02(.140)$ & 2.358 & $.020 *$ & .260 & .129 \\
Hay frecuentes intimimadiones en el centro & $1.18(.520)$ & $1.02(.533)$ & 2.960 & $.004 * *$ & .303 & .150 \\
\hline \multicolumn{2}{c}{ *Nivel de significación $<.05$} & $* *$ Nivel de significación $<.01$ & & &
\end{tabular}

En el centro B (con programa de mediación), han resultado significativos dos ítems relacionados con el clima de centro, que se indican en la tabla 5. La pregunta sobre la relación que se tiene con los compañeros, indica que los estudiantes en el tiempo 2 se llevan peor con sus compañeros de clase, respecto al tiempo $1(\mathrm{t}=3.210, \mathrm{p}=.002, \mathrm{~d}$ de Cohen $=.34, \mathrm{r}=.16)$. También hay diferencias en el ítem en el que se pregunta si se producen discusiones entre alumnos y profesores $(\mathrm{t}=-3.209, \mathrm{p}=.002, \mathrm{~d}$ de Cohen $=-$ $.35, \mathrm{r}=-.17)$. En esta ocasión los estudiantes indican que tras el paso del tiempo, hay más enfrentamientos entre alumnos y profesores, que al inicio de curso.

Tabla 5: Diferencias intragrupo del tiempo 1 al 2 en los ítems en Clima de Centro para el centro $B$ (con programa de mediación)

\begin{tabular}{|c|c|c|c|c|c|c|}
\hline \multirow[b]{2}{*}{ Centro B } & tiempo 1 & tiempo 2 & & & & \\
\hline & $\mathrm{M}(\mathrm{SD})$ & $\mathrm{M}(\mathrm{SD})$ & $\mathrm{T}$ & $\begin{array}{c}\mathrm{p} \\
\text { intragrupo }\end{array}$ & $\mathrm{D}$ & $\mathrm{r}$ \\
\hline Cómo te llevas con tus compañeros & $2.85(.480)$ & $2.66(.637)$ & 3.210 & $.002 *$ & .034 & .016 \\
\hline $\begin{array}{l}\text { Hay enfrentamientos entre alumnos y } \\
\text { profesores }\end{array}$ & $1.13(.864)$ & $1.43(.867)$ & -3.209 & $.002 *$ & -.35 & -.17 \\
\hline
\end{tabular}

\section{Discusión}

El objetivo que se propuso la investigación fue el de evaluar el posible impacto de un programa de ayuda entre iguales de reciente implantación, en los tres niveles de variables indicadoras de posibles cambios: individual (actitudes), grupal (rol) y 
organizacional (clima de centro), comparando dos institutos de Educación Secundaria. Uno contaba con un programa de ayuda entre iguales de reciente implantación en su segundo año, y el otro no realizaba ningún tipo de intervención específica como medida de prevención de conflictos. Los resultados encontrados, tanto de los análisis intergrupo como intragrupo, no apoyan la primera hipótesis planteada en la que se esperaban mejoras de un tiempo a otro, en el centro con intervención, para las variables actitudes y roles.

Se esperaba una mayor clasificación en los roles positivos o en defensa de la víctima, en el centro que cuenta con el programa de mediación, así como una mejora de las actitudes províctima. Sin embargo, no existen diferencias para los centros (con y sin programa). En este sentido, los resultados obtenidos a nivel intergrupo, en el tiempo 1 no muestran diferencias en las variables roles y actitudes, lo que indica una situación inicial similar para los dos centros. En el tiempo 2, la intervención planteada en el programa de ayuda entre iguales de reciente implantación, no parece haber tenido ningún efecto sobre las variables roles y actitudes. En estudios anteriores (Cowie, 1998; Menesini et al. 2003; Palladino et al. 2012) se apoya una mejora sustancial de las actitudes províctima que no implican necesariamente una conducta (como es el caso de los roles) y que por lo tanto, pueden resultar más fáciles de modificar tras el programa de intervención, pero en esta ocasión, las actitudes no han mejorado.

Respecto a la variable clima escolar, no se apoya la hipótesis inicial, que presuponía que no existirían diferencias significativas entre los centros tras la intervención, debido a la poca trayectoria del programa en el centro con intervención. Sí existen diferencias significativas ya en el tiempo 1, para algunos de los ítems, que favorecen más la situación inicial del centro con programa, y en otras ocasiones al centro sin programa. En el tiempo 2, en el centro sin programa de intervención, los resultados apoyan una mejora en el clima de centro, respecto al primer momento en el que se recogieron los datos. Los alumnos afirman que ha mejorado la opinión que tienen de ellos los compañeros, los padres participan más en la vida del centro, se dan menos peleas entre alumnos y profesores y entre los propios alumnos, y se ha reducido la frecuencia de intimidaciones en el centro, y también de ciberbullying. Por tanto, en este caso existen diferencias significativas a favor del centro sin programa de intervención, en el cual paradójicamente mejora el clima de centro, a pesar de no contar con ninguna estrategia de intervención explícita. 
Pero ¿por qué en el centro con el programa alumno mediador no se aprecia ninguna mejora, e incluso, empeoran algunos aspectos del clima de centro en el tiempo 2? Según diferentes estudios, programas con menos de dos o tres años de trayectoria no es probable que contribuyan de forma completa a mejorar todo lo que comporta el clima de centro, como la relación entre los compañeros, con el profesorado, entre otros aspectos (Boqué, 2004; Houlston y Smith, 2009). Se debe considerar que la eficacia de los programas contra el bullying mejora cuando éstos se desarrollan de forma continua, desde una perspectiva de largo plazo, más que como una intervención puntual o a corto plazo (Carney y Merrell, 2001).

En este caso, el clima del centro con programa de mediación ha empeorado según los alumnos, que afirman que se llevan peor con los compañeros y que han aumentado los enfrentamientos alumno-profesor respecto al primer tiempo. Este hecho puede explicarse según autores como Salmivalli, Kaukiainen y Voeten (2005) desde la perspectiva de que el clima de centro empeora tras la puesta en marcha de un programa, debido a un bajo grado de implicación en la puesta en marcha del programa por parte de los agentes implicados, ó simplemente, puede deberse a que al trabajar estos temas, el alumnado es más consciente de la presencia de situaciones de intimidación y maltratoescolar, y por lo tanto, informa más de ello en las respuestas de los cuestionarios. De hecho, autores como Cowie, (1998); Cowie y Olafsson, (2000); Cowie y Wallace, (2000); Houlston, Smith y Jessel, (2009); Naylor y Cowie, (1999); Ortega y del Rey, (2001); Smith y Watson, (2004); indican que puede haber un aumento de los conflictos de manera que no se produzcan las mejoras esperadas, que los programas muestran cuando el tiempo de implantación es mayor. Andrés (2007), apunta tras resultados similares, que el aumento de los conflictos tras la implantación de dichos programas en los centros, se atribuye, en parte, al efecto de la sensibilización y toma de conciencia que se producen en los primeros momentos de su inserción.

Finalmente, entre las limitaciones del estudio, señalar en primer lugar, que hubiese sido interesante involucrar a todo el personal de los centros y a las familias en las actividades de prevención de los programas de ayuda entre iguales (Bradshaw, 2013, 2015), y por tanto, analizar sus respuestas, en los ítems relacionados con el clima de centro (Waasdorp, Bradshaw y Duong, 2011). Por otra parte, otra limitación del presente estudio es no haber incluido elementos de carácter más objetivo en la evaluación del impacto del programa, como por ejemplo, número de conflictos, casos de acoso 
notificados, partes de faltas por peleas, expulsiones por temas de acoso... Aún así, los resultados obtenidos apoyan la evidencia de ausencia de mejora en los primeros años de implantación del programa de ayuda entre iguales, como medida de prevención de las situaciones de acoso escolar. Por lo tanto, los usuarios de este tipo de programas deben ser conscientes de este hecho para evitar el abandono temprano de la intervención, sabiendo que la eficacia de los mismos se logra pasado un tiempo desde la puesta en marcha en el centro, de manera constante por todos los miembros de la comunidad educativa.

\section{Referencias}

Andrés, M.S. (2007). Los sistemas de ayuda entre iguales como instrumentos de mejora de la convivencia en la escuela: evaluación de una intervención. (Tesis doctoral). UniversidadAutónoma de Madrid. Madrid. http://redined.mecd.gob.es/xmlui/handle/11162/83871

Andrés, S., y Gaymard, S. (2014). The perception of school climate in two secondary schools during the implementation of a peer support program. Journal of Research in Educational Psychology, 12(2), 509-540.

http://dx.doi.org/10.14204/ejrep.33.13052

Banerjee, R., Robinson, C., y Smalley, D. (2012). Evaluation of the beatbullying peer mentoring programme. Brighton: University of Sussex.

Björkqvist, K., Lagerspetz, K., y Kaukiainen, A. (1992). Do girls manipulateand boys fight? Development trends in regard to direct and indirect aggression. Aggressive Behavior, 18, 117-127.

Boqué, M.C. (2004). Mediación escolar: unidos ante el conflicto. Perspectiva CEP, 8, 55-69.

Bradshaw, C.P. (2013). Preventing bullying through positive behavioral interventions and supports (PBIS): A multitiered approach to prevention and integrations. Theory into Practice, 52, 288-295.

http://dx.doi.org/10.1080/00405841.2013.829732 
Bradshaw, C.P. (2014). The role of families in preventing and buffering the effects of bullyin. Journal of the Amrican Medical Association Pedriatics, 168, 991993.http://dx.doi.org/10.1001/jamapedriatics.2014.1627

Bradshaw, C.P. (2015). Translating research to practice bullying prevention. American Psychologist Association, 70(4), 344-353. http://dx.doi.org/10.1037/a0038929

Camodeca, M., yGoossens, F.A. (2005). Children's opinions on effective strategies to cope with bullying: The importance of bullying role and perspective. Educational Research, 47, 93-105.

Carney, A., y Merrell, K. (2001). Bullying in schools. Perspectives on understanding and preventing an international problem. School Psychology International, 22(3), 364-382.

Cerezo, F. y Méndez, I. (2013). Agresoresen bullying y conductasantisociales. European Journal of Investigation in Health, Psychology and Education, 3(1), 514.

Cook, C.R., Williams, K.R., Guerra, N.G., Kim, T.E., y Sadek, S. (2010). Predictors of bullying and victimization in childhood and adolescence: A meta-analytic investigation. School Psychology Quarterly, 25, 65-83.

Copeland, W.E., Wolke, D., Lereya, S.T., Shanahan, L., Worthman, C., y Costello, E.J. (2014). Childhood bullying involvement predicts low-grade in flammation into adulthood. Proceedings of the National Academy of Sciences, 111, 7570-7575.

Cowie, H. (1998). Perspectives of teachers and pupils on the experience of peer support against bullying. Educational Research and Evaluation, 4, 108-125.

Cowie, H., y Olafsson, R. (2000). The role of peer support in helping the victims of bullying in a school with high levels of aggression. School Psychology International, 21(1), 79-95.

Cowie, H., y Wallace, P. (2000). Peer support in action. From standing by to stand by.Londres, RU: Sage Publications.

Cowie, H., Naylor, P., Tallamelli, L., Chauhan, P., y Smith, P.K. (2002). Knowledge, use of and attitudes toward peer support: a 2-year follow-up to the Prince's Trust survey. Journal of Adolescence, 25, 453-467. 
Cowie, H. (2014). Understanding the role of bystanders and peer support in school bullying. The International Journal of Emocional Education, 6, 26-32.

Defensor del Pueblo y UNICEF (2006). Informe Violencia Escolar: El Maltrato entre iguales en la Educación Secundaria Obligatoria 1999-2006. Documentos Defensor del Pueblo: Madrid. Publicaciones de la Oficina del Defensor del Pueblo. Informes y documentos: Informesmonográficos.

Del Rey, R., y Ortiga, R. (2001). El programa de ayuda entre iguales en el contexto del proyecto Sevilla Antiviolencia Escolar. Revista de Educación, 326, 297-310.

Díaz-Aguado, M.J., Martínez, R., y Martín, J. (2013). El acoso entre adolescentes en España. Prevalencia, papeles adoptados por todo el grupo y características a las que se atribuyen la victimización. Revista de Educación, 362, 348-379. http://dx.doi.org/10.4438/1988-592X-RE-2011-362-164

DiBasilio, A. (2008). Reducing bullying in middle school students through the use of peer leaders. (Unpublished Master Thesis): University of Chicago: Illinois. http://files.eric.ed.gov/fulltext/ED501251.pdf

Domitrovich, C.E., Bradshaw, C.P., Poduska, J., Hoagwood, K., Buckley, J., Olin, S.. et. al. (2008). Maximizing the implementation quality of evidence-based preventive interventions in schools: A conceptual framework. Advances in School Mental Health Promotion, 1(3), 6-28.

http://dx.doi.org/10.1080/1754730X.2008.9715730

Evans, C.B.R., Fraser, M.W., y Cotter, K.L. (2014). The effectiveness of school-based bullying prevention programs: A systematic review. Aggression and Violent Behavior, 19, 532-544.

Farrington, D.P., y Ttofti, M.M.(2009). School-based programs to reduce bullying and victimization (Campbell Systematic Reviews No. 6). Oslo, Norway: Campell Corporation. http://dx.doi.org/10.1177/0002716202250789

Gázquez, J.L., Cangas, A.J., Padilla, D., Cano, A., y Pérez, P. (2005). Assessment by pupils, teachers and parent of school coexistence problems in Spain, France, Austria and Hungary. Global psychometric data. International Journal of Psychology and Psychological Therapy, 5, 101-112. 
Goossens, F.A., Olthof, T., y Dekker, P.H. (2006). New participant role scales: Comparison between various criteria for assigning roles and indications for their validity. Aggressive Behavior, 32, 343-357.

Houlston, C., y Smith, P.K. (2009). The impact of a peer counseling scheme the address bullying in an all-girl London secondary school: A short-term longitudinal study. British Journal of Educational Psychology, 79, 69-86.

Houlston, C., Smith, P.K., y Jessel, J. (2009). Investigating the extent and use of peer support initiatives in English schools. Educational Psychology, 29(3), 325-344.

Informe TALIS (OCDE) (2009). Estudio Internacional sobre la Enseñanza y el Aprendizaje. Madrid: Instituto de Evaluación del Ministerio de Educación.

Lane-Garon, P.S., y Richardson, T. (2003). Mediator mentors: Improving school climate, nurturing student disposition. Conflict Resolution Quarterly, 21, 47-67.

Lee, S., Kim, Ch.J., y Kim, D.H. (2013). A meta-analysis of the effect of school-based anti-bullying programs. Journal of Child Health Care, 3, 1-18.

Menesini, E., Codecasa, E., Benelli, B., y Cowie, H. (2003). Enhancing children's responsibility totake action against bullying: evaluation of a befriending intervention in Italian middle schools. Aggressive Behavior, 29, 1-14.

Naylor, P., y Cowie, H. (1999). The effectiveness of peer support systems in challenging school bullying: the perspectives and experiences of teachers and pupils. Journal of Adolescence, 22, 462-479.

Naylor, P., Cowie, H., y Del Rey, R. (2001). Doping strategies of secondary children in response to being bullied. Child Psychology \& Psychiatry Review, 6(3), 114-120.

Olweus, D. (1993). Bully/victim problems among schoolchildren: Long-term consequences and an effective intervention program. EnS. Hodgins (Ed.), Mental Disorder and Crime, (pp. 317-349). Thousand Oaks, CA: Sage Publications.

Olweus, D., Limber, S.P., Flerx, V.C., Mullin, N., Riese, J., y Snyder, M. (2007). Olweus Bullying Prevention Program: Schoolwide guide. Center City, MN: Hazelden.

Oñate, A., y Piñuel, I. (2006). Informe Cisneros X "Acoso y violencia escolar en España”. Madrid: Instituto de Innovación Educativa y Desarrollo Directivo. 
Ortega, R., y del Rey, R. (2001). Aciertos y desaciertos del Proyecto Sevilla Antiviolencia Escolar (SAVE). Revista de Educación, 324, 253-270.

Ortega, R., Del Rey, R., y Mora-Merchán, J.A. (2004). SAVE model: an anti-bullying intervention in Spain. En P.K. Smith, D. Pepler y K. Rigby (Eds.), Bullying in schools. How successful can interventions be? (pp. 167-185). Cambridge University Press.

Palladino, B.E., Nocentini, A., y Menesini, E. (2012). Online and offline peer led models against bullying and cyberbullying. Psicothema, 24, 634-639.

Pepler, D., Smith, P.K., and Rigby, K. (2004). Looking back and looking forward: Implications for making interventions work effectively. En P. K. Smith, D. Pepler, and K. Rigby (Eds.), Bullying in schools: How successful can interventions be? (pp. 307-335). United Kingdom: Cambridge University Press.

Rigby, K., y Slee, P.T. (2008). Interventions to reduce bullying. International Journal of Adolescent Medicine and Health, 20(2), 165-183.

Reijntjes, A., Kamphuis, J.H., Prinzie, P., y Telch, M.J. (2010). Peer victimization and internalizing problems in children: A meta-analysis of longitudinal studies. Child Abuse \& Neglect, 34, 244-252.

Reijntjes, A., Kamphuis, J.H., Prinzie, P., Boelen, P.A., Van der Schoot, M., y Telch, M.J. (2011). Prospective linkages between peer victimization and externalizing problems in children: A meta-analysis. Aggressive Behavior, 37, 215-222.

Salmivalli, C., Lagerspetz, K., Björkqvist, K., Österman, K., y Kaukiainen, A. (1996). Bullying as a group process. Participant roles and their relations to social status within the group. Aggressive Behavior, 22, 1-15.

Salmivalli, C., y Voeten, M. (2004). Connections between attitudes, group norms, and behavior in bullying situations. International Journal of Behavioral Development, $28,246-258$.

Salmivalli, C., Kaukiainen, A., y Voeten, M. (2005). Anti-bullying intervention: Implementation and outcome. British Journal of Educational Psychology, 75, 465-487.

Sharp, S., y Cowie, H. (1998). Counselling and supportingchildren in distress. Londres, RU : Sage Publications. 
Smith, P.K. (2003). Violence in schools. The response in Europe. Londres, RU: Routledge Falmer.

Smith, P.K., y Watson, D. (2004). Evaluation of the CHIPS (Childline in Partnership with Schools) programme. Research report RR570. Nottingham: DfES publications.

Tofti, M., Farrington, D., Losël, F., y Loeber, R. (2011). Effectiveness of school-based programs to reduce bullying: A systematic and meta-analytic review. Journal of Experimental Criminology, 7, 27-56.

Torrego, J.C., y Galán, A. (2008). Investigación evaluativa sobre el programa de mediación de conflictos en centros escolares. Revista de Educación, 347, 369-394.

Usó, I., y Villanueva, L. (en revisión). Impact of peer mediation programs to prevent bullying behaviors in secondary schools. Infancia y Aprendizaje.

Waasdorp, T.E., Bradshaw, C.P., y Duong, J. (2011). The link between parents' perceptions of the school and their responses to school bullying: Variation by child characteristics and the forms of victimization. Journal of Educational Psychology, 103, 324-335. http://dx.doi.org/10.1037/a0022748

Yeager, D.S., Fong, C.J., Lee, H.Y., y Espelage, D.L. (2015). Decline in efficacy of anti-bullyingprograms amongolder adolescents: Theory and three-levelmetaanalysis. Journal of Applied Developmental Psychology, 37, 36-51. 


\section{CAPÍTULO 5. CONCLUSIONES GENERALES}





\section{CAPÍTULO 5. CONCLUSIONES GENERALES}

A lo largo de este trabajo, se ha tratado de conocer más a fondo los sistemas de ayuda entre iguales, y en concreto el impacto, ventajas y eficacia que tiene el programa alumno mediador, para fomentar la convivencia y prevenir el acoso escolar en los centros de Educación Secundaria Obligatoria.

Por tanto, se ha tratado de registrar y analizar tres niveles diferentes de indicadores de un posible cambio: individual (actitudes), grupal (roles), organizacional (clima de centro), comparando tres institutos de la provincia de Castellón, en dos tiempos diferentes. Uno contaba con el programa alumno mediador por cuarto curso en el centro (larga trayectoria en la implantación), otro contaba también con el programa alumno mediador desde hacía un curso en el centro (reciente implantación), y el tercero no contaba con ningún programa de intervención para prevenir las situaciones de bullying en su centro.

El primer objetivo consistía en exponer las características y fases a tener en cuenta para la implantación de un sistema de ayuda entre iguales en los centros de Enseñanza Secundaria Obligatoria. Dicho objetivo, tras la revisión realizada, nos permite concluir que antes de implementar un programa de estas características, se deben tener en cuenta aspectos como los siguientes: es fundamental contar con el apoyo del claustro, así como realizar de manera minuciosa la toma de decisiones importantes, según el modelo de programa que se vaya a implementar, como por ejemplo: determinar si la participación de los alumnos ayudantes/mediadores es rotativa o no, decidir si se pueden integrar alumnos que previamente se han etiquetado como agresores, como futuros alumnos ayudantes/mediadores, o decidir el formato, horario y lugar, donde se realizará la ayuda entre iguales. También se debe pautar cómo seleccionar a los alumnos ayudantes/mediadores, tratando de fomentar la participación de los chicos, puesto que siempre son más chicas las que se deciden a participar en estos programas, dada su prosocialidad. Se deberá realizar difusión del programa a dos niveles, por una parte con el fin de captar alumnos ayudantes/mediadores, y por otro, ofrecer el programa a la comunidad educativa. Finalmente, se deberá evaluar el proceso seguido, tanto por parte de los alumnos como del profesorado implicado en el proceso de ayuda.

El segundo objetivo que se había establecido era el de conocer la eficacia del programa alumno mediador en los centros de secundaria, a partir de las variables individuales 
(actitudes), sociogrupales (roles) y organizacionales (clima de centro), comparando un centro con programa de larga trayectoria de implantación y otro que no contase con el programa.

Los análisis realizados apoyan la existencia de diferencias significativas en la variable roles para el centro sin programa de mediación, al comparar los dos tiempos en los que se recaban los datos. El centro con programa de mediación, no revierte efectos positivos, pero sí previene una escalada negativa de los roles implicados en el acoso escolar (Defensor de Pueblo y Unicef, 2006; Menesini, Codecasa, Benelli y Cowie, 2003; Rigby y Slee, 2008).

Por otra parte, tras la intervención, se produce un aumento de las actitudes a favor y en defensa de las víctimas de acoso escolar (Cowie, 1998; Menesini et. al., 2003; Palladino, Nocentini y Menesini, 2012; Salmivalli y Voeten, 2004; Salmivalli, Kaukiainen y Voeten, 2005). Una conclusión en este sentido es que las actitudes no implican conductas más visibles en el grupo-clase, quizás por ese motivo, se observan más cambios que en la variable roles. Por tanto, se puede concluir que se producen mejoras en la variable actitudes en defensa de la víctima de situaciones de intimidación y maltrato, y en menor grado, pueden verse mejorados los roles que adoptan los estudiantes ante este tipo de situaciones.

Respecto a la variable clima de centro se puede concluir que los programas de ayuda entre iguales, a través de la mejora de la convivencia, favorecen aspectos como la cooperación y las relaciones interpersonales, de manera que las interacciones que se producen en el aula y en el centro mejoran la participación activa de toda la comunidad educativa en general. Por tanto, tras la intervención de los programas de mediación escolar el clima de centro se percibe como más positivo y seguro (Cowie, 1998; LaneGaron and Richardson, 2003).

El tercer objetivo pretendía comparar las opiniones de los alumnos y profesores sobre la eficacia de los programas basados en la ayuda de iguales. Por parte del estudiantado, sí se perciben cambios significativos en el programa con intervención, respecto a la disminución de peleas, enfrentamientos, etc., que son actuaciones que pueden negativizar el ambiente del aula y del centro. Pero el profesorado de dicho centro, no informa de una mejora del clima como resultado de la intervención en comparación con los alumnos, como se ha afirmado en otros estudios (De Los Reyes y Kazdin, 2005; 
Youngstrom, et. al., 2009). Este hecho, este hecho puede deberse a que no se perciban diferencias por la escasa muestra de profesorado entrevistado, o a que el propio profesorado tenga una concepción diferente de los episodios de acoso escolar, la cual condiciona sus respuestas (Bradshaw, Sawyer y O’Brennan, 2007; Langberg, Epstein y Becker, 2012; Waasdorp, Pas, O’Brennan y Bradshaw, 2011). Por tanto, se puede concluir, que existe una visión general positiva sobre el clima de centro según el estudiantado, cuando se tiene instaurado un programa de ayuda entre iguales desde hace cuatro cursos, pero que puede no ser compartida por el profesorado.

Finalmente, en el cuarto objetivo específico, se proponía analizar el impacto del factor tiempo de implementación de un programa en un centro, sobre la eficacia de los sistemas de ayuda. Este último objetivo pretendía valorar la eficacia de los programas con menos tiempo de trayectoria en los centros, puesto que algunos autores han indicado que para la consolidación de un programa de mediación escolar, la media es de tres años (Boqué, 2004) y otros, han apuntado que los programas con menos de dos años de trayectoria en los centros, tienen pocas probabilidades de contribuir de forma completa a mejorar el clima de centro (Houlston y Smith, 2009). En esta ocasión, los resultados son paradójicos, puesto que el centro que cuenta con el programa de mediación de reciente implantación, no experimenta mejoras en ninguna de las tres variables analizadas: roles, actitudes y clima de centro, como cabía esperar. Pero el centro sin intervención sí mejora su clima escolar, frente al centro con programa.

Es decir, se confirman los resultados obtenidos por algunos autores, que indican la posibilidad de que aumenten los conflictos en las primeras etapas de implementación de los programas en los centros (Cowie, 1998; Houlston, Smith y Jessel, 2009; Ortega, Del Rey y Mora-Merchán, 2004; Salmivalli y Kaukiainen, 2002; Smith, 2003; Smith y Watson, 2004), o simplemente, que la puesta en marcha directamente, no disminuya los casos de maltrato (Naylor y Cowie, 1999). Por tanto, todo esto, apunta a la necesidad de que los centros que implanten estos programas, conozcan la posibilidad de un posible “efecto rebote" en la primera fase de la puesta en marcha de los mismos. Respecto a las recomendaciones previas a la implantación de los programas de ayuda entre iguales en los centro, cabe incorporar en ellas la posibilidad de que se produzca este "efecto rebote", y por tanto, los resultados de mejora no sean evidentes en los primeros momentos de funcionamiento del programa en el centro. No se deberían esperar resultados inmediatos o a corto plazo, ya que no son habituales. 
Como resumen final puede decirse que tras la intervención de un programa de ayuda entre iguales, suelen producirse mejoras en las actitudes províctima de los estudiantes de ese centro. En la variable roles es más difícil experimentar cambios, pero los resultados apoyan que con la intervención al menos se previene la escalada negativa de los roles. Por último, el factor tiempo que lleva implementado el programa en el centro, parece ser importante, puesto que programas con breve trayectoria, no muestran los mismos efectos positivos, que en el centro en el que ya está instaurado el programa desde hace más tiempo.

Para finalizar, se indican las limitaciones encontradas en el presente trabajo, que pueden suponer inicios e hipótesis para investigaciones futuras.

- Además de un enfoque cuantitativo, existe la necesidad de integrar el enfoque cualitativo en este estudio, como grupos de discusión, diarios de sesiones o cuestionarios de carácter abierto de valoración y grado de satisfacción de los alumnos con el programa.

- Es necesario en investigaciones futuras, recabar más información sobre la variable clima de centro, recogiendo datos de todo el profesorado, personal de administración y servicios, equipo directivo, departamento de orientación y familias, así como de los alumnos mediadores, puesto que dicha variable puede ser, por su complejidad, moduladora de las variables roles y actitudes.

- Existe la necesidad de estudios longitudinales que permitan conocer la evolución de prevención de la violencia escolar, ya que la eficacia de los programas de prevención, es más probable y evidente cuanto mayor sea el tiempo de implantación en el centro educativo.

- No se han tenido en cuenta en este estudio la influencia de variables moduladoras que se deberían incluir en estudios futuros para conocer su relación con el acoso escolar, como el género, la edad, el rendimiento académico, las habilidades sociales y la inteligencia emocional.

- Cabe ahondar más en las nuevas estrategias de prevención del ciberbullying basadas en los sistemas de ayuda entre iguales: los ciberayudantes i cibermediadores, tal y como se contempla en el Nuevo Plan Nacional de Convivencia Escolar que el Ministerio de Educación publicará entre los meses de Noviembre y Diciembre de 2015. 
A pesar de las limitaciones encontradas, se puede afirmar que los sistemas de ayuda entre iguales, como el programa alumno mediador, con una puesta en marcha bien definida y con un plan de seguimiento institucionalizado, pueden mejorar la convivencia de toda la comunidad educativa y prevenir las situaciones de acoso escolar que se dan en los centros de educación secundaria. 



\section{B. REFERENCIAS BIBLIOGRÁFICAS}





\section{REFERENCIAS BIBLIOGRÁFICAS}

Adrián J.E., y Clemente, R.A. (2004). Convivencia escolar en secundaria. [CD-ROM]. Valencia: Generalitat valenciana.

Anderson, C.S. (1982). The search for school climate: A review of the research. Review of Educational Research, 52(3), 368-420.

Andrés, S. (2001). Evaluación de un Sistema de Ayuda entre iguales. El clima escolar y las habilidades sociales del alumnado como indicadores de cambio. Trabajo de investigación inédito. Madrid: Universidad Autónoma. Departamento de Psicología Evolutiva y de la Educación.

Andrés, S., y Barrios, A. (2006). El modelo del alumno ayudante a discusión: la opinión de los alumnos participantes y sus beneficiarios. Revista Electrónica de Investigación Psicoeducativa, 4 (2), 311-332.

Andrés, S., y Barrios, A. (2009). De la violencia ala convivencia en la escuela: El camino que muestran los estudios más recientes. Revista Complutense de Educación, 20 (1), 205-227.

Andrés, S., Barrios, A., y Martín, E. (2005). Evaluación de un programa de ayuda entre iguales en educación secundaria por medio de grupos de discusión: la opinión de los alumnos participantes. En J.A. Del Barrio e I. Fajardo (Comps) Nuevos contextos psicológicos y sociales en educación. Buscando respuestas (pp. 311332). Santander: INFAD, Psicoex.

Arellano, N. (2008). Violencia entre pares escolares (bullying) y su abordaje a través de la mediación escolar y los sistemas de convivencia. Informe de Investigaciones Educativas, Vol. XXII, $N^{o} 2$.

Avilés, J.M. (2006). Bullying: el maltrato entre iguales. Agresores, víctimas y testidos en la escuela. Salamanca: Amaru Ediciones.

Avilés, J.M., Torres, N., y Vian, M.V. (2008). Equipos de ayuda, maltrato entre iguales y convivencia escolar. Revista Electrónica de Investigación Psicoeducativa, 16, 863-886. 
Arró, M., Villanueva, L., y Traver, J. (2006). El Alumno-Amigo: Un sistema de ayuda entre iguales. Ponencia presentada en las Jornadas de Fomento de la Investigación. Castellón: Universitat Jaume I.

Azeredo, C.M., Rinaldi, A.E.M., de Moraes, C.L., Levy, R.B., y Menezes, P.R. (2015). School bullying: A systematic review of contextual-level risk factors in observational studies. Aggression and Violent Behavior, 22, 65-76.

Belsky, J. (1980). Child maltreatment: An ecological integration. American Psychologist, 35, 320-335.

Belsey, B. (2005). Cyberbullying: An emerging threat to the "always on" generation. Recuperado el 28/09/2015 de http://www.cyberbullying.ca

Besag, V.E. (1989). Bullies and victims. Philadelphia: Open University Press.

Björkqvist, K., Ekman, K., y Lagerspetz, K.M.J. (1982). Bullies and victims: their ego picture, ideal ego picture, and normative ego picture. Scandinavian Journal of Psychology, 23, 307-313.

Boulton, M.J., Trueman, M., Chau, C., Whitehand, C., y Amatya, K. (1999). Concurrent and longitudinal links between friendship and peer victimisation: implications for befriending interventions. Journal of Adolescence, 22, 461-466.

Bradshaw, C.P., Sawyer, A.L., y O’Brennan, L.M. (2007). Bullying and peer victimization at school: Perceptual differences between students and school staff. School Psychology Review, 36, 361-382.

Bradshaw, C.P. (2015). Trasnlating Reasearch to Prectice in Bullying Prevention. Infocop, en American Psychologist Association, 70(4), 344-353. http://dx.doi.org/10.1037/a0038929

Bronfrenbrenner, U. (1979). La ecología del desarrollo humano. Barcelona: Paidós.

Campbell, M.A. (2005). Cyber Bullying: An old problem in a new guise? Australian Journal of Guidance and Counselling, 15 (1), 68-76. 
Cartwright, N. (1995). Combating bullying in a secondary school in the United Kingdom. Journal for a Just and Caring Education, 3, 345-53.

Cava, M.J. (2009). La utilidad de la mediación como estrategia de resolución y prevención de conflictos en el ámbito escolar. Informació Psicològica, 95, 1526.

Cole, T. (1987). Kids helping kids. University of Victoria. BC.

Cowie, H. (1995). Approaches to Peer Support: Befriending, Counselling and Mediation. Young Minds Newsletter. Issue, 23.

Cowie, H. (1998). Perspectiva of teachers and pupils on the experience of peer support against bullying. Educational Research and Evaluation, 4, 108-125.

Cowie, H., y Olafsson, R. (2000). The role of peer support in helping the victims of bllying in a school with high levels of aggression. School Psychology International, 21, 79-95.

Cowie, H., y Sharp, S. (1996). Peer counselling in schools. London: D. Fulton Publishers.

Cowie, H., y Sharp, S. (1998). Counselling and supporting children in distress. London: Sage Publications.

Cowie, H., y Wallace, P. (2000, 2006). Peer Support in action. From standing by to stand by. Londres: Sage Publication.

Cowie, H., Naylor, P., Talamelli, L., Chauhan, P. y Smith, P. K. (2002). Knowledge, use of and attitudes towards peer support. Journal of Adolescence, 25(5), 453467.

Cowie, H., Boardman, C., Dawkins, J. y Jennifer, D. (2004). Emotional Health and Well-being: A Practical Guide for Schools. London: Sage. 
Cowie, H. y Smith, P. K. (2012). La ayuda entre iguales como instrumento para la mejora de la seguridad en los centros educativos y para le reduccion del bullying y la violencia. En A. Ovejero, P. K. Smith y S. Yubero (Eds.), El Acoso escolar y su prevención (pp. 263-285). Madrid: Biblioteca Nueva.

Cowie, H. (2014). Understanding the role of bystanders and peer support in school bullying. The International Journal of Emotional Education, 6(1), 26-32.

Cremin, H. (2007). Peer Mediation. London: Open University Press.

Defensor del Pueblo y UNICEF (2006). Informe Violencia Escolar: El Maltrato entre iguales en la Educación Secundaria Obligatoria 1999-2006. Documentos Defensor del Pueblo: Madrid.

Del Barrio, C., Barrios, A., Granizo, L., Van der Meulen, K., Andrés, S., y Gutiérrez, H. (2011). Contribuyendo al bienestar emocional de los compañeros: evaluación del Programa Compañeros Ayudantes en un instituto madrileño. European Journal of Education and Psychology, 4 (1), 5-17. doi: 10.1989/ejep.v4il.73.

De Los Reyes, A., y Kazdin, A.E. (2005). Informant discrepancies in the assessment of childhood psychopathology: A critical review, theoretical framework, and recommendations for further study. Psychological Bulletin, 131, 483-509.

Díaz-Aguado, M.J. (1996). Escuela y tolerancia. Madrid: Pirámide.

Díaz-Aguado, M.J. (2006). Del acoso escolar a la cooperación en las aulas. Madrid: Pearson Educación.

DOGV Decreto 233/2004, de 22 de octubre, del Consell de la Generalitat Valenciana, por el que se crea el Observatorio para la Convivencia Escolar en los centros de la Comunidad Valenciana.

DOGV Orden de 25 de noviembre de 2005, de la Conselleria de Cultura, Educación y Deporte, por la que se regula la notificación de las incidencias que alteren la convivencia escolar, enmarcada dentro del Plan de Prevención de la Violencia y Promoción de la Convivencia (PREVI). 
DOGV Orden de 31 de marzo de 2006, de la Conselleria de Cultura, Educación y Deporte, por la que se regula el plan de convivencia de los centros docentes.

DOGV Decreto 39/2008, de 4 de abril, del Consell, sobre la convivencia en los centros docentes no universitarios sostenidos con fondos públicos y sobre los derechos y deberes del alumnado, padres, madres, tutores o tutoras, profesorado y personal de administración y servicios.

DOGV Orden 62/2014, de 28 de julio, de la Conselleria de Educación, Cultura y Deporte, por la que se actualizan los planes de convivencia y se establecen los protocolos de actuación e intervención ante supuestos de violencia escolar.

Erwin, P. (1998). Friendship in childhood and adolescence. Londres: Routledge.

Farrington, D.P., y Ttofti, M.M. (2009). School-based programs to reduce bullying and victimization (Campbell Systematic Reviews No. 6). Oslo, Norway: Campell Corporation, http://dx.doi.org/10.1177/0002716202250789

Fernández, I. (1998). Prevención de la violencia y resolución de conflictos. El clima escolar como factor de calidad. Madrid: Narcea.

Fernández, I., y Orlandini, G. (2001). La ayuda entre iguales. Cuadernos de Pedagogía, 304, 97-100.

Fernández, I., y Quevedo, G. (1989). Violence, Bullying and Counselling in the Iberican Península. London: International Perspective.

Fernández, I., y Quevedo, G. (1991).Como te chives verás. Cuadernos de Pedagogía, 193, 69-71.

Fernández, I., Villaoslada, E., y Funes, S. (2002). Conflicto en el centro escolar. El modelo de alumno ayudante como estrategia de intervención educativa. Madrid: Catarata.

Gardner, H. (1999) Intelligence Reframed. Multiple intelligences for the 21st century, New York: Basic Books. 
Gázquez, J.L., Cangas, A.J., Padilla, D., Cano, A., y Pérez, P. (2005). Assessment by pupils, teachers and parent of school coexistence problems in Spain, France, Austria and Hungary. Global psychometric data. International Journal of Psychology and Psychological Therapy, 5, 101-112.

Gómez, B., y Palacios, R. (1998). Ayudados desde fuera. El teléfono amigo. En Ortega, R. La convivencia escolar: qué es y cómo abordarla. Sevilla: Consejería de Educación y Cultura. Junta de Andalucía.

Hawkins, D.L., Pepler, D.J., y Craig, W.M. (2001). Naturalistic observations of peer interventions in bullying. Social Development, 10, 512-527.

Hymel, S. McClure, R., Miller, M., Shumka, E., and Trach, J. (2015). Addressing school bullying: Insights from theories of group processes. Journal of Applied Developmental Psychology, 37, 16-24.

Hodges, E.V.E., y Perry, D.G. (1999). Personal and interpersonal consequences of victimization by peers. Journal of Personality and Social Psychology, 76, 677685.

Houlston, C., Smith, P.K. y Jessel, J. (2011). The Relationship between use of schoolbased peer support initiatives and the social and emotional well-being of bullied and non-bullied students. Children \& Society, 25(4), 293-305.

Huesmann, L.R., Moise-Titus, J., Podolski, C., y Eron, L. (2003). Longitudinal relations between children's exposure to TV violence and their aggressive and violent behavior in young adulthood: 1977-1992. Developmental Psychology, 39, 2, 201-221.

Instituto de Evaluación del Ministerio de Educación. TALIS (OCDE). Estudio Internacional sobre la Enseñanza y el Aprendizaje. Informe español 2009. Madrid.

Juvonen, J., y Galvan, A. (2008). Peer influence in involuntary social groups: Lessons from research on bullying. En M. Prinstein y K. Dodge (Eds.), Peer influence processes among youth (pp. 225-244). New York: Guilford Press. 
Kowalski, R.M., y Limber, S.P. (2007). Electronic bullying among moddle school students. Journal of Adolescent Helath, 41(6), Supplement, S22-S30.

Lane-Garon, P.S., and Richardson, T. (2003). Mediator mentors: Improving school climate, nurturing student disposition. Conflict Resolution Quarterly, 21, 47-67.

Langberg, J.M., Epstein, J.N., y Becker, S.P. (2012). Evaluation of the homework, organization and planning skills (HOPS) intervention for middle school students with attention deficit hyperactivity disorder as implemented by school mental health providers. School Psychology Review, 41, 342-364.

Lee, S., Kim, Ch.J., y Kim, D.H. (2013). A meta-analysis of the effect of school-based anti-bullying programs. Journal of Child Health Care, 3, 1-18.

Li, Q. (2006). Cyberbullying in Schools, A research of gender differences. School Psychology International, 21(2), 157-170.

Martínez, B., y Musitu, G. (2014). Violencia escolar en la adolescencia: una mirada hacia las víctimas. FOCAD. Formación Continuada a Distancia. Consejo General de la Psicología de España. ISSN: 1989-3906.

Menesini, E., Codecasa, E., Benelli, B., y Cowie, H. (2003). Enhancing children's responsibility totake action against bullying: evaluation of a befriending intervention in Italian middle schools. Aggressive Behavior, 29, 1-14.

Mora-Merchán, J.A., y Ortega, R. (2007). Las nuevas formas de bullying y violencia escolar. En R. Ortega, J. A. Mora-Merchán y T. Jäger (Eds.), Actuando contra el bullying y la violencia escolar. El papel de los medios de comunicación, las autoridades locales y de Internet E-book. Extraído el 28 de septiembre de 2015 desde http://www.bullying-in-school.info.

Naylor, P., y Cowie, H. (1999). The effectiveness of peer support Systems in challenging school bullying: The perspectives and experiences of teachers and pupils. Journal of Adolescent, 22, 1-13.

Olweus, D. (1978). Aggression in the schools: Bullies and whipping boys. Washington, D. C.: Hemisphere (Wiley). 
Olweus, D. (1993). Bullying at school. What we know and what we can do. Oxford: Blackwell.

Olweus, D. (1998). Conductas de Acoso y amenazas entre escolares. Barcelona: Paidós.

Olweus, D. (2001). Peer harassment: A critical analysis and some important issues. En J. Juvonen y S. Graham (Eds.), Peer harassment in school: the plight of the vulnerable and victimized (pp. 3-20). New York: Guilford Press.

Olweus, D., Limber, S.P., Flerx, V.C., Mullin, N., Riese, J., y Snyder, M. (2007). Olweus Bullying Prevention Program: Schoolwide guide. Center City, MN: Hazelden.

Oñate, A., y Piñuel, I. (2007). Informe Cisneros VII: Violencia y acoso escolar en alumnos de Primaria, ESO y Bachiller. Instituto de Innovación educativa y Desarrollo directivo. Madrid. 2005.

Ortega, R. (1998). La convivencia escolar: qué es y cómo abordarla. Sevilla: Consejería de Educación y Ciencia. Junta de Andalucía.

Ortega, R. (2006). Psicología de la enseñanza y desarrollo personal de personas y comunidades. México: F.D.C.

Ortega, R., y Mora-Merchán, J.A. (2000). Violencia escolar: Mito o realidad. Sevilla: Mergablum, Edición y Comunicación.

Ortega, R., y del Rey, R. (2001). Aciertos y desaciertos del Proyecto Sevilla Antiviolencia Escolar (SAVE). Revista de Educación, 324, 253-270.

Ortega, R. y Del Rey, R. (2003). La violencia escolar. Estrategias de prevención. Barcelona: Graó.

Ortega, R., y Del Rey, R. (2007). Violencia escolar: claves para comprenderla y afrontarla. Escuela Abierta, 10, 77-89.

Ortega-Ruiz, R., Casas, J.A., and del Rey, R. (2014). Towards the construct of cyberconvivencia/Hacia el constructo ciberconvivencia. Infancia y Aprendizaje, 37, 602-628 
Ovejero, A. (1998). Las relaciones humanas. Psicología social teórica y aplicada. Madrid: Biblioteca Nueva.

Palladino, B.E., Nocentini, A., y Menesini, E. (2012). Online and offline peer led models against bullying and cyberbullying. Psicothema, 24, 634-639.

Patchin, J.W., e Hinduja, S. (2006). Bullies move beyond the schoolyard: A preliminary look at Cyberbullying. Youth Violence and Juvenile Justice, 4, 148-169.

Piaget, J. (1974). El juicio moral en el niño. Barcelona: Fontanella (original 1932).

Pikas, A. (1989). The common concern method for the treatment os mobbing. En E. Roland y E. Munthe (Eds.), Bullying an international perspective (pp. 91-104). London. David Fulton Publishers.

Randall, P. (1996). A community approach to bullying. Staffordshire: Trentham Books.

Raskauskas, J., y Stolz, A.D. (2007). Involvement in traditional and electronic bullying among adolescents. Developmental Psychology, 43, 564-575.

Rigby, K., y Slee, P.T. (2008). Interventions to reduce bullying. International Journal of Adolescent Medicine and Health, 20(2), 165-183.

Roland, E., e Idsøe, T. (2001). Aggression and bullying. Aggressive Behavior, 27(6), 446-462. Doi: 10.1002/ab.1029

Salmivalli, C., Lagerspetz, K., Björkqvist, K., Österman, K., y Kaukiainen, A. (1996). Bullying as a group process. Participant roles and their relations to social status within the group. Aggressive Behavior, 22, 1-15.

Salmivalli, C. (1998). Intelligent, attractive, well-behaving, unhappy: the structure of adolescents' selfconcept and its relations to their social behavior. Journal of Research on Adolescence, 8, 333-354.

Salmivalli, C. (1999). Participant role approach to school bullying: implications for interventions. Journal of Adolescence, 22, 453-459.

Salmivalli, C., y Nieminen, E. (2002). Proactive and reactive aggression among shool bullies, victims, and bully-victims. Aggressive Behavior, 28(1), 30-44. 
Salmivalli, C., y Voeten, M. (2004). Connections between attitudes, group norms, and behavior in bullying situations. International Journal of Behavioral Development, $28,246-258$.

Salmivalli, C., Kaukiainen, A., and Voeten, M. (2005). Anti-bullying intervention: Implementation and outcome. British Journal of Educational Psychology, 75, 465-487.

Salmivalli, C. (2009). Bullying and the peer group: A review. Aggression and Violent Behavior, 15, 112-120.

Smith, P.K., Shu, S., y Madsen, K. (2001). Characteristics of victims of school bullying: Developmental changes in coping strategies and skills. En J. Juvonen \& S. Graham (Eds.), Peer Harassment in School (pp. 332-351). New York: Guilford Publications.

Smith, P.K., Talamelli, L., Cowie, H., Naylor, P., y Chauchan, P. (2004). Profiles of non-victims, escaped victims, continuing victims and new victims of school bullying. Brithish Journal of Educational Psychology, 74, 565-581.

Smith, P.K., y Watson, D. (2004). Evaluation oh the CHIPS (ChildLine in Partnership with Schools) programme. Reasearch repport RR570. Nottingham: DfES publications.

Smith, P.K. (2006). Ciberacoso: naturaleza y extensión de un nuevo tipo de acoso dentro y fuera de la escuela. Comunicación presentada al Congreso Educación Palma de Mallorca.

Smith, P.K., Mahdavi, J., Carvalho, C., y Tippett, N. (2006). An investigation into cyberbullying, its forms, awareness and impact, and the relationship between age and gender in cyberbullying. Research Brief No. RBX03-06. London: DfES.

South, C., y Wood, J. (2006). Bullying in prisons: The importance of perceived social status, prisonization, and moral disengagement. Aggressive Behavior, 32, 490501. 
Smith, P.K. (2011). Why interventions to reduce bullying and violence in schools may (or may not) succeed: Comments on this Special Section. International Journal of Behavioral Development, 35, 419-423.

Sutton, J., y Smith, P. K. (1999). Bullying as a group process: An adaptation of the participant role approach.Aggressive Behavior, 25, 97-111.

Taylor, A. (1996). Comparison study of bullying rates in three schools with antibullying programmes and three control schools with no anti-bullying programmes in Northern Ireland. Tesis doctoral no publicada. University of Ulster at Jordanstown, Belfast, Northern Ireland.

Torrego, J.C. (Coord.) (2000). La mediación en instituciones educativas. Madrid: Narcea.

Torrego, J.C. (Coord.) (2001). Nuevos enfoques de actuación ante el conflicto y la convivencia escolar. En Fernández, I. (Coord). Guía para la convivencia en el aula (pp. 171-181). Madrid: Escuela Española.

Torrego, J.C. (Coord.). (2006). Modelo integrado de mejora de la convivencia. Estrategias de mediación y tratamiento de conflictos. Barcelona: Graó.

Torrego, J.C. (Coord.) (2012). La ayuda entre iguales para mejorar la convivencia escolar: manual para la formación de alumnos/as ayudantes. Madrid: Narcea.

Trianes, M.V. (2000). La violencia en contextos escolares. Málaga: Aljibe.

Uranga, M. (1998). Mediación, negociación y habilidades para el conflicto en el marco escolar. En Casamayor, G. (Coord.), Cómo resolver conflictos. La disciplina en la enseñanza secundaria (pp. 143-159). Barcelona: Aljibe.

Vettenburg, N. (1999). Violence in schools, awareness-raising, prevention, penalties. General report Council of Europe Publishing, 29-60.

Vreeman, R.C., and Carroll, A.E. (2007). A systematic review of school-based interventions to prevent bullying. Archives of Pediatrics and Adolescent Medicine, 161, 78-88. 
Vygotsky, L. (1978). Mind in society. Cambridge, MA: Harvard University Press.

Waasdorp, T.E., Pas, E.T., O’Brennan, L.M., y Bradshaw, C.P. (2011). A multilevel perspective on the climate of bullying: Discrepancies among students, school staff, and parents. Journal of School Violence, 10, 115-132.

Whitney, I., y Smith, K. (1993). A survey of the nature and extent of bullying in junior/middle and secondary schools. Educational Research, 35, 3-25.

Willard, N. (2004). "I can't see you - youy can't see me. How the use of information and communication technologies can impact eesponsible behavior". Center for safe and responsible internet use. Extraído el 29 de septiembre de 2015 desde: http://new.csriu.org/cyberbully/docs/cbcteducator.pdf

Willard, N. (2006). Cyberbullying and cyberthretas, efectively managing internet use rissks in schools. Extraído el 29 de septiembre de 2015 desde http://new.csriu.org/cyberbully/docs/cbctpresentation.pdf

Yeager, D.S., Fong, C.J., Lee, H.Y., y Espelage, D.L. (2015). Decline in efficacy of anti-bullying programs among older adolescents : Theory and three-level metaanalysis. Journal of Applied Developmental Psychology, 37, 36-51.

Youngstrom, E., Loeber, R., y Stouthamer-Loeber, M. (2000). Patterns and correlates of agreement between parent, teacher, and male adolescent ratings of externalizing and internalizing problems. Journal of Consulting and Clinical Psychology, 68, 1038-1050. 


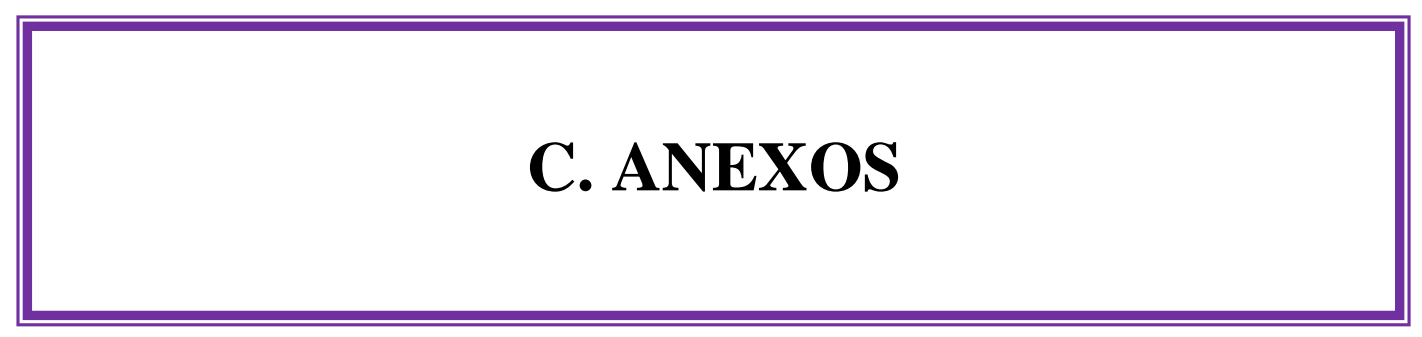



Anexo I: Cuestionario de Roles para estudiantes, Escala "Adivina Quien" (Salmivalli, et. al., 2006) 


\section{Escala de Salmivalli et al. 2006.}

UNIVERSITAT

JAUME•I

\section{№ Identificación:}

Chico

Chica

Curso y grupo:

Centro:

Fecha de nacimiento:

\section{ADIVINA QUIEN}

\begin{tabular}{|c|c|}
\hline 1. Se ríe de los que están siendo molestados & \\
\hline 2. Se pone de parte de la víctima & \\
\hline 3.No hace nada, ni se pone de parte de nadie & \\
\hline 4. Avisa a otros para que vengan a ayudar a la víctima & \\
\hline 5. Siempre piensa en formas nuevas de fastidiar a la víctima & \\
\hline 6. Llama a otros para que vean la agresión & \\
\hline 7. Se une a la agresión, si otro ha empezado & \\
\hline 8. Ayuda al agresor sujetando o inmovilizando a la víctima & \\
\hline 9. Intenta que los demás dejen de meterse con alguien & \\
\hline 10. Es el jefe de la pandilla & \\
\hline 11. Normalmente no está allí, siempre está lejos & \\
\hline 12. Siempre se meten con él/ella & \\
\hline 13. Le dice cosas al agresor, como "Demuéstrale quien mand & aquî" \\
\hline 14. Normalmente suele estar allí, aunque no esté haciendo na & \\
\hline 15. Consigue que los demás se unan a molestar a otros & \\
\hline 16. Empieza a atacar o a molestar & \\
\hline 17. Ni siquiera sabe nada de la agresión & \\
\hline 18. Anima con gritos al agresor & \\
\hline 19. Finge no darse cuenta de lo que pasa & \\
\hline 20. Le cuenta a un adulto que se están metiendo con alguien & \\
\hline
\end{tabular}


Anexo II: Cuestionario de Actitudes para estudiantes, Escala de "Rigby \& Slee", 1991 
№ Identificación:

Chico

Chica

Curso y grupo: Centro:

Fecha de nacimiento:

Lee cuidadosamente cada una de las siguientes frases y señala si estás de acuerdo, o en desacuerdo con ella. Hazlo rodeando cada una de las respuestas.

1. Los chicos de los que se burlan un montón normalmente se lo merecen.

De acuerdo No sé En desacuerdo

2. Un agresor es en realidad un cobarde.
De acuerdo
No sé
En desacuerdo

3. Los chicos no deberían quejarse cuando les molestan/agreden.
De acuerdo
No sé
En desacuerdo

4. Es gracioso ver cómo se ofenden algunos chicos cuando les molestan.
De acuerdo
No sé
En desacuerdo

5. Alguien debería llamarles la atención a los chicos que molestan a otros más débiles que ellos.
De acuerdo
No sé
En desacuerdo

6. Los chicos blandos me ponen enfermo.
De acuerdo
No sé
En desacuerdo

7. Nadie debería meterse con alguien más débil que él/ella.
De acuerdo
No sé
En desacuerdo

8. A nadie le gustan los "pringados".
De acuerdo
No sé
En desacuerdo

9. Me pone nervioso ver cómo se meten con alguien sin razón.
De acuerdo
No sé
En desacuerdo

10. Me gusta cuando alguien se pone de parte de los chicos que son molestados/agredidos.
De acuerdo
No sé
En desacuerdo 
Anexo III: Cuestionario para estudiantes sobre el estado inicial de la convivencia escolar, de Ortega y Del Rey, 2003 


\section{Cuestionario para estudiantes \\ (Ortega y Del Rey, 2003)}

№ Identificación:

Chico

Chica

\section{Curso y grupo: \\ Centro: \\ Fecha de nacimiento:}

Con este cuestionario esperamos recoger información para saber cómo van las cosas en tu centro y qué se puede hacer para mejorar. Por eso te pedimos que contestes con sinceridad y propongas ideas e iniciativas.

1. ¿Cómo te llevas con tus compañeros?

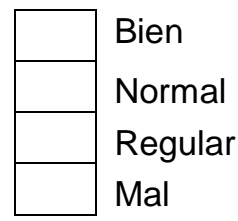

2. ¿Y con los profesores?

\begin{tabular}{|l|l}
\hline & Bien \\
\hline & Normal \\
& Regular \\
& Mal
\end{tabular}

3. ¿Qué opinión crees que tienen de ti tus compañeros?

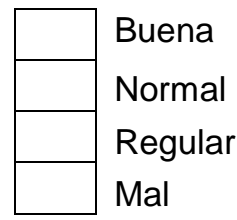

4. ¿Qué opinión crees que tienen de ti tus profesores?

\begin{tabular}{|l|l|}
\hline & Buena \\
\cline { 1 - 1 } Normal \\
\cline { 1 - 1 } Regular \\
\cline { 1 - 1 } Mal
\end{tabular}

5. ¿Hay diferencias en las normas de clase de unos profesores y otros?
Algunas
Ninguna

6. ¿Participan los padres y madres en la vida del centro?

\begin{tabular}{|l|l|}
\hline & La mayoría \\
\hline & Algunos \\
\hline & Casi ninguno \\
\hline & Ninguno
\end{tabular}


7. ¿En qué participan? (Escríbelo, si es necesario en los espacios vacíos).

\begin{tabular}{|c|}
\hline En nada \\
\hline En el AMPA \\
\hline Recoger las notas \\
\hline En las fiestas \\
\hline Si su hijo o hija van mal \\
\hline Van si los llaman \\
\hline \\
\hline
\end{tabular}

8. ¿Cuánto se repiten las siguientes situaciones en tu centro? (Márcalas con una X).

\begin{tabular}{|l|l|l|l|l|}
\hline & Nada & Poco & Regular & Mucho \\
\hline Enfrentamientos entre los alumnos y el profesor & & & & \\
\hline Malas palabras en clase & & & & \\
\hline No se respestan las normas & & & & \\
\hline Los alumnos se insultan & & & & \\
\hline Los alumnos se pelean & & & & \\
\hline Hay grupitos que no se llevan bien & & & & \\
\hline Hay chicos que no están integrados y se sienten solos & & & & \\
\hline Los profesores van cada uno a lo suyo & & & \\
\hline Los alumnos piensan que los profesores no los entienden & & & & \\
\hline Los alumnos están desmotivados, se aburren & & & \\
\hline
\end{tabular}

9. De las situaciones anteriores, ¿cuáles y de qué manera te afectan personalmente?

10. ¿Cuántas veces te han intimidado o maltratado algunos de tus compañeros o compañeras?

\begin{tabular}{|l|l}
\hline & Nunca \\
\hline & Pocas veces \\
Muchas veces
\end{tabular}

11. Si tus compañeros te han intimidado en alguna ocasión ¿desde cuándo se producen estas situaciones?

\begin{tabular}{|l|l}
\hline & Nadie me ha intimidado nunca \\
Desde hace una semana \\
Desde hace un mes \\
Desde principios de curso \\
Desde siempre
\end{tabular}

12. ¿Hay alguien más que te intimide con frecuencia?

\begin{tabular}{|l|l}
\hline & No \\
\hline & Sí (si quieres dinos quién)
\end{tabular} 
13. Si te han intimidado en alguna ocasión ¿por qué crees que lo hicieron? (puedes elegir más de una respuesta).

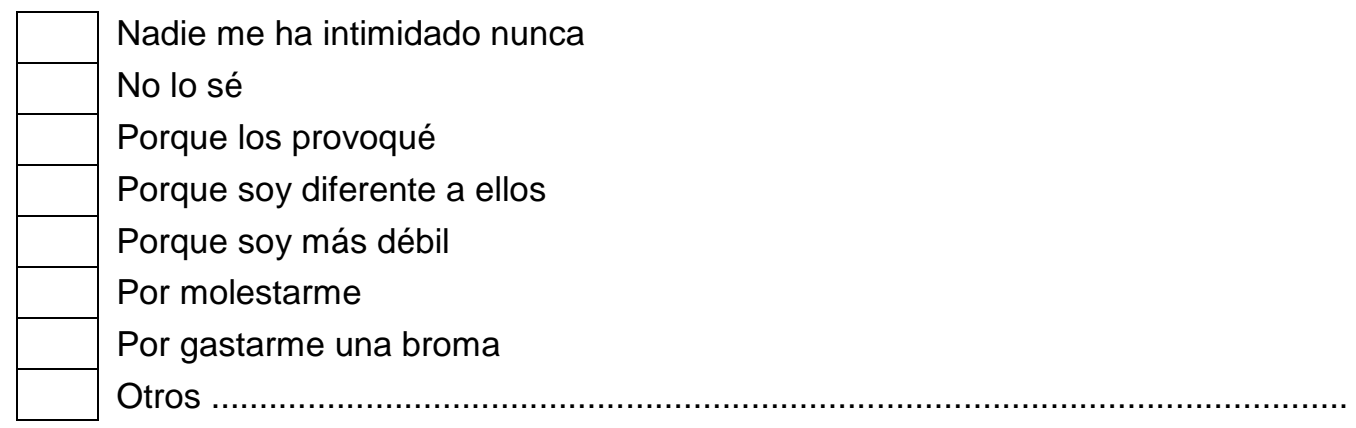

14. ¿En qué clase suelen estar los chicos y chicas que suelen intimidar a sus compañeros? (puedes elegir más de una respuesta).

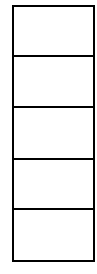

No lo sé

En la misma clase

En el mismo curso, pero en otra clase

En un curso superior

En un curso inferior

15. ¿Quiénes suelen ser los que intimidan a sus compañeros o compañeras?
$\square$ No lo sé
Un chico
Un grupo de chicos
Una chica
Un grupo de chicas
Un grupo de chicos y chicas

16. ¿En qué lugares se suelen producir estas situaciones de intimidación o maltrato? (puedes elegir más de una respuesta).

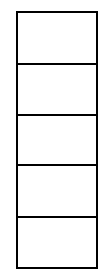

No lo sé

En la clase

En el patio

En la calle

Otros

17. ¿Quién suele parar las situaciones de intimidación?
\begin{tabular}{|l|}
\hline \\
\hline \\
\hline
\end{tabular}
No lo sé
Nadie
Algún profesor
Algún compañero 
18. Si alguien te intimida ¿hablas con alguien de lo que te sucede? (puedes elegir más de una respuesta).

\begin{tabular}{|c|}
\hline intimida \\
\hline No hablo con nadie \\
\hline Con los profesores \\
\hline Con mi familia \\
\hline Con compañer \\
\hline
\end{tabular}

19. ¿Serías capaz de intimidar a alguno de tus compañeros en alguna ocasión?

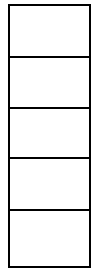
Nunca
No lo sé
Sí, si me provocan
Sí, si mis amigos lo hacen
Otras razones

20. ¿Serías capaz de enviar un mensaje por e-mail o al móvil para intimidar a alguno de tus compañeros en alguna ocasión?

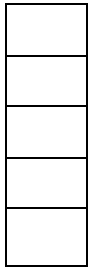

Nunca

No lo sé

Sí, si me provocan

Sí, si mis amigos lo hacen

Otras razones

21. ¿Has recibido mensajes por e-mail o en tu móvil para intimidarte en alguna ocasión?

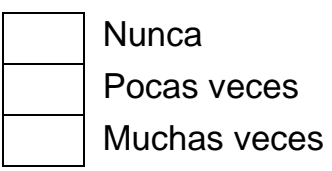

22. Si has intimidado a alguno de tus compañeros, ¿te ha dicho alguien algo al respecto? (puedes elegir más de una respuesta).

\begin{tabular}{|l|}
\hline \\
\hline \\
\hline \\
\hline \\
\hline \\
\hline
\end{tabular}

No he intimidado nadie

Nadie me ha dicho nada

Sí, a mis profesores les ha parecido mal

Sí, a mi familia le ha parecido mal

Sí, a mis compañeros les ha parecido mal

Sí, mis profesores me dijeron que estaba bien

Sí, mi familia me dijo que estaba bien

Sí, mis compañeros me dijeron que estaba bien 
23. Si has participado en situaciones de intimidación hacia tus compañeros ¿por qué lo hiciste? (puedes elegir más de una respuesta).

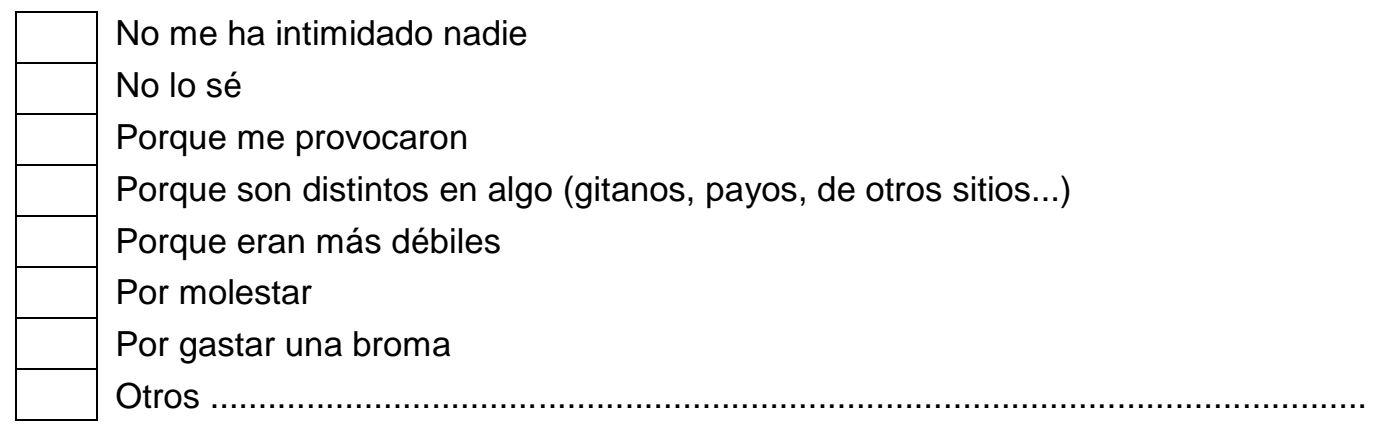

24. ¿Cuáles son a tu parecer las dos formas más frecuentes de intimidación o maltrato entre compañeros?

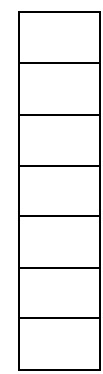

No lo sé

Poner motes o dejar en ridículo

Hacer daño físico (pegar, dar patadas, empujar)

Robo

Amenazas

Rechazo, aislamiento, no juntarse

Otros

25. ¿Con qué frecuencia se dan intimidaciones en tu centro?

\begin{tabular}{|l|l}
\hline & Nunca \\
Pocas veces \\
Muchas veces
\end{tabular}

26. ¿Cuántas veces has participado en intimidaciones a tus compañeros?

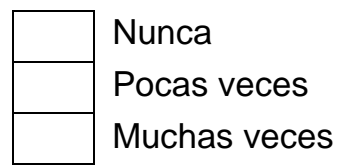

27. ¿Qué piensas de los chicos y chicas que intimidan a otros compañeros?
Nada, paso del tema
Me parece mal
Es normal que pase entre compañeros
Hacen bien, tendrán sus motivos

28. ¿Por qué crees que algunos chicos intimidan a otros? (puedes elegir más de una respuesta).

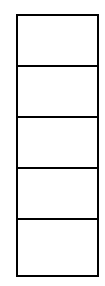

No lo sé

Por que se meten con ellos

Porque son más fuertes

Por gastar una broma

Otras razones 
29. ¿Qué sueles hacer cuando un compañero intimida a otro?

\begin{tabular}{|l|}
\hline \\
\hline
\end{tabular}

Nada, paso del tema

Nada, aunque creo que debería hacer algo

Aviso a alguien que pueda parar la situación

Intento cortar la situación personalmente

30. ¿Crees que habría que solucionar este problema?

$$
\begin{array}{|l|l}
\hline & \text { No sé } \\
\hline & \text { No } \\
\text { Sí } \\
\hline & \text { No se puede solucionar }
\end{array}
$$

31. ¿Qué propuestas o actividades sugerirías que se realizaran en el centro para mejorar las relaciones entre todos?

32. ¿Quién debe hacer esas actividades?

33. ¿Qué crees que debes hacer tú mismo o misma?

Muchas gracias 

Anexo IV: Cuestionario para el profesorado sobre el estado inicial de la convivencia escolar, de Ortega y Del Rey, 2003 


\section{Cuestionario para el profesorado (Ortega y Del Rey, 2003)}

UNIVERSITAT

JAUME•I

Tutor/a de: $\quad 1 \%$ ESO $\square \quad 3 \%$ ESO

Hombre $\square$ Mujer

Edad:

Años trabajados:

Años trabajados en este centro:

Nos interesa conocer tu opinión sobre tu centro, por lo que te pedimos que contestes sinceramente a este cuestionario.

1. ¿Cómo dirías que te llevas con tus compañeros?

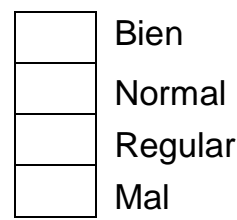

2. ¿Y con los alumnos y alumnas?

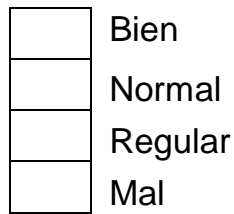

3. ¿Cómo crees que te perciben tus compañeros? ¿Qué visión crees que tienen de ti?
$\square$
Muy positiva
Ni buena ni mala
No me conocen realmente
Creo que tienen mala imagen de mí

4. ¿Y tus alumnos y alumnas?

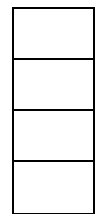

Muy positiva

Ni buena ni mala

No me conocen realmente

Creo que tienen mala imagen de mí

5. ¿Crees que hay diferencias entre tus normas de clase y las de otros profesores?

\begin{tabular}{|l|l}
\hline & Muchas \\
\hline & Algunas, poco importantes \\
Ninguna \\
No sé
\end{tabular}

6. ¿Cómo es tu relación con las familias de tus alumnos y alumnas?

\begin{tabular}{|l|l}
\hline & Muy buena \\
\hline & Buena \\
\hline & Regular \\
& Mala \\
\hline & Inexistente
\end{tabular}


7. ¿En qué medida crees que las familias deben participar en la convivencia del centro?.

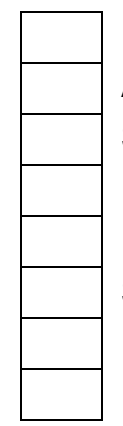

En el AMPA

Atención a resultados académicos

Si su hijo o hija van mal

En cosas complementarias

En los planes de convivencia

Si son llamados

8. En tu opinión, ¿cuánto se repiten las siguientes situaciones en tu centro? (Márcalas con una X).

\begin{tabular}{|l|l|l|l|l|}
\hline & Nada & Poco & Regular & Mucho \\
\hline Enfrentamientos entre los grupos de alumnos y el profesor & & & & \\
\hline Malas contestaciones en clase & & & & \\
\hline No se respestan las normas & & & & \\
\hline Los alumnos se insultan & & & & \\
\hline Los alumnos se pelean & & & & \\
\hline Hay grupitos que no se llevan bien & & & & \\
\hline Hay chicos que no están integrados y se sienten solos & & & & \\
\hline Los profesores van cada uno a lo suyo & & & & \\
\hline Los alumnos piensan que los profesores no los entienden & & & & \\
\hline Los alumnos están desmotivados, se aburren & & & \\
\hline
\end{tabular}

9. De las situaciones anteriores, ¿cuáles y de qué manera te afectan personalmente?

10. Marca con una $X$ el valor entre 1 y 5 de las siguientes frases según tu grado de acuerdo, siendo 1 totalmente en desacuerdo, y 5 totalmente de acuerdo.

\begin{tabular}{|c|c|c|c|c|c|}
\hline \multirow{2}{*}{$\begin{array}{l}\text { Las relaciones interpersonales son uno de los objetivos más importantes en el desarrollo de mi } \\
\text { curriculum. }\end{array}$} & 1 & 2 & 3 & 4 & 5 \\
\hline & & & & & \\
\hline Las agresiones y situaciones violentas son un grave problema en mi centro. & & & & & \\
\hline Los problemas de violencia dependen, sobre todo, del contexto social y familiar del alumnado. & & & & & \\
\hline $\begin{array}{l}\text { El profesor se encuentra indefenso ante los problemas de disciplina y agresiones del } \\
\text { alumnado. }\end{array}$ & & & & & \\
\hline El propio profesor es en ocasiones el objeto de ataque del alumnado. & & & & & \\
\hline Los padres de los alumnos a menudo empeoran las situaciones de conflicto. & & & & & \\
\hline En los casos de violencia, me siento respaldado por el resto de compañeros de mi centro. & & & & & \\
\hline En mi clase, suelo controlar y atajar los conflictos y agresiones, no llegando a ser un problema. & & & & & \\
\hline $\begin{array}{l}\text { Los profesores, sin ayuda de otros profesionales, no estamos preparados para resolver los } \\
\text { problemas de malas relaciones y violencia en la escuela. }\end{array}$ & & & & & \\
\hline $\begin{array}{l}\text { Para eliminar los problemas de violencia es necesario que el equipo completo de profesores } \\
\text { tome conciencia y se decida a actuar. }\end{array}$ & & & & & \\
\hline $\begin{array}{l}\text { Para eliminar los problemas de violencia entre compañeros que se producen en la escuela, hay } \\
\text { que implicar a las familias. }\end{array}$ & & & & & \\
\hline $\begin{array}{l}\text { La carga lectiva e instruccional actúa como una exigencia que impide dedicarse a asuntos } \\
\text { como los problemas de malas relaciones interpersonales. }\end{array}$ & & & & & \\
\hline $\begin{array}{l}\text { Para eliminar los problemas de violencia y mejorar las relaciones interpersonales hay que } \\
\text { modificar el currículum. }\end{array}$ & & & & & \\
\hline $\begin{array}{l}\text { Considero que comenzar un proyecto de intervención sobre las agresiones y violencia en este } \\
\text { centro es una idea muy buena. }\end{array}$ & & & & & \\
\hline
\end{tabular}


Si has valorado con 3, 4 y 5 la frase anterior, ¿Estarías dispuesto a participar en un proyecto para desarrollar estrategias de intervención sobre este tema?

11. ¿Qué propuestas o actividades sugerirías que se realizaran en el centro para mejorar las relaciones entre todos?

12. ¿Quién las llevaría a cabo?

13. ¿En qué actividades te involucrarías tú personalmente?

Muchas gracias 